Sônia Maria Fabris Luiz

\title{
Impacto de dois níveis de obesidade grave sobre as alterações osteoarticulares e funcionais de joelho e pé
}

Tese apresentada á Faculdade de Medicina da Universidade de São Paulo para obtenção do título de Doutor em Ciências

Programa Ciências em Gastroenterologia Orientador: Prof. Dr. Joel Faintuch

São Paulo

2012 
Dados Internacionais de Catalogação na Publicação (CIP)

Preparada pela Biblioteca da

Faculdade de Medicina da Universidade de São Paulo

Creprodução autorizada pelo autor

Luiz, Sônia Maria Fabris

Impacto de dois níveis de obesidade grave sobre as alterações osteoarticulares e funcionais de joelho e pé / Sônia Maria Fabris Luiz. -- São Paulo, 2012.

Tese(doutorado)--Faculdade de Medicina da Universidade de São Paulo.

Programa de Ciências em Gastroenterologia.

Orientador: Joel Faintuch.

Descritores: 1.Obesidade mórbida 2.Pé plano 3.Cirurgia bariátrica 4.Osteoartrite 5.Questionários

USP/FM/DBD-222/12 


\section{Dedicatória}

Dedico este projeto aos meus pais Elza e Hélio, em agradecimento pela vida, pelo amor,

pela convivência e ensinamentos.

Homenageio carinhosamente aos meus irmãos,

pelo apoio e estímulo.

Em particular á Shirley por me orientar, auxiliar e ser minha referência profissional.

Em especial ao meu esposo,

Renato,

amigo, parceiro, incentivador e que sempre confiou em minha capacidade.

Ao meu querido filho,

Renato Junior, pela paciência, colaboração e por ser a realização do meu maior sonho. 


\section{Agradecimentos}

A Deus que iluminou meu caminho, me deu forças e condições para

que eu chegasse até aqui...

Agradeço àqueles que me acompanharam durante a realização deste trabalho e me ajudaram a chegar até este momento...

Ao colega de profissão e amigo, Estevão Luis Paes Mendes, pela acolhida e disponibilização do equipamento.

Ao Dr. Sérgio Luis Brienze, Dr. Gilberto Borges de Brito e funcionários do Ambulatório de Cirurgia do Aparelho Digestivo da FAMERP, pela recepção e disponibilização, durante o período da minha pesquisa.

Á Dra. Isabela Souza Sitta, pela amizade, colaboração e realização dos laudos radiográficos.

Á Dra. Inês Cristina Batista Fonseca, pela disponibilidade e realização, das análises estatísticas.

Aos pacientes do Ambulatório de Cirurgia do Aparelho Digestivo da FAMERP, pela colaboração e participação, nesta pesquisa. 


\section{Agradecimento Especial}

Ao meu orientador e mestre, Prof. Dr. Joel Faintuch, pela confiança, incentivo e por dividir comigo seu amplo conhecimento científico.

Ao Instituto Ajinomoto pelo apoio financeiro, e pela contribuição importante na realização da presente pesquisa. 


\section{NORMATIZAÇÃO ADOTADA}

Esta tese está de acordo com as seguintes normas, em vigor no momento desta publicação:

Referências: adaptado de International Committee of Medical Journals Editors (Vancouver).

Universidade de São Paulo. Faculdade de Medicina. Divisão de Biblioteca e Documentação. Guia de apresentação de dissertações, teses e monografias. Elaborado por Anneliese Carneiro da Cunha, Maria Julia de A. L. Freddi, Maria F. Crestana, Marinalva de Souza Aragão, Sueli Campos Cardoso, Valéria Vilhena. 3a Ed. São Paulo: Divisão de Biblioteca e Documentação; 2011.

Abreviaturas dos títulos dos periódicos de acordo com List of Journals Indexed in Index Medicus. 


\section{SUMÁRIO}

Lista de siglas e símbolos

Lista de figuras

Lista de tabelas

Lista de gráficos

Resumo

Summary

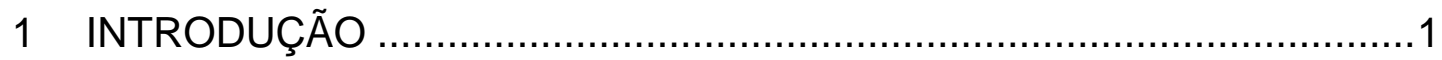

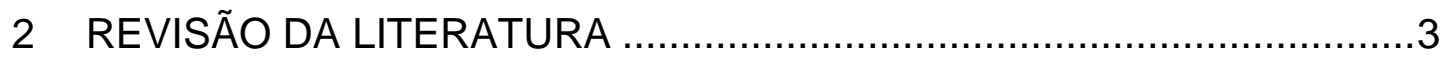

2.1 Obesidade no Brasil .........................................................

2.2 Obesidade e Problemas musculoesqueléticos............................4

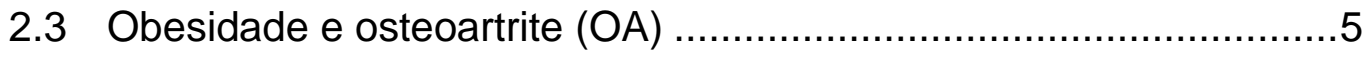

2.4 Obesidade e Pé .......................................................... 6

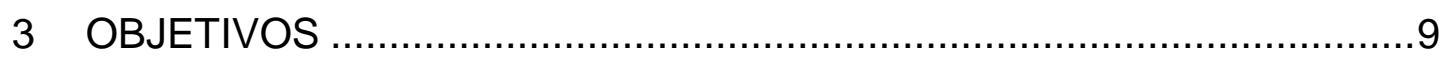

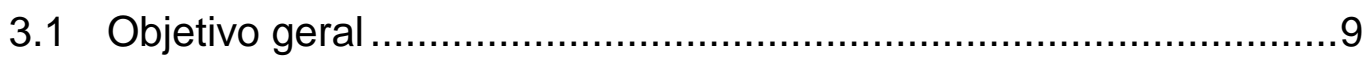

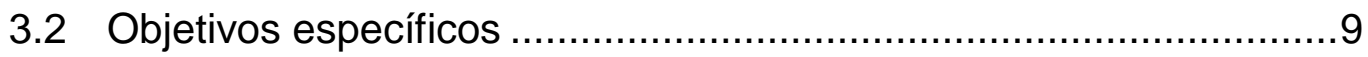

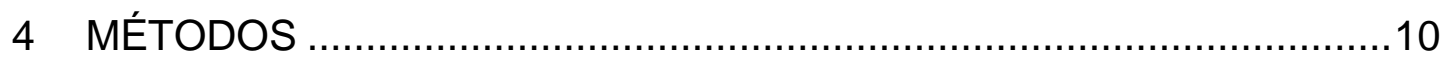

4.1 Amostra da população ......................................................... 10

4.2 Delineamento ............................................................... 11

4.3 Critérios de inclusão.......................................................11

4.4 Critérios de exclusão.........................................................11

4.5 Desenho experimental .................................................. 12

4.6 Variáveis analisadas ....................................................... 14

4.6.1 Medidas antropométricas ............................................ 14

4.6.2 Avaliação radiológica................................................ 14

4.6.3 Avaliação baropométrica - Índice de Staheli (IS) ...............19

4.6.4 Questionários ....................................................22

4.7 Análise estatística .........................................................23 
5.1 Resultados encontrados entre IMC e Avaliação Radiológica.........26

5.1.1 IMC e Osteoartrite de joelho .............................................26

5.1.2 IMC e ângulo tálus-primeiro metatarso (T1M) ...................26

5.2 Resultados encontrados entre IMC e avaliação baropométrica -

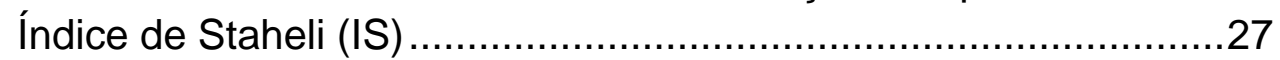

5.3 Resultados encontrados entre IMC e as questões qualitativas

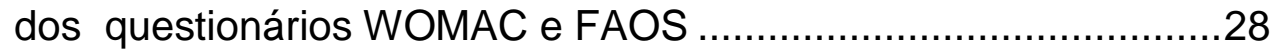

5.4 Resultados encontrados entre Osteoartrite (OA) versus

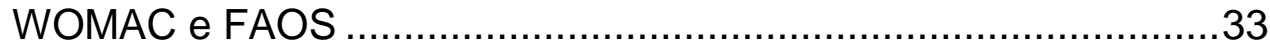

5.5 Resultados encontrados entre T1M versus WOMAC e FAOS .......33

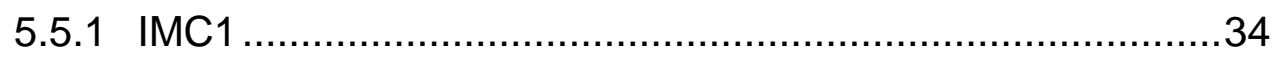

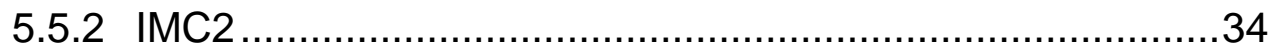

5.6 Resultados encontrados entre Índice de Staheli (IS) versus

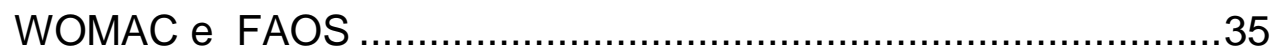

5.7 Resultados encontrados entre Osteoartrite $(\mathrm{OA})$ versus ângulo

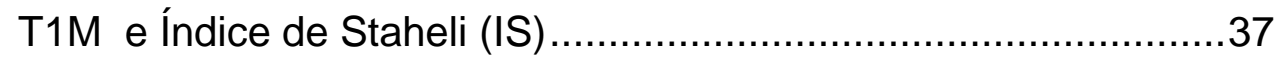

5.8 Resultados encontrados entre ângulo T1M e Índice de Staheli

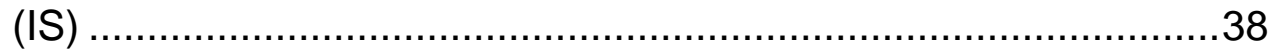

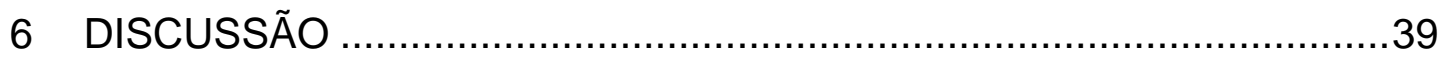

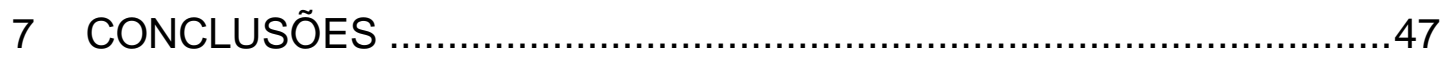

8 ANEXOS

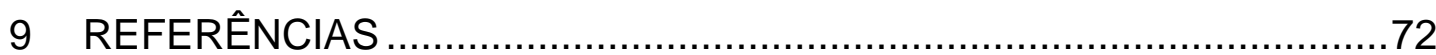




\section{LISTA DE SIGLAS}

\begin{tabular}{|c|c|}
\hline ALM & arco longitudinal medial \\
\hline AP & anteroposterior \\
\hline AVD & atividade de vida diária \\
\hline CAPPesq & $\begin{array}{l}\text { Comissão de Ética para Análise de Projetos de Pesquisa } \\
\text { do Hospital das Clínicas da faculdade de Medicina da } \\
\text { Universidade de São Paulo }\end{array}$ \\
\hline DP & desvio padrão \\
\hline EMR & armazenamento de registros médicos eletrônicos \\
\hline FAMERP & Faculdade de Medicina de São José do Rio Preto \\
\hline FAO & $\begin{array}{l}\text { Organização das Nações Unidas para Agricultura e } \\
\text { Alimentação }\end{array}$ \\
\hline FAOS & Foot and Ankle Outcome Score \\
\hline FUNFARME & $\begin{array}{l}\text { Fundação Faculdade Regional de Medicina de São José } \\
\text { do Rio Preto }\end{array}$ \\
\hline IBGE & Instituto Brasileiro de Geografia e Estatística \\
\hline IC & intervalo de confiança \\
\hline IMC & índice de massa corporal \\
\hline IS & índice de Staheli \\
\hline K-L & Kellgren\&Lawrence \\
\hline KOOS & Knee Injury and Osteoarthritis Outcome Score \\
\hline$n$ & tamanho da amostra \\
\hline OA & osteoartrite \\
\hline OMS & Organização Mundial da Saúde \\
\hline$P / A^{2}$ & peso dividido pela altura ao quadrado \\
\hline POF & Pesquisa de Orçamentos Familiares \\
\hline
\end{tabular}


QV

TCLE

WOMAC qualidade de vida

termo de consentimento livre esclarecido

Western Ontario and McMaster Universities

Osteoarthritis Index 


\section{LISTA DE SÍMBOLOS}

$\begin{array}{ll}\mathrm{cm} & \text { centímetro } \\ \mathrm{Hz} & \text { hertz } \\ \mathrm{Kg} / \mathrm{m}^{2} & \text { quilograma por metro quadrado } \\ \mathrm{kV} & \text { quilovolt } \\ \mathrm{mAS} & \text { miliAmpere/segundo } \\ \% & \text { porcentagem } \\ < & \text { menor } \\ = & \text { igual a } \\ > & \text { maior que } \\ \pm & \text { mais ou menos } \\ \leq & \text { menor ou igual a } \\ \geq & \text { maior ou igual a } \\ 0 & \text { grau }\end{array}$




\section{LISTA DE FIGURAS}

Figura 1 - Fluxograma das etapas do protocolo experimental

Figura 2 - Radiografia bilateral de joelho com carga (AP) sem presença OA - Grau zero ................................................16

Figura 3 - Radiografia bilateral de joelho com carga (AP) e com presença de OA - Grau IV ...............................................16

Figura 4 - Radiografia do pé com carga (perfil). Mensuração ângulo

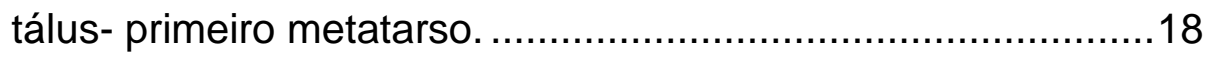

Figura 5 - Impressão plantar - pé cavo ……………………………....19

Figura 6 - Impressão plantar - pé normal .............................................19

Figura 7 - Impressão plantar - pé plano ……………………………....19

Figura 8 - Representação gráfica do cálculo do índice de Staheli. ...........20

Figura 9 - Impressão plantar fornecida pelo baropômetro ……………….....21

Figura 10 - Visão geral do baropodômetro …………….............................21

Figura 11 - Posicionamento do sujeito na plataforma do aparelho .............21 


\section{LISTA DE TABELAS}

Tabela 1 - Características gerais da amostra de acordo com o índice de massa corporal - IMC .............................................25

Tabela 2 - Frequência relativa do IMC versus dor no joelho e rigidez articular obtida pelo questionário WOMAC

Tabela 3 - Frequência relativa do IMC versus dor no pé obtida pelo questionário FAOS

Tabela 4 - Frequência relativa do IMC versus nível dificuldade funcional obtida pelos questionários WOMAC E FAOS

Tabela 5 - Frequência relativa do IS versus dor no joelho obtida pelo questionário WOMAC

Tabela 6 - Frequência relativa entre osteoartrite de joelho e ângulo tálus- primeiro metatarso e Índice de Staheli estratificados.....37

Tabela 7 - Características bioquímicas e metabólicas da amostra da população de acordo com o IMC

Tabela 8 - $\quad$ Frequência relativa de OA versus dor no joelho e rigidez articular obtida pelo questionário WOMAC

Tabela 9 - Frequência relativa de OA versus dor no pé obtido pelo questionário FAOS

Tabela 10 - Frequência relativa de OA versus nível dificuldade funcional obtida pelo questionário WOMAC e FAOS

Tabela 11 - Frequência relativa de T1M estratificado versus dor no joelho e rigidez articular obtida pelo questionário WOMAC .....65

Tabela 12 - Frequência relativa de T1M estratificado versus dor no pé obtida pelo questionário FAOS

Tabela 13 - Frequência relativa de T1M estratificado versus nível de dificuldade funcional obtida pelos questionários WOMAC e FAOS

Tabela 14 - Frequência relativa do IS versus dor no pé obtida pelo questionário FAOS

Tabela 15 - Frequência relativa do IS versus nível de dificuldade funcional obtida pelo questionário FAOS 


\section{LISTA DE GRÁFICOS}

Gráfico 1 - Frequência relativa da estratificação de osteoartrite de joelho em relação a IMC1 e IMC2 ……...........................................26

Gráfico 2 - Frequência relativa da estratificação do ângulo $T 1 M$ em relação a IMC1 e IMC2

Gráfico 3 - Frequência relativa da estratificação do Índice de Staheli em relação a IMC1 e IMC2 ………………………..................28

Gráfico 4 - Comparação entre T1M estratificado versus IMC1 e IMC2 ao

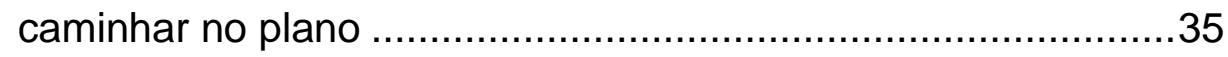

Gráfico 5-Correlação entre ângulo $\mathrm{T} 1 \mathrm{M}$ estratificado versus IS estratificado. 


\section{RESUMO}

Luiz SMF. Impacto de dois níveis de obesidade grave sobre as alterações osteoarticulares e funcionais de joelho e pé [tese]. São Paulo: Faculdade de Medicina, Universidade de São Paulo; 2012. 82p.

INTRODUÇÃO: A obesidade pode favorecer uma série de problemas musculoesqueléticos e está associada com dor e deficiência funcional. Este estudo teve por objetivo analisar a influência de dois níveis de obesidade grave (40 a $50 \mathrm{Kg} / \mathrm{m}^{2}$ versus maior $50 \mathrm{Kg} / \mathrm{m}^{2}$ ) sobre as alterações osteoarticulares e funcionais do joelho e pé em candidatos á cirurgia bariátrica. MÉTODOS: Foram analisados 81 indivíduos com indicação de gastroplastia com derivação intestinal em $\mathrm{Y}$ em Roux. Os indivíduos foram estratificados de acordo com IMC em dois grupos, sendo IMC1 (40,0 a 49,6 $\left.\mathrm{Kg} / \mathrm{m}^{2}\right)$ e IMC2 $\left(50,0\right.$ a $\left.81,3 \mathrm{Kg} / \mathrm{m}^{2}\right)$. A população foi submetida á análise radiológica de joelho para verificação de osteoartrite (escala de KellgrenLawrence); Raio-x do pé para mensuração do ângulo tálus-primeiro metatarso (T1M); impressão plantar para cálculo do índice de Staheli (IS) e questionários funcionais, Western Ontario and McMaster Universities Ostheoarthritis Index (WOMAC) e Foot and Ankle Outcome Score (FAOS). $\mathrm{Na}$ análise estatística para as variáveis classificatórias foi executado o teste qui-quadrado ou teste exato de Fisher (frequência esperada $\leq 5$ ). RESULTADOS: O gênero predominante foi feminino $(77,8 \%)$, a média de idade de $40,7 \pm 10,0$ anos e o IMC médio de $50,2 \pm 7,7 \mathrm{Kg} / \mathrm{m}^{2}$. Observou-se associação significativa entre $\operatorname{IMC} / \mathrm{T} 1 \mathrm{M}(\mathrm{p}=0,03)$ e não significante para IMC/osteoartrite joelho e IMC/IS ( $p>0,05)$. Dor e dificuldades funcionais foram mais prevalentes no grupo de superobesos $(p<0,05)$. CONCLUSÕES: A obesidade extremamente avançada (superobesidade) acentua a alteração da morfologia do arco plantar, favorecendo a instalação do pé pronado. Adicionalmente tem influência marcante sobre sintomatologia de dor e as alterações funcionais do joelho e do pé.

Descritores: 1.Obesidade mórbida 2.Pé plano 3.Cirurgia bariátrica 4.Osteoartrite 5.Questionários 


\section{SUMMARY}

Luiz SMF. Impact of two levels of severe obesity on osteoarticular and functional changes of knee and foot [thesis]. São Paulo: "Faculdade de Medicina, Universidade de São Paulo"; 2012. 82p.

Obesity can promote a variety of musculoskeletal disorders and is associated with pain and functional disability. This study aimed to analyze the influence of two levels of severe obesity (40 to $50 \mathrm{~kg} / \mathrm{m}^{2}$ versus $50 \mathrm{~kg} / \mathrm{m}^{2}$ higher) on osteoarticular and functional changes of the knee and foot in candidates for bariatric surgery. METHODS: We analyzed 81 subjects which were stratified according to BMI in two groups, with BMl1 $\left(40,0\right.$ to $\left.49,6 \mathrm{~kg} / \mathrm{m}^{2}\right)$ and BMI2 $\left(50,0\right.$ to $\left.81,3 \mathrm{~kg} / \mathrm{m}^{2}\right)$. The population underwent radiological analysis for knee osteoarthritis (Kellgren-Lawrence scale); $x$-ray of the foot to measure the talus-first metatarsal angle (T1M); footprint to calculate the Staheli index (SI) and functional questionnaires, Western Ontario and McMaster Universities Ostheoarthritis Index (WOMAC) and Foot and Ankle Outcome Score (FAOS). Statistical analysis for categorical variables was performed the chi-square or Fisher's exact test (expected frequency $\leq 5$ ). RESULTS: The predominant gender was female $(77,8 \%)$, mean age was $40,7 \pm 10,0$ years and mean BMI $50,2 \pm 7,7 \mathrm{Kg} / \mathrm{m}^{2}$. There was a significant association between $\mathrm{BMI} / \mathrm{T} 1 \mathrm{M}$ $(p=0,03)$ and not significant for BMl / knee osteoarthritis and BMl / SI $(p>0,05)$. Pain and functional disability were more prevalent in the group of superobese $(p<0,05)$. CONCLUSIONS: Superobesity promotes additional alteration of the morphology of the plantar arch, favoring the installation of pronated foot. It has an important influence on symptoms of pain and functional changes of the knee and foot.

Descriptors: 1 .Morbid obesity 2.Flatfoot 3 .Bariatric surgery 4 .Osteoarthritis 5.Questionnaires 


\section{INTRODUÇÃO}

A obesidade representa uma ameaça crescente á saúde da população mundial. Atualmente, é considerada um dos maiores desafios de saúde pública e representa grande preocupação em função de sua expansão epidêmica ${ }^{1,2,3}$.

Eleva o risco de desenvolvimento de uma série de doenças crônicas não transmissíveis, incluindo doença cardiovascular, osteoarticulares, endócrinas, neoplásicas, além de transtornos físicos e psicológicos ${ }^{1,2,4}$. Indivíduos que apresentam graus severos de obesidade (superobesos), têm seus riscos elevados ${ }^{3}$ e consequentemente são afetados de forma mais severa por estas doenças, o que contribui para uma má qualidade de vida ${ }^{5}$.

A obesidade influencia de forma negativa em muitas condições ortopédicas, aumentando sua prevalência e interferindo negativamente no resultado de tratamento destas condições ${ }^{6-9}$. As limitações funcionais e estruturais impostas pelo persistente excesso de peso, produzem alterações no pé, tornozelo, joelho e quadril, aumentando a vulnerabilidade a lesões nestas articulações ${ }^{9,10}$.

A magnitude de altas cargas e a sustentação contínua de peso, pelo joelho e pé, pode desencadear desconforto e dor musculoesquelética, osteoartrite $^{11-15}$, fraturas ${ }^{10}$, desvios posturais ${ }^{16}$, tendinite e fasceíte plantar ${ }^{8}$, além de rebaixamento ou perda da altura do arco longitudinal medial (pé plano) ${ }^{7}$. 
A dor e o desconforto associados a estas alterações, principalmente na osteoartrite $(\mathrm{OA})$ de joelho, interferem na função e mobilidade e limitam a capacidade de realizar exercícios físicos com a finalidade de perda de peso, o que agrava ainda mais o problema da obesidade ${ }^{17,18}$.

Apesar destes efeitos deletérios, há pouca informação disponível sobre a associação destas alterações em obesos graves e superobesos, do ponto de vista funcional e estrutural do joelho e pé.

Analisar o impacto da obesidade sobre estas estruturas pode propiciar informações importantes na adequação de medidas que levem ao alívio dos sintomas e controle destas afecções, pois embora a cirurgia bariátrica amenize o quadro, problemas residuais são frequentes, exigindo atenção ao longo do seguimento pós-operatório. 


\section{REVISÃO DA LITERATURA}

\subsection{Obesidade no Brasil}

A obesidade no Brasil vem seguindo a tendência mundial. Nas últimas três décadas, o processo de transição nutricional no Brasil, evidencia um paradoxo: o declínio da desnutrição em crianças e adultos e o aumento em ritmo acelerado da prevalência do sobrepeso e obesidade ${ }^{19}$.

No Brasil, cerca de 38 milhões de brasileiros com mais de 20 anos estão acima do peso. Dentre este total, mais de 10 milhões são considerados obesos, de acordo com padrões da Organização Mundial de Saúde (OMS) e Organização das Nações Unidas para Agricultura Alimentação (FAO) ${ }^{20}$.

Já a população de obesos graves (IMC superior a $40 \mathrm{Kg} / \mathrm{m}^{2}$ ) é de aproximadamente 609 mil pessoas, com estimativa de percentual de 0.64 (IC 95\%; 0.55 - 0.74) da população brasileira. Sendo a ocorrência maior, em indivíduos de baixa renda e do gênero feminino, com média nacional de 0.95\% contra $0.32 \%$ no masculino. Em quase 30 anos (1974 - 2003), o percentual desta população cresceu $255 \%$, sendo o maior crescimento no gênero masculino, $700 \%{ }^{21,22}$.

Dados da quinta edição da Pesquisa de Orçamentos Familiares (POF 2008-2009), do Instituto Brasileiro de Geografia e Estatística (IBGE), revelaram que este aumento ocorreu em todas as regiões (principalmente na 
região sul); em todas as faixas etárias e de renda do país. O excesso de peso (sobrepeso) em homens apresentou o maior crescimento de 18,5\% para $50.1 \%$, ultrapassando o de mulheres que saltou de $28.7 \%$ para $48 \%$. Este crescimento foi mais evidente nos homens com maior rendimento $(61,8 \%)$. Nesse grupo também se concentra o maior percentual de obesos, $16,9 \%$ entre as mulheres e $12.4 \%$ no grupo masculino ${ }^{20}$.

\subsection{Obesidade e Problemas musculoesqueléticos}

Obesidade aumenta a prevalência e tem efeito negativo em várias condições ortopédicas ${ }^{6}$

Complicações musculoesqueléticas são frequentemente relacionadas ao excesso de peso corporal ${ }^{8,9,11,23}$. Por vezes incapacitante, sua frequência, em função do crescimento da obesidade, também tem aumentado, juntamente com a carga social, econômica e o detrimento da qualidade de vida destes indivíduos ${ }^{12}$. Entretanto, poucos trabalhos publicados na literatura ratificam essa relação em muitas condições musculoesqueléticas ${ }^{11}$.

Indivíduos obesos apresentam maior incidência de dor e disfunção musculoesquelética quando comparados com indivíduos eutróficos ${ }^{11}$. Ombro, coluna vertebral, joelho, pé e tornozelo são regiões frequentemente afetadas ${ }^{6}$. 


\subsection{Obesidade e osteoartrite (OA)}

A associação mais documentada é a osteoartrite de joelho. Atualmente a relação índice de massa corporal (IMC) e osteoartrite de joelho estão bem estabelecidas e esta se intensifica de acordo com incremento do IMC. Mulheres obesas têm aproximadamente quatro vezes mais OA de joelho ${ }^{24}$.

Obesidade é certamente o fator de risco modificável mais importante para o surgimento, progressão e sintomas da OA da articulação do joelho. Entretanto o efeito causal não se deve apenas ao suporte excessivo e repetitivo do peso corporal, visto ser baixa a prevalência de OA nas articulações do quadril e tornozelo ${ }^{11,25}$. A deterioração fisiológica induzida pelo envelhecimento, também contribui para esta alteração, sendo cada vez mais necessário o tratamento cirúrgico de artroplastia de joelho nestes indivíduos ${ }^{25}$.

As cargas a que o joelho está exposto é resultante da ação conjunta de forças externas (gravidade e reações do solo) quase sempre dependentes da massa corporal. Em posição ortostática esta equivale aproximadamente a $43 \%$ do peso corpóreo, o que também se reflete na marcha, principalmente no início da fase de apoio ${ }^{26}$.

A perda de peso pode influenciar diretamente nos problemas musculoesqueléticos, amenizando a sintomatologia e melhorando a função muscular das áreas afetadas ${ }^{6,12}$.

Recentes estudos, baseados em quatro meta-análises, demonstraram que indivíduos submetidos á cirurgia bariátrica tiveram melhora da dor e da função na $O A$ de joelho, e que, portanto o tratamento cirúrgico contribui favoravelmente na melhora das condições musculoesqueléticas ${ }^{11,27,28,29}$. 


\subsection{Obesidade e Pé}

O pé é a base, sólida e estável, de apoio de todo nosso peso corporal. Responsável por absorver continuamente altas forças de reação do solo durante as atividades da vida diária. O arco longitudinal medial é o componente principal de absorção e dissipação dessas forças na região plantar, principalmente durante a deambulação ${ }^{30,31}$.

Dor e disfunção podal são altamente prevalentes, mesmo em pessoas mais jovens. Atinge $14 \%$ de adolescentes e $42 \%$ de adultos maiores de 42 anos. Está associada ao sexo feminino, envelhecimento, aumento do IMC e da relação cintura-quadril, resultando em um impacto negativo na qualidade de vida destes indivíduos ${ }^{32,33}$.

A obesidade pode provocar diversas alterações clínicas, funcionais e estruturais nos pés, que incluem desde alterações biomecânicas como pé plano, alteração do coxim gorduroso plantar, aumento da pressão e área plantar, fraqueza muscular e alterações da marcha ${ }^{9,34,35}$.

A estrutura do arco longitudinal do pé (ALM) tem sido descrita como uma das mais importantes características estruturais do pé, a qual influencia acentuadamente a função estática e dinâmica do mesmo ${ }^{36,37}$. Anormalidades na altura do arco plantar podem alterar significativamente a biomecânica das extremidades inferiores, predispondo o surgimento de lesões ${ }^{38,39}$, desequilíbrios e condições instáveis de funcionalidade como pés cavos e planos ${ }^{40}$. 
A avaliação do ALM do pé é considerada um parâmetro importante na classificação do tipo de pé. Tem implicações no exame clínico, bem como no prognóstico e tratamento da patologia ${ }^{40}$. De acordo com a altura do arco plantar, o pé pode ser classificado em cavo, normal e plano ${ }^{36}$.

Pé plano ou pronado caracteriza-se por um rebaixamento ou perda do arco longitudinal medial (ALM), quando em posição ortostática ${ }^{41,42}$. A pronação contínua é causa primária de desconforto e disfunção nos membros inferiores, ocasionando dor articular e distensão muscular ${ }^{36}$.

O arco longitudinal medial tem sido utilizado como principal referência no diagnóstico de pé plano ${ }^{43,44}$. Existem vários métodos, direto e indireto, para se classificar o $\mathrm{ALM}^{45,46}$.

O exame radiográfico constitui-se em um método direto, confiável e seguro, na avaliação das estruturas do ALM em posição ortostática com descarga de peso ${ }^{47,48}$. Diferentes medidas têm sido propostas para se avaliar a altura do $\mathrm{ALM}^{49,50,51}$, entre estas, o ângulo tálus-primeiro metatarso tem sido descrito como um dos mais fidedignos ${ }^{51}$. Entretanto não há um consenso, clínico ou radiológico, sobre qual o melhor método e/ou medida para se avaliar pé plano ou pronado ${ }^{52}$.

A impressão plantar é um método indireto, comumente usado na avaliação do $\mathrm{ALM}^{36,37,53}$, sendo que, existem vários métodos para a avaliação da mesma ${ }^{54,55}$. Alguns autores questionam seu uso para se classificar o $\mathrm{ALM}^{47,56}$, outros entretanto, a consideram um método confiável ${ }^{36,37,53,55}$. Kanatli et al estabeleceram correlação positiva entre impressão plantar e a avaliação radiológica do $\mathrm{ALM}^{44}$. 
A obesidade destaca-se como um dos fatores que contribuem para planificar o arco plantar ${ }^{7}$, influenciando desta forma, o formato do pé ${ }^{57}$.

Fabris et al constataram que indivíduos obesos apresentam alteração significativa no formato do pé e nos valores de pressão plantar. Onde a área de contato com o solo e o pico de pressão aumenta com o aumento do IMC, e que indivíduos obesos têm uma tendência maior ao pé plano, quando comparados com indivíduos não obesos ${ }^{34}$.

Estudos demonstram que a redução do peso corporal, após cirurgia bariátrica, alivia de forma acentuada as patologias do arco plantar, principalmente no que se referem as dores musculares crônicas. ${ }^{11,17,58}$. 


\section{OBJETIVOS}

\subsection{Objetivo geral}

Analisar a influência de dois níveis de obesidade grave (IMC de 40 a $50 \mathrm{Kg} / \mathrm{m}^{2}$ versus maior $50 \mathrm{Kg} / \mathrm{m}^{2}$ ) sobre as alterações osteoarticulares e funcionais de joelho e pé.

\subsection{Objetivos específicos}

- Verificar a presença e classificar o nível de osteoartrite de joelho;

- Verificar e classificar a morfologia do pé;

- Avaliar a influência dos dois níveis de obesidade sobre dor e disfunção de joelho e pé. 


\section{MÉTODOS}

\subsection{Amostra da população}

A amostra da população foi constituída de 81 pacientes obesos classe III (IMC > $\left.40 \mathrm{~kg} / \mathrm{m}^{2}\right)$, todos com indicação de tratamento cirúrgico da obesidade; selecionados aleatoriamente no ambulatório multidisciplinar de tratamento da obesidade do Hospital de Base da Faculdade de Medicina de São José do Rio Preto (FUNFARME/FAMERP).

Os participantes da pesquisa assinaram um Termo de Consentimento Livre e Esclarecido - TCLE - (Anexo A), de acordo com a resolução 196/196 do Conselho Nacional de Saúde.

Este protocolo foi aprovado pela Comissão Ética do Hospital das Clínicas (CapPesq) sob número 197/10 (Anexo B) e pelo Comitê de Ética em Pesquisa da Faculdade de Medicina de São José do Rio Preto (FAMERP) sob número 6608/2010 ( Anexo C). 


\subsection{Delineamento}

Estudo transversal e sem intervenção clínica e/ou terapêutica, realizado no período de janeiro/2011 a fevereiro de 2012.

\subsection{Critérios de inclusão}

Esta pesquisa definiu como critérios de inclusão:

- Idade entre 18 - 65 anos;

- Ambos os sexos;

- Pacientes com indicação de tratamento cirúrgico da obesidade;

- Ambulatoriais e com índice de massa corporal $>40 \mathrm{Kg} / \mathrm{m}^{2} \mathrm{sem}$ comorbidades ou $>35 \mathrm{Kg} / \mathrm{m}^{2}$ com comorbidades;

- Consentimento livre e informado

\subsection{Critérios de exclusão}

- Sequelas neurológicas com comprometimento locomotor; que impeçam o posicionamento estático no aparelho;

- Sequelas ortopédicas que impossibilitem o apoio plantar;

- Presença de pé diabético ou úlcera venosa 
- Uso de auxiliares de deambulação ou incapacidade de se manter em ortostatismo sem auxiliares;

- Doenças cognitivas, moléstia de Alzheimer, quadros demenciais;

- Indivíduos sem capacidade de entendimento ou se recusando a participar do projeto.

- Uso contínuo de medicação utilizada no tratamento de transtornos osteoarticulares crônicos, fundamentados nos registros hospitalares e prescritos por médico.

\subsection{Desenho experimental}

O diagrama abaixo ilustra graficamente as etapas que foram desenvolvidas (Figura 1). 


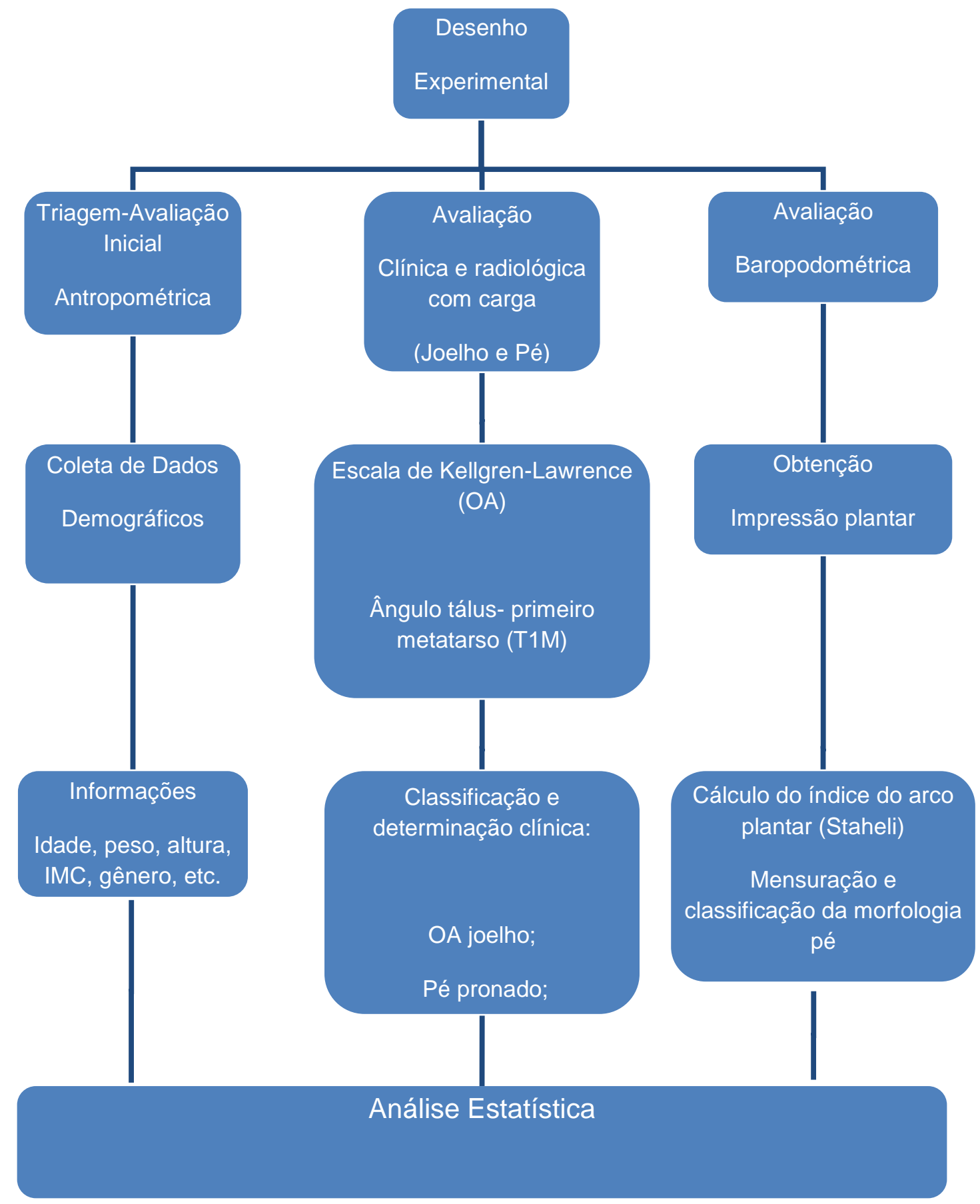

Figura 1 - Fluxograma das etapas do protocolo experimental 


\subsection{Variáveis analisadas}

\subsubsection{Medidas antropométricas}

Medidas antropométricas de massa corporal e estatura foram obtidas de todos os indivíduos, para a determinação do índice de massa corporal (IMC), que trata da relação do peso em quilogramas e a altura em metros quadrados $\left(\mathrm{P} / \mathrm{A}^{2}\right)^{59}$. Para tal, utilizou-se uma balança digital com estadiômetro.

\subsubsection{Estratificação}

Para melhor caracterização os indivíduos foram classificados em dois grupos, a saber: IMC1 valores compreendidos entre 40,0 a 49,6 $\mathrm{Kg} / \mathrm{m}^{2}$; IMC2 valores entre 50,0 a $81,3 \mathrm{Kg} / \mathrm{m}^{2}$. Posteriormente os dados demográficos, análise radiológica, índice de Staheli e questionários foram confrontados entre si e com o IMC.

\subsubsection{Avaliação radiológica}

Todos os indivíduos foram submetidos á avaliação radiológica realizada, cegamente, por um médico radiologista, que consistiu de radiografia bilateral das articulações de joelho (anteroposterior) e pés (perfil), em posição ortostática, com carga sobre os membros inferiores. 


\subsubsection{Joelhos}

Os raios-x da articulação tibiofemural tiveram por objetivo avaliar a presença de osteoartrite de joelho $(\mathrm{OA})$, através dos critérios de KellgrenLawrence (K-L), onde grau zero significa sem sinais de OA; grau I diminuição duvidosa do espaço articular, grau II - OA mínima; grau III - OA moderada e grau IV significa OA severa ${ }^{60}$ (Figuras 2 e 3 ).

As radiografias foram realizadas de acordo com as normas padronizadas pelo serviço de radiologia da instituição. A incidência em anteroposterior (AP) foi realizada com o membro em extensão e apoio bipodal. À distância tubo-filme foi de um metro e o raio centrado no polo inferior da patela, exposição de 60 quilovolt $(k V)$ e 60 de miliAmpere/segundo (mAS). Cada articulação do joelho foi analisada separadamente e, para efeito de análise dos dados, considerou-se a classificação do joelho com maior grau de comprometimento. 


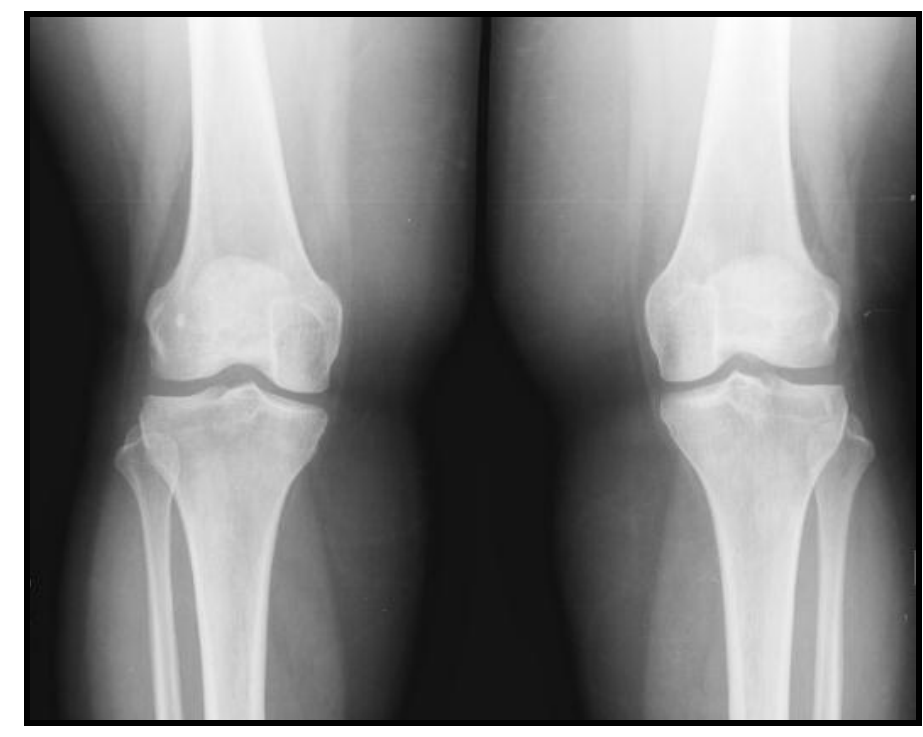

Figura 2 - Radiografia bilateral de joelho com carga (AP) sem presença $O A$ - Grau zero

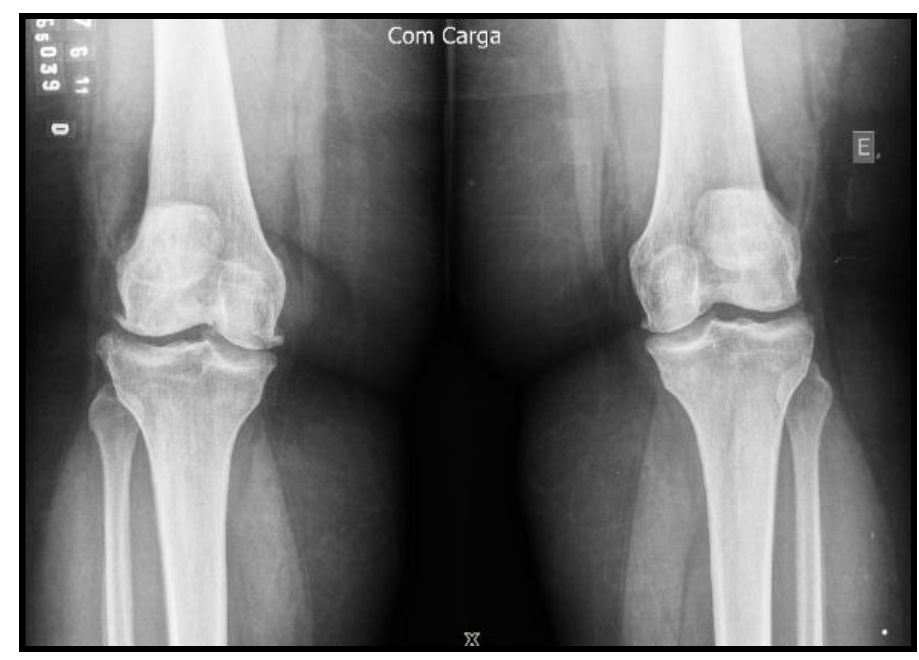

Figura 3 - Radiografia bilateral de joelho com carga (AP) e com presença de OA - Grau IV 


\subsubsection{Pés}

As radiografias de ambos os pés (perfil) tiveram o propósito de calcular o ângulo de Meary ou tálus-primeiro metatarso (T1M) a fim de se mensurar o colapso do arco longitudinal do pé e consequentemente classificar a morfologia do mesmo, em plano. Este mede o alinhamento do antepé em relação ao retropé. É um ângulo formado pelo eixo longitudinal do osso tálus com o eixo longitudinal do primeiro metatarso. Demonstra o grau de inclinação do tálus e o aumento da pronação do retropé. Valores maiores que quatro graus são considerados pés planos, de $15^{\circ}$ a $30^{\circ}$ pé plano moderado e maiores do que $30^{\circ}$ são considerados severos ${ }^{48,49,61}$. (Figura 4). As radiografias foram obtidas usando protocolo padrão da instituição. Paciente em posição ortostática, com o peso distribuído igualmente entre os pés. $O$ pé foi posicionado com a borda medial do retropé paralelamente ao filme. O raio central foi direcionado horizontalmente em direção ao nível da base do terceiro metatarso, a $90^{\circ}$ graus com o filme, a uma distância foco-filme de um metro e exposição de 60 quilovolt (KV) e 60 miliAmpere/segundo (mAS.)

Após a obtenção das radiografias efetuou-se mensuração do ângulo T1M. Para garantir a precisão dos resultados, foi traçada uma linha perpendicular na região posterior e na cabeça do osso tálus a fim de se demarcar o ponto médio e consequentemente o eixo longitudinal do mesmo. O mesmo foi realizado na região da cabeça e corpo do primeiro metatarso. Em seguida traçou-se uma linha sobre o eixo longitudinal do 
tálus e do primeiro metatarso, mensurando-se assim o ângulo formado entre eles (Figura 4).

Para melhor caracterização deste ângulo, os indivíduos foram estratificados em dois grupos de acordo com os valores obtidos: grupo 1 (G1) de $4^{\circ}$ a $10^{\circ}$ e grupo $2(G 2)$ de $10^{\circ}$ a $15^{\circ}$.

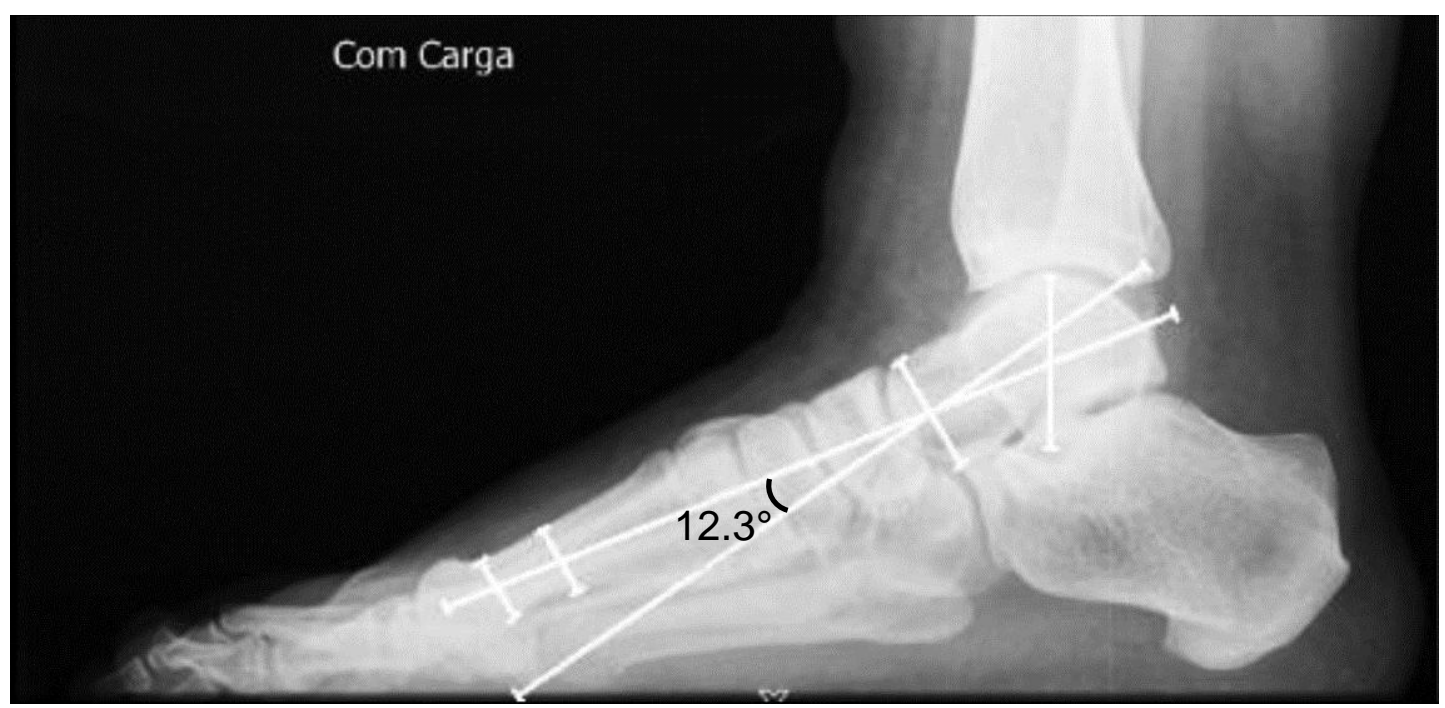

Figura 4 - Radiografia do pé com carga (perfil). Mensuração ângulo tálusprimeiro metatarso.

As medidas das angulações foram realizadas e armazenadas no Sistema de Arquivo e Comunicação de Imagem (EMR - Armazenamento de registros médicos eletrônico - VEPRO). 


\subsubsection{Avaliação baropométrica - Índice de Staheli (IS)}

Este índice se refere á mensuração indireta da altura do arco plantar e permite classificar o mesmo em cavo, normal e plano ${ }^{48,55,62}$. As figuras 5,6 e 7 exemplificam a impressão plantar de pé cavo, normal e plano, respectivamente, fornecidas pelo baropodômetro.

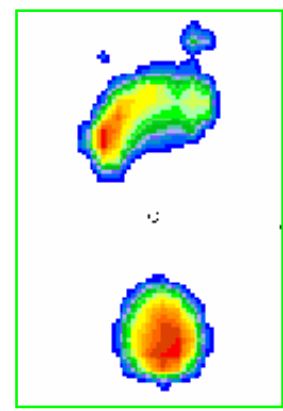

Figura 5

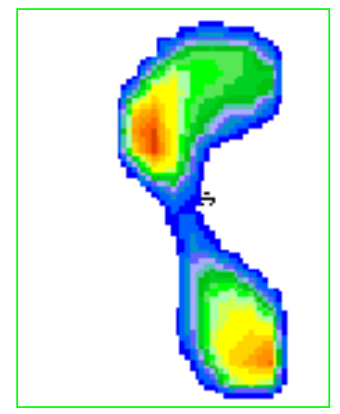

Figura 6

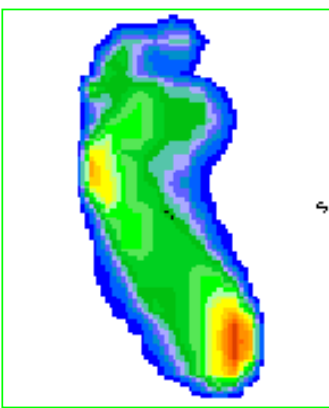

Figura 7

Os métodos indiretos (mais comuns) referem-se á análise da impressão plantar, onde se estabelece uma relação entre a região central e a região posterior do pés ${ }^{36,55}$. Para este estudo o método escolhido foi o índice de Staheli ${ }^{55}$ adaptado. Para tal, traçou-se uma reta horizontal (denominada $A$ ) na metade do istmo plantar e outra reta, também horizontal (denominada $B$ ), coincidindo com a metade da impressão do calcâneo. Para padronizar os locais exatos de demarcação do istmo plantar e da metade da impressão do calcâneo, foi traçada uma reta longitudinal (denominada $L$ ), no sentido anteroposterior da impressão plantar. A reta $A$ foi traçada exatamente na metade da reta $L$, e a reta $B$ coincidindo com $1 / 6$ da mesma ${ }^{63}$ (Figura 8). Procedeu-se então a divisão da reta $A$ pela reta $B$. Para os valores 
encontrados de 0.3 a 1.0 centímetro, o pé foi considerado normal, para os valores superiores a 1.0 centímetro, ou seja, quando o valor da reta $A$ for maior do que o da reta $B$, o pé foi classificado como plano. Para o valor inferior a 0.3 centímetro, foram considerados cavos ${ }^{55}$. Em relação ao índice de Staheli (IS); os indivíduos foram estratificados em grupo I de 0.3 a 1 centímetro e grupo II > 1centímetro.

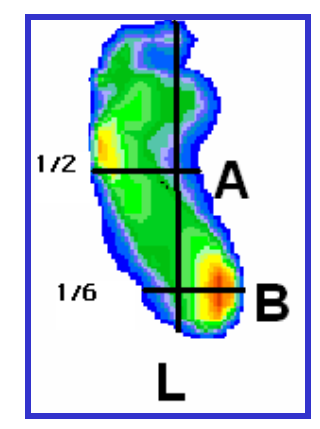

Figura 8 - Representação gráfica do cálculo do índice de Staheli.

Imagens da impressão plantar foram coletadas a fim de se mensurar e calcular o índice do arco plantar (Figura 9). Para a obtenção de impressão plantar (footprint) utilizou-se um aparelho de baropodometria computadorizado, composto por uma plataforma de força de 1600 sensores capacitivos, $90 \times 75$ centímetros de diâmetro e frequência amostral de $50 \mathrm{~Hz}$ (Figura 10). Foi solicitado aos indivíduos, que se colocassem em posição ortostática, apoio bipodal e com os pés descalços sobre a plataforma do aparelho (Figura 11). O aparelho foi calibrado individualmente, através do peso corporal e tamanho do pé. Os dados coletados foram analisados pelo software FootChecker® $3.1 \mathrm{e}$ armazenados em banco de dados, para posterior análise. 


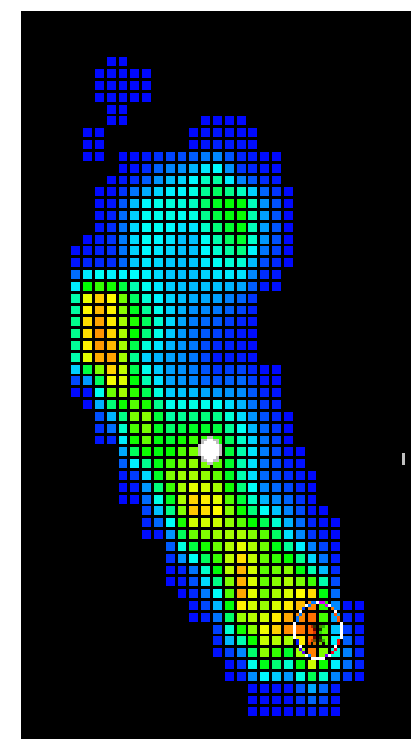

Figura 9 - Impressão plantar fornecida pelo baropômetro

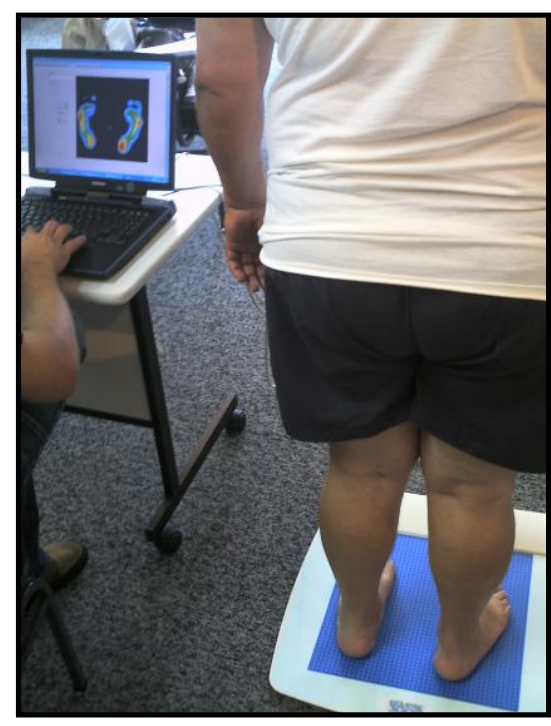

Figura 10 - Visão geral do baropodômetro

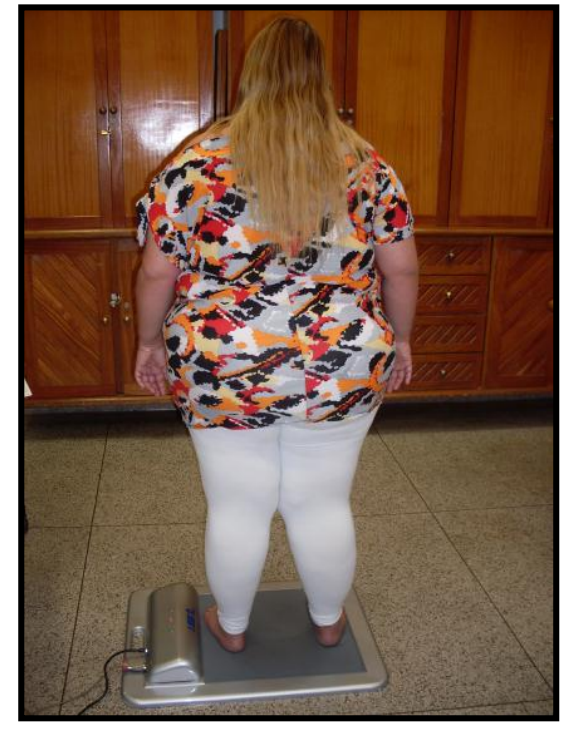

Figura 11 - Posicionamento do sujeito na plataforma do aparelho 


\subsubsection{Questionários}

A pesquisa contemplou a aplicação de três questionários (Anexo D). O primeiro incluiu dados demográficos, como idade, sexo, peso, altura, assim como outros dados pessoais.

O segundo se referiu ao questionário Western Ontario and McMaster Universities Osteoarthritis Index (WOMAC) em sua versão validada para a língua portuguesa ${ }^{64}$ e que permite avaliar dor, rigidez articular e função física (nas últimas 48 horas) associados á osteoartrite (OA) de joelho ou quadril.

É composto por 24 itens, onde utiliza para todos os itens a classificação: nenhuma, pouca, moderada, intensa e muito intensa. Estas correspondem a uma escala ordinal de 0 a 4 . Maior pontuação no WOMAC indica pior dor, rigidez e limitação funcional. É rápido e de fácil aplicabilidade ${ }^{1}$.

Para a avaliação da função e sintomas do pé e tornozelo, utilizou-se como instrumento o Foot and Ankle Outcome Score (FAOS) também validado para a língua portuguesa. Este tem por objetivo avaliar a percepção do indivíduo em relação aos transtornos relacionados ao pé e tornozelo, tendo como base á semana anterior em que o questionário foi respondido. É de fácil aplicação e compreensão. Constituído de cinco subescalas: dor, outros sintomas, atividades de vida diária (AVD), esporte e recreação e qualidade de vida (QV) em relação ao pé e tornozelo. Cada questão tem pontuação variando de 0 a 4, sendo então calculado um escore para cada subescala, onde 100 pontos significa sem sintomas e zero indica sintomas extremos ${ }^{65}$. Seu conteúdo baseia-se no Knee Injury and Osteoarthritis Outcome Score (KOOS) ${ }^{66}$. 
Neste estudo optou-se por não pontuar o escore final, tanto para WOMAC quanto para o FAOS, mas confrontar todas as questões de cada subescala, com as demais variáveis investigadas (IMC, raio-x joelho, raio- $\mathrm{X}$ pé e impressão plantar), a fim de se verificar, de forma específica, uma possível relação entre os sintomas percebidos pelo indivíduo e as demais variáveis analisadas.

\subsection{Análise estatística}

As análises estatísticas foram executadas pelo software $S P S S^{\oplus} 7.5$. Para as variáveis classificatórias (IMC, OA, T1M, IS, WOMAC e FAOS), utilizou-se o teste qui-quadrado ou teste Exato de Fisher ( quando resultado esperado em $20 \%$ ou mais das caselas da tabela for $\leq 5$ ). Foi considerado nível de significância de $5 \%(p<0,05)^{67}$. 


\section{RESULTADOS}

Inicialmente foram recrutados para este estudo 84 indivíduos, sendo que três foram excluídos, representando 3,7\% da amostra inicial, um devido a pé diabético (úlcera em região plantar esquerda) e dois por apresentarem dificuldade de deambulação e incapacidade de se manter na posição ortostática, sem auxílio de bengala canadense. Como consequência, 81 indivíduos foram efetivamente incluídos neste protocolo ( $n=81$; idade $40,7 \pm 10,0$ anos; gênero $77,8 \%$ feminino; IMC $50,2 \pm 7,7 \mathrm{Kg} / \mathrm{m}^{2}$ ). Os mesmos foram estratificados em IMC1 e IMC2.

Em todos os indivíduos foram realizados testes hematológicos e bioquímicos para avaliação das principais comorbidades, que não revelaram diferenças entre os dois grupos (Anexo E).

A tabela abaixo demonstra as características gerais e a estratificação da amostra (Tabela 1). 
Tabela 1 - Características gerais da amostra de acordo com o índice de massa corporal - IMC

\begin{tabular}{|c|c|c|c|}
\hline CARACTERÍSTICAS & $\begin{array}{c}\text { TOTAL } \\
40 \text { a } 81,3 \\
\left(\mathrm{Kg} / \mathrm{m}^{2}\right) \\
\text { n } 81\end{array}$ & $\begin{array}{c}\text { IMC1 } \\
40 \text { a } 49,6 \\
\left(\mathrm{Kg} / \mathrm{m}^{2}\right) \\
\text { n } 46\end{array}$ & $\begin{array}{c}\text { IMC2 } \\
50 \text { a } 81,3 \\
\left(\mathrm{Kg} / \mathrm{m}^{2}\right) \\
\text { n } 35\end{array}$ \\
\hline \multicolumn{4}{|l|}{ Idade; Anos } \\
\hline média \pm DP & $40,7 \pm 10,0$ & $42,2 \pm 9,5$ & $38,7 \pm 10,5$ \\
\hline Gênero; \% & 77,8 feminino & 87,0 feminino & 65,7 feminino \\
\hline \multicolumn{4}{|l|}{ OA; Kellgren-Lawrence; \% } \\
\hline Grau 0 & $1(1,2)$ & $1(2,2)$ & $0(0,0)$ \\
\hline Grau 1 & $14(17,3)$ & $8(17,4)$ & $6(17,1)$ \\
\hline Grau 2 & $32(39,5)$ & $22(47,8)$ & $10(28,6)$ \\
\hline Grau 3 & $28(34,6)$ & $12(26,1)$ & $16(45,7)$ \\
\hline Grau 4 & $6(7,4)$ & $3(6,5)$ & $3(8,6)$ \\
\hline $\begin{array}{l}\text { T1M; grau } \\
\text { média } \pm D P\end{array}$ & $10,7 \pm 1,3$ & $10,6 \pm 1,3$ & $10,9 \pm 1,3$ \\
\hline $\begin{array}{l}\text { IS; cm; } \\
\text { média } \pm D P\end{array}$ & $0,9 \pm 0,2$ & $0.9 \pm 0,2$ & $0,9 \pm 0,2$ \\
\hline
\end{tabular}

Abreviações: \%, porcentagem; cm, centímetro; DP, desvio padrão; IS, índice de Staheli; $\mathrm{Kg} / \mathrm{m}^{2}$, Quilograma/metro quadrado; $\mathrm{OA}$, osteoartrite; $\mathrm{T} 1 \mathrm{M}$, ângulo tálus-primeiro metatarso. Os valores entre parênteses referem-se á porcentagem. 


\subsection{Resultados encontrados entre IMC e Avaliação Radiológica}

\subsubsection{IMC e Osteoartrite de joelho}

De acordo com o escore de Kellgren \& Lawrence $81,5 \%$ da amostra em estudo apresentou escore $\geq 2$. (Gráfico1).

Gráfico 1 - Frequência relativa da estratificação de osteoartrite de joelho em relação a IMC1 e IMC2

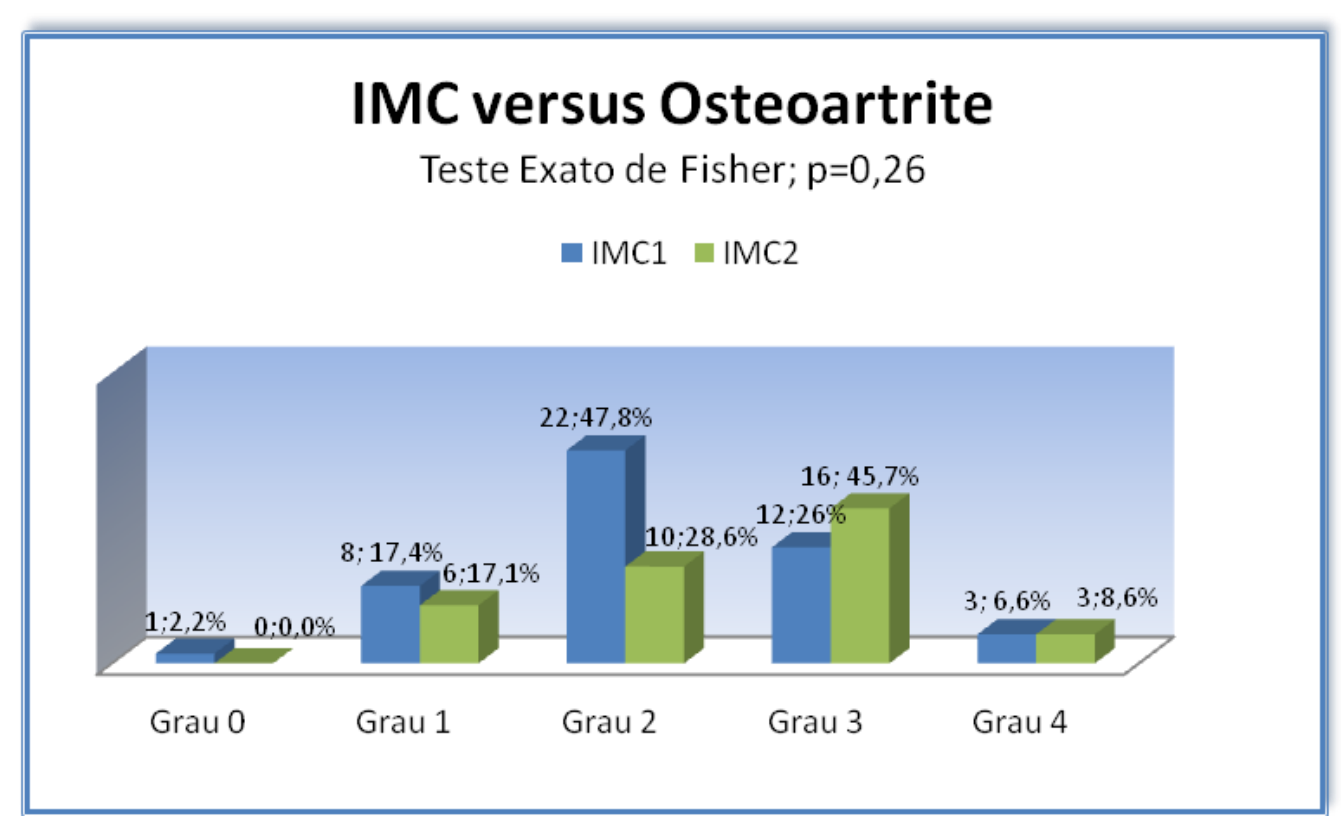

5.1.2 IMC e ângulo tálus-primeiro metatarso (T1M)

Dos 81 indivíduos selecionados, 100\% apresentaram ângulo maior que $4^{\circ}$ graus, considerados como pés planos de acordo com a literatura ${ }^{48,49}$, sendo que 24 indivíduos (29,6\%) pertenciam ao G1 e 57 indivíduos (70,4\%) ao G2. 
O gráfico 2 apresenta a associação significa $(p=0,03)$ do IMC com o ângulo T1M. Ao se estratificar a população observou-se que quanto maior o IMC maior o ângulo T1M.

Gráfico 2 - Frequência relativa da estratificação do ângulo T1M em relação a IMC1 e IMC2

\section{IMC versus T1M}

$x^{2}=4,609 ; G L=1 ; p=0,03$

$\square \mid \mathrm{MC1}=\mathrm{MC2}$

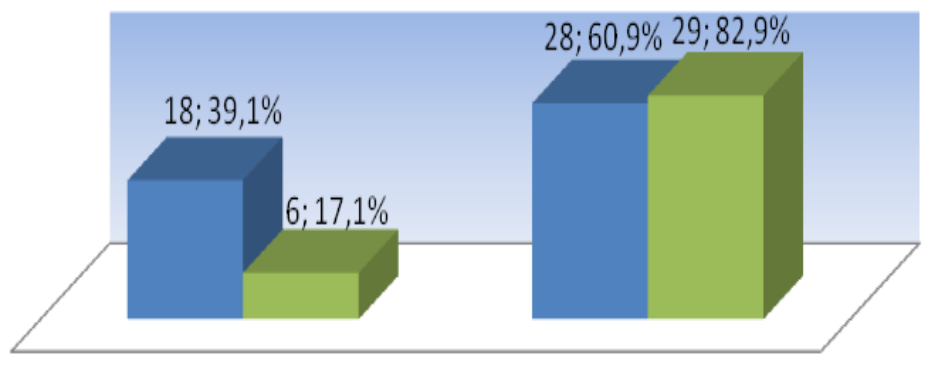

G1

G2

5.2 Resultados encontrados entre IMC e avaliação baropométrica - Índice de Staheli (IS)

A maioria dos indivíduos selecionados apresentou, de acordo com a classificação de Staheli, morfologia de pé considerada normal (62; 76,5 \%) e (19; 23,5\%) morfologia de pé considerado plano . Neste estudo não foi possível verificar a associação entre o IMC e o índice de Staheli $(p=0,67)$. Ao se estratificar a população por IMC não houve melhora desta correlação (Gráfico 3). 
Gráfico 3 - Frequência relativa da estratificação do Índice de Staheli em relação a IMC1 e IMC2

\section{IMC versus IS \\ $\mathrm{X}^{2}=0.175 ; \mathrm{GL}=1 ; \mathrm{p}=0,67$ \\ -IMC1 $=$ IMC2}

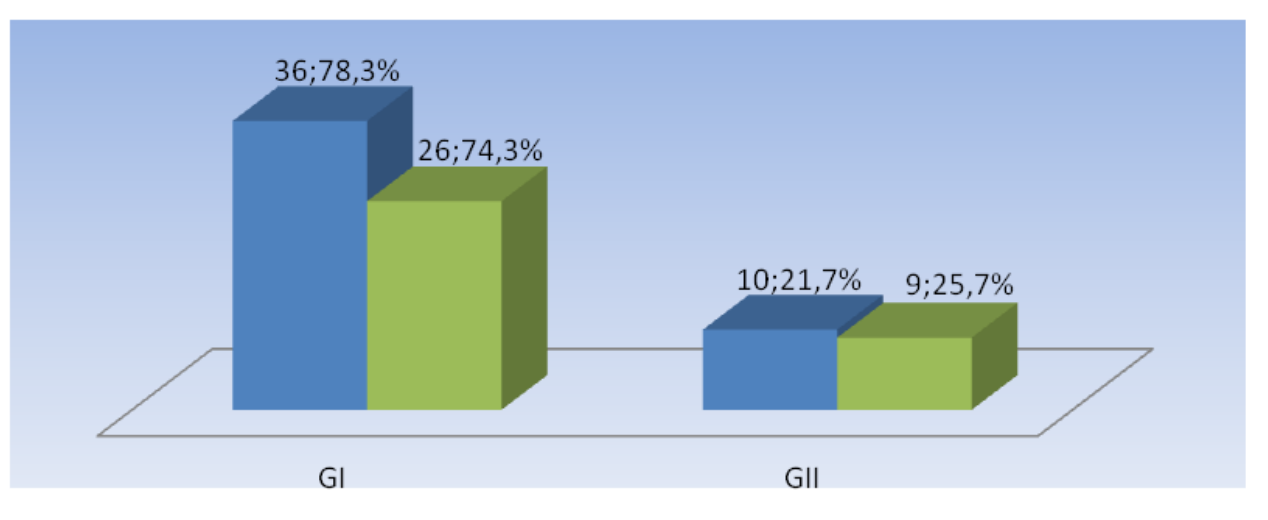

5.3 Resultados encontrados entre IMC e as questões qualitativas dos questionários WOMAC e FAOS

A tabela 2 apresenta os resultados entre o IMC e a variável dor e rigidez articular de joelho, obtidos pelo questionário WOMAC. 
Tabela 2 - Frequência relativa do IMC versus dor no joelho e rigidez articular obtida pelo questionário WOMAC

\begin{tabular}{|c|c|c|c|c|c|}
\hline VARIÁVEIS & \multicolumn{2}{|c|}{$\begin{array}{l}\text { IMC1 } \\
n=46\end{array}$} & \multicolumn{2}{|r|}{$\begin{array}{l}\text { IMC2 } \\
n=35\end{array}$} & \multirow[t]{2}{*}{ ANÁLISE } \\
\hline \multicolumn{5}{|c|}{ Dor nos joelhos durante as últimas 48 hs } & \\
\hline \multicolumn{6}{|c|}{ Caminhando em lugar plano } \\
\hline Nenhuma & 21 & $(45,7)$ & 5 & $(14,3)$ & \multirow{3}{*}{$\begin{array}{l}\text { Fisher } \\
p=0,01\end{array}$} \\
\hline Pouca a Moderada & 14 & $(30,4)$ & 17 & $(48,6)$ & \\
\hline Intensa a Muito intensa & 11 & $(23,9)$ & 13 & $(37,1)$ & \\
\hline \multicolumn{6}{|c|}{ Subindo/descendo escadas } \\
\hline Nenhuma & 14 & $(30,4)$ & 2 & $(5,7)$ & \multirow{3}{*}{$\begin{array}{l}\text { Fisher } \\
p=0,02\end{array}$} \\
\hline Pouca a Moderada & 9 & $(19,6)$ & 11 & $(31,4)$ & \\
\hline Intensa a Muito intensa & 23 & $(50,0)$ & 22 & $(62,9)$ & \\
\hline \multicolumn{3}{|l|}{ A noite deitado na cama } & \multicolumn{3}{|c|}{$(n=34)$} \\
\hline Nenhuma & 27 & $(58,7)$ & 10 & $(29,4)$ & \multirow{3}{*}{$\begin{array}{l}\text { Fisher } \\
p=0,01\end{array}$} \\
\hline Pouca a Moderada & 13 & $(28,3)$ & 20 & $(58,8)$ & \\
\hline Intensa a Muito intensa & 6 & $(13,0)$ & 4 & $(11,8)$ & \\
\hline \multicolumn{6}{|l|}{ Ao sentar/deitar } \\
\hline Nenhuma & 18 & $(39,1)$ & 7 & $(20,0)$ & \multirow{3}{*}{$\begin{array}{c}x^{2}=3,487 \\
\quad G L=2 ; \\
p=0,2\end{array}$} \\
\hline Pouca a Moderada & 17 & $(37,0)$ & 18 & $(51,4)$ & \\
\hline Intensa a Muito intensa & 11 & $(23,9)$ & 10 & $(28,6)$ & \\
\hline \multicolumn{6}{|l|}{ Ficando em pé } \\
\hline Nenhuma & 11 & $(23,9)$ & 4 & $(11,4)$ & \multirow{3}{*}{$\begin{array}{l}\text { Fisher } \\
p=0,2\end{array}$} \\
\hline Pouca a Moderada & 16 & $(34,8)$ & 11 & $(31,4)$ & \\
\hline Intensa a Muito intensa & 19 & $(41,3)$ & 20 & $(57,2)$ & \\
\hline \multicolumn{6}{|c|}{ Rigidez articular } \\
\hline \multicolumn{6}{|l|}{ Rigidez Matinal } \\
\hline Nenhuma & 16 & $(34,8)$ & 7 & $(20,0)$ & \multirow{3}{*}{$\begin{array}{c}x^{2}=2,704 \\
\quad G L=2 ; \\
p=0,26\end{array}$} \\
\hline Pouca a Moderada & 20 & $(43,5)$ & 16 & $(45,7)$ & \\
\hline Intensa a Muito intensa & 10 & $(21,7)$ & 12 & $(34,3)$ & \\
\hline \multicolumn{6}{|l|}{ Rigidez Durante o dia } \\
\hline Nenhuma & 20 & $(43,5)$ & 8 & $(22,8)$ & \multirow{3}{*}{$\begin{array}{l}\text { Fisher } \\
p=0,09\end{array}$} \\
\hline Pouca a Moderada & 18 & $(39,1)$ & 22 & $(62,9)$ & \\
\hline Intensa a Muito intensa & 8 & $(17,4)$ & 5 & $(14,3)$ & \\
\hline
\end{tabular}

Abreviação: IMC; índice de massa corporal; IMC1, 40 a 49,6 Kg/m²; IMC2, 50 a 81,3 kg/m² Os valores entre parênteses referem-se á porcentagem. 
O IMC teve influência significativa sobre dor na região de pé/tornozelo, em oito das nove situações avaliadas (Tabela 3).

Tabela 3 - Frequência relativa do IMC versus dor no pé obtida pelo questionário FAOS

\begin{tabular}{|c|c|c|c|c|c|}
\hline \multicolumn{2}{|l|}{ VARIÁVEIS } & \multicolumn{2}{|l|}{$\begin{array}{l}\text { IMC1 } \\
n=46\end{array}$} & \multirow[t]{2}{*}{$\begin{array}{l}\text { IMC2 } \\
\mathrm{n}=35\end{array}$} & \multirow[t]{2}{*}{ ANÁLISE } \\
\hline \multicolumn{4}{|c|}{ Dor no Pé/Tornozelo na última semana } & & \\
\hline \multicolumn{6}{|l|}{ Frequência } \\
\hline Nunca & 9 & $(19,6)$ & 0 & $(0,0)$ & Fisher \\
\hline Mensal/Semanal & 8 & $(17,4)$ & 3 & $(8,6)$ & $p=0,004$ \\
\hline Diária/Sempre & 29 & $(63,0)$ & 32 & $(91,4)$ & \\
\hline \multicolumn{6}{|c|}{ Rodando sobre seu pé/tornozelo } \\
\hline Nenhuma & 16 & $(34,8)$ & 2 & $(5,7)$ & Fisher \\
\hline Pouca a Moderada & 13 & $(28,3)$ & 22 & $(62,9)$ & $p=0,001$ \\
\hline Intensa a Muito intensa & 17 & $(36,9)$ & 11 & $(31,4)$ & \\
\hline \multicolumn{6}{|l|}{ Forçando pé baixo } \\
\hline Nenhuma & 17 & $(36,9)$ & 2 & $(5,7)$ & Fisher \\
\hline Pouca a Moderada & 13 & $(28,3)$ & 24 & $(68,6)$ & $p=0,0002$ \\
\hline Intensa a Muito intensa & 16 & $(34,7)$ & 9 & $(25,7)$ & \\
\hline \multicolumn{6}{|l|}{ Forçando pé cima } \\
\hline Nenhuma & 16 & $(34,7)$ & 4 & $(11,4)$ & \multirow{3}{*}{$\begin{array}{l}\text { Fisher } \\
p=0,04\end{array}$} \\
\hline Pouca a Moderada & 17 & $(37,0)$ & 20 & $(57,2)$ & \\
\hline Intensa a Muito intensa & 13 & $(28,3)$ & 11 & $(31,4)$ & \\
\hline \multicolumn{6}{|c|}{ Andando em superfície plana } \\
\hline Nenhuma & 14 & $(30,4)$ & 1 & $(2,9)$ & \multirow{3}{*}{$\begin{array}{l}\text { Fisher } \\
p=0,001\end{array}$} \\
\hline Pouca a Moderada & 15 & $(32,6)$ & 21 & $(60,0)$ & \\
\hline Intensa a Muito intensa & 17 & $(37,0)$ & 13 & $(37,1)$ & \\
\hline \multicolumn{6}{|l|}{ Subindo/descendo escada } \\
\hline Nenhuma & 11 & $(23,9)$ & 0 & $(0,0)$ & \multirow{3}{*}{$\begin{array}{c}\text { Fisher } \\
p=0,0008\end{array}$} \\
\hline Pouca a Moderada & 11 & $(23,9)$ & 18 & $(51,4)$ & \\
\hline Intensa a Muito intensa & 24 & $(52,2)$ & 17 & $(48,6)$ & \\
\hline \multicolumn{6}{|l|}{ Repouso no leito } \\
\hline Nenhuma & 25 & $(54,4)$ & 9 & $(25,7)$ & \multirow{3}{*}{$\begin{array}{l}\text { Fisher } \\
p=0,005\end{array}$} \\
\hline Pouca a Moderada & 15 & $(32,6)$ & 24 & $(68,6)$ & \\
\hline Intensa a Muito intensa & 6 & $(13,0)$ & 2 & $(5,7)$ & \\
\hline \multicolumn{6}{|l|}{ Ao sentar/deitar } \\
\hline Nenhuma & 16 & $(34,8)$ & 5 & $(14,3)$ & \multirow{3}{*}{$\begin{array}{l}\text { Fisher } \\
p=0,09\end{array}$} \\
\hline Pouca a Moderada & 23 & $(50,0)$ & 25 & $(71,4)$ & \\
\hline Intensa a Muito intensa & 7 & $(15,2)$ & 5 & $(14,3)$ & \\
\hline \multicolumn{6}{|l|}{ Em pé } \\
\hline Nenhuma & 9 & $(19,6)$ & 0 & $(0,0)$ & \multirow{3}{*}{$\begin{array}{l}\text { Fisher } \\
p=0,01\end{array}$} \\
\hline Pouca a Moderada & 10 & $(21,7)$ & 11 & $(31,4)$ & \\
\hline Intensa a Muito intensa & 27 & $(58,7)$ & 24 & $(68,6)$ & \\
\hline
\end{tabular}

Abreviação: IMC, índice de massa corpórea; IMC1, 40 a 49,6 Kg/m²; IMC2, 50 a 81,3 Kg/m² Os valores entre parênteses referem-se á porcentagem. 
A análise dos resultados sobre a capacidade funcional, i.e, dificuldade em realizar determinadas funções, demonstrou que o IMC, juntamente com sua estratificação, interferiram de forma significativa sobre algumas situações. As atividades funcionais estão descritas na tabela 4.

Tabela 4 - Frequência relativa do IMC versus nível dificuldade funcional obtida pelos questionários WOMAC E FAOS

\begin{tabular}{|c|c|c|c|c|c|}
\hline VARIÁVEIS & \multicolumn{2}{|c|}{$\begin{array}{l}\text { IMC1 } \\
n=46\end{array}$} & \multicolumn{2}{|c|}{$\begin{array}{l}\mathrm{IMC2} \\
\mathrm{n}=35\end{array}$} & ANÁLISE \\
\hline \multicolumn{6}{|c|}{ Nível dificuldade para realizar as seguintes funções } \\
\hline \multicolumn{6}{|c|}{ Descer escadas } \\
\hline Nenhuma & 10 & $(21,7)$ & 8 & $(22,9)$ & \multirow{3}{*}{$\begin{array}{c}x^{2}=0,890 \\
\quad G L=2 ; \\
p=0,7\end{array}$} \\
\hline Pouca a Moderada & 16 & $(34,8)$ & 9 & $(25,7)$ & \\
\hline Intensa a Muito intensa & 20 & $(43,5)$ & 18 & $(51,4)$ & \\
\hline \multicolumn{6}{|l|}{ Subir escadas } \\
\hline Nenhuma & 8 & $(17,4)$ & 5 & $(14,3)$ & \multirow{3}{*}{$\begin{array}{l}\text { Fisher } \\
p=0,4\end{array}$} \\
\hline Pouca a Moderada & 14 & $(30,4)$ & 7 & $(20,0)$ & \\
\hline Intensa a Muito intensa & 24 & $(52,2)$ & 23 & $(65,7)$ & \\
\hline \multicolumn{6}{|c|}{ Levantar-se estando sentada } \\
\hline Nenhuma & 10 & $(21,7)$ & 3 & $(8,6)$ & \multirow{3}{*}{$\begin{array}{l}\text { Fisher } \\
p=0,1\end{array}$} \\
\hline Pouca a Moderada & 20 & $(43,5)$ & 23 & $(65,7)$ & \\
\hline Intensa a Muito intensa & 16 & $(34,8)$ & 9 & $(25,7)$ & \\
\hline \multicolumn{6}{|l|}{ Ficar em pé } \\
\hline Nenhuma & 9 & $(19,6)$ & 1 & $(3,0)$ & \multirow{3}{*}{$\begin{array}{l}\text { Fisher } \\
p=0,08\end{array}$} \\
\hline Pouca a Moderada & 16 & $(34,8)$ & 13 & $(39,4)$ & \\
\hline Intensa a Muito intensa & 21 & $(45,6)$ & 19 & $(57,6)$ & \\
\hline \multicolumn{6}{|c|}{ Abaixar-se pegar algo chão } \\
\hline Nenhuma & 10 & $(21,7)$ & 2 & $(5,7)$ & \multirow{3}{*}{$\begin{array}{l}\text { Fisher } \\
p=0,07\end{array}$} \\
\hline Pouca a Moderada & 12 & $(26,1)$ & 7 & $(20,0)$ & \\
\hline Intensa a Muito intensa & 24 & $(52,2)$ & 26 & $(74,3)$ & \\
\hline \multicolumn{6}{|l|}{ Andar no plano } \\
\hline Nenhuma & 16 & $(34,8)$ & 4 & $(11,4)$ & \multirow{3}{*}{$\begin{array}{l}\text { Fisher } \\
p=0,04\end{array}$} \\
\hline Pouca a Moderada & 19 & $(41,3)$ & 18 & $(51,4)$ & \\
\hline Intensa a Muito intensa & 11 & $(23,9)$ & 13 & $(37,2)$ & \\
\hline \multicolumn{6}{|l|}{ Entrar e sair carro } \\
\hline Nenhuma & 12 & $(26,1)$ & 3 & $(8,6)$ & \multirow{3}{*}{$\begin{array}{l}\text { Fisher } \\
p=0,1\end{array}$} \\
\hline Pouca a Moderada & 16 & $(34,8)$ & 18 & $(51,4)$ & \\
\hline Intensa a Muito intensa & 18 & $(39,1)$ & 14 & $(40,0)$ & \\
\hline \multicolumn{6}{|l|}{ Ir fazer compras } \\
\hline Nenhuma & 13 & $(28,3)$ & 3 & $(8,6)$ & \multirow{3}{*}{$\begin{array}{l}\text { Fisher } \\
p=0,1\end{array}$} \\
\hline Pouca a Moderada & 20 & $(43,4)$ & 19 & $(54,3)$ & \\
\hline Intensa a Muito intensa & 13 & $(28,3)$ & 13 & $(37,1)$ & \\
\hline
\end{tabular}


Tabela 4 - Frequência relativa do IMC versus nível dificuldade funcional obtida pelo questionário WOMAC E FAOS - "conclusão"

\begin{tabular}{|c|c|c|c|c|c|}
\hline VARIÁVEIS & \multicolumn{2}{|c|}{$\begin{array}{l}\text { IMC1 } \\
\mathrm{n}=46\end{array}$} & \multicolumn{2}{|c|}{$\begin{array}{l}\text { IMC2 } \\
n=35\end{array}$} & \multirow[t]{2}{*}{ ANÁLISE } \\
\hline \multicolumn{5}{|c|}{ Nível dificuldade para realizar as seguintes funções } & \\
\hline \multicolumn{6}{|l|}{ Calçar meias } \\
\hline Nenhuma & 8 & $(17,4)$ & 1 & $(2,9)$ & \multirow{3}{*}{$\begin{array}{l}\text { Fisher } \\
p=0,02\end{array}$} \\
\hline Pouca a Moderada & 12 & $(26,1)$ & 4 & $(11,4)$ & \\
\hline Intensa a Muito intensa & 26 & $(56,5)$ & 30 & $(85,7)$ & \\
\hline \multicolumn{6}{|l|}{ Levantar-se da Cama } \\
\hline Nenhuma & 11 & $(23,9)$ & 5 & $(14,3)$ & \multirow{3}{*}{$\begin{array}{l}\text { Fisher } \\
p=0,5\end{array}$} \\
\hline Pouca a Moderada & 21 & $(45,7)$ & 20 & $(57,1)$ & \\
\hline Intensa a Muito intensa & 14 & $(30,4)$ & 10 & $(28,6)$ & \\
\hline \multicolumn{6}{|l|}{ Tirar meias } \\
\hline Nenhuma & 8 & $(17,4)$ & 2 & $(5,7)$ & \multirow{3}{*}{$\begin{array}{l}\text { Fisher } \\
p=0,04\end{array}$} \\
\hline Pouca a Moderada & 12 & $(26,1)$ & 4 & $(11,4)$ & \\
\hline Intensa a Muito intensa & 26 & $(56,5)$ & 29 & $(82,9)$ & \\
\hline \multicolumn{6}{|l|}{ Ficar deitado leito } \\
\hline Nenhuma & 19 & $(41,3)$ & 9 & $(25,7)$ & \multirow{3}{*}{$\begin{array}{l}\text { Fisher } \\
p=0,05\end{array}$} \\
\hline Pouca a Moderada & 16 & $(34,8)$ & 22 & $(62,9)$ & \\
\hline Intensa a Muito intensa & 11 & $(23,9)$ & 4 & $(11,4)$ & \\
\hline \multicolumn{6}{|l|}{ Entrar/sair banho } \\
\hline Nenhuma & 22 & $(47,8)$ & 9 & $(25,7)$ & \multirow{3}{*}{$\begin{array}{l}\text { Fisher } \\
p=0,03\end{array}$} \\
\hline Pouca a Moderada & 15 & $(32,6)$ & 22 & $(62,9)$ & \\
\hline Intensa a Muito intensa & 9 & $(19,6)$ & 4 & $(11,4)$ & \\
\hline \multicolumn{6}{|l|}{ Se sentar } \\
\hline Nenhuma & 13 & $(28,3)$ & 5 & $(14,3)$ & \multirow{3}{*}{$\begin{array}{l}\text { Fisher } \\
p=0,35\end{array}$} \\
\hline Pouca a Moderada & 24 & $(52,2)$ & 22 & $(62,8)$ & \\
\hline Intensa a Muito intensa & 9 & $(19,5)$ & 8 & $(22,9)$ & \\
\hline \multicolumn{6}{|c|}{ Sentar/ levantar vaso sanitário } \\
\hline Nenhuma & 11 & $(23,9)$ & 3 & $(8,6)$ & \multirow{3}{*}{$\begin{array}{l}\text { Fisher } \\
p=0,10\end{array}$} \\
\hline Pouca a Moderada & 20 & $(43,5)$ & 23 & $(65,7)$ & \\
\hline Intensa a Muito intensa & 15 & $(32,6)$ & 9 & $(25,7)$ & \\
\hline \multicolumn{6}{|c|}{ Fazer tarefas domésticas pesadas } \\
\hline Nenhuma & 8 & $(17,4)$ & 2 & $(5,7)$ & \multirow{3}{*}{$\begin{array}{l}\text { Fisher } \\
p=0,15\end{array}$} \\
\hline Pouca a Moderada & 14 & $(30,4)$ & 8 & $(22,9)$ & \\
\hline Intensa a Muito intensa & 24 & $(52,2)$ & 25 & $(71,4)$ & \\
\hline \multicolumn{6}{|c|}{ Fazer tarefas domésticas leves } \\
\hline Nenhuma & 13 & $(28,2)$ & 2 & $(5,7)$ & \multirow{3}{*}{$\begin{array}{l}\text { Fisher } \\
p=0,03\end{array}$} \\
\hline Pouca a Moderada & 13 & $(28,3)$ & 15 & $(42,9)$ & \\
\hline Intensa a Muito intensa & 20 & $(43,5)$ & 18 & $(51,4)$ & \\
\hline
\end{tabular}

Abreviação: IMC, índice de massa corpórea ; IMC1, 40 a 49,6 Kg/m²; IMC2, 50 a 81,3 Kg/m² Os valores entre parênteses referem-se á porcentagem. 


\subsection{Resultados encontrados entre Osteoartrite (OA) versus WOMAC E FAOS}

Os resultados demonstraram não haver relação entre $O A$ (classificação radiológica de Kellgren-Lawrence), com as variáveis de dor no joelho $(p>0,05)$, assim como para as dificuldades funcionais. Verificou-se significância apenas para dor no pé/tornozelo na realização do movimento de forçar o pé para cima $(p=0,01)$, para baixo $(p=0,01)$ e dor ao girar sobre o próprio pé $(p=0,02)$. Para as demais subclasses: frequência $(p=0,08)$, andar no plano $(p=0,70)$, subir/descer escadas $(p=0,08)$, em repouso no leito $(p=0,26)$, sentar/deitar $(p=0,43)$ e ficar em pé $(p=0,27)$, não se evidenciou nenhuma relação (Anexo $F$, Tabelas 8, 9 e 10).

\subsection{Resultados encontrados entre T1M versus WOMAC e FAOS}

Em função do efeito do IMC sobre T1M, foi verificada a associação com T1M e as variáveis levantadas com o questionário WOMAC e FAOS (dor joelho, dor no pé/tornozelo e nível de dificuldade), para cada grupo de IMC separadamente: IMC1 e IMC2. 


\subsubsection{IMC1}

Não foi possível verificar relação significativa entre $\mathrm{T} 1 \mathrm{M}$ e as subclasses de dor no joelho e rigidez articular $(p>0,05)$. $O$ mesmo se evidenciou em relação á dor no pé/tornozelo $(p>0,05)$ (Anexo $G$, Tabelas 11 e 12).

Em relação ás atividades funcionais e suas dificuldades, pode-se observar associação significativa $(p=0,04)$ entre $T 1 M$ e a função de andar em superfície plana, sendo que $34,78 \%$ referiram não ter dificuldade, $41,30 \%$ têm dificuldade leve á moderada e $23,91 \%$ sentem dificuldade intensa a muito intensa. As demais subclasses de dificuldades foram não significativas $(p>0,05)$ (Anexo G, Tabela 13).

\subsubsection{IMC2}

Verificou-se correlação positiva apenas entre o ângulo T1M e dor na articulação do joelho, ao caminhar no plano $(p=0,02)$. $O$ ângulo $T 1 M$ não teve influência sobre a frequência e intensidade de dor no pé $(p>0,05)$, assim como, sobre as dificuldades funcionais $(p>0,05)$ (Anexo $G$, Tabelas 11,12 e 13).

O gráfico abaixo demonstra a comparação do IMC estratificado com a estratificação do ângulo T1M (G1 e G2) e dor no joelho ao caminhar no plano (Gráfico 4). 
Gráfico 4 - Comparação entre T1M estratificado versus IMC1 e IMC2 ao caminhar no plano

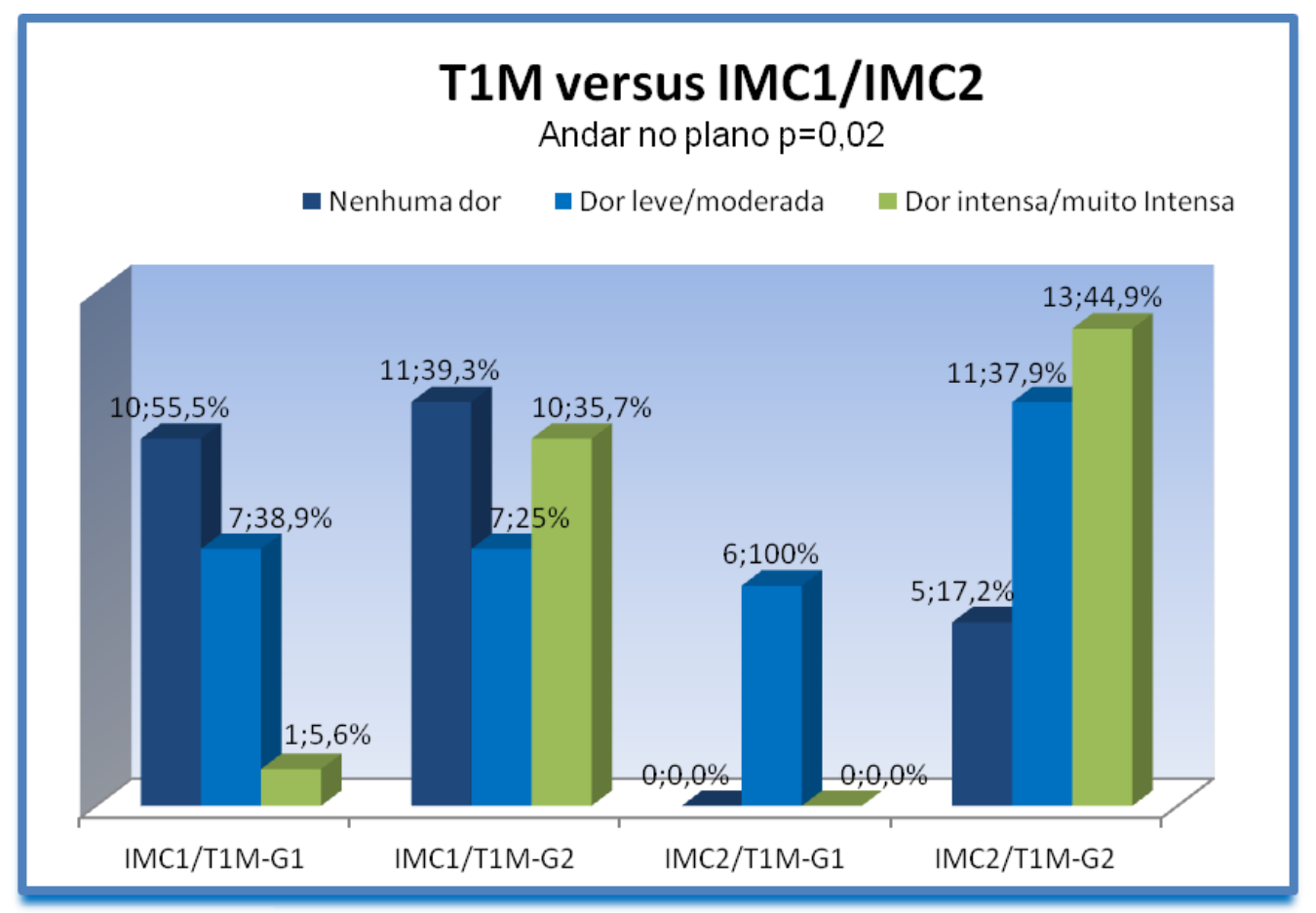

\subsection{Resultados encontrados entre Índice de Staheli (IS) versus WOMAC e FAOS}

Foi avaliada a associação entre IS, grau I e II, com as subclasses dor no joelho, dor no pé/tornozelo e dificuldades funcionais.

A tabela 5 evidencia o resultado na subclasse dor no joelho. A análise mostrou que houve associação quanto a caminhar no plano $(p=0,04)$ e que indivíduos com IS grau II tiveram maior incidência e intensidade de dor ao caminhar $(52,6 \%)$ do que aqueles que têm grau I $(22,6 \%)$. 
Tabela 5 - Frequência relativa do IS versus dor no joelho obtida pelo questionário WOMAC

\begin{tabular}{lccc}
\hline VARIÁVEIS & IS - GI & IS - GII & \multirow{2}{*}{ ANÁLISE } \\
& $\mathrm{n}=62$ & $\mathrm{n}=19$ & \\
\hline
\end{tabular}

Dor nos joelhos durante as últimas $48 \mathrm{hs}$

Caminhando em lugar plano

$\begin{array}{lccccl}\text { Nenhuma } & 22 & (35,5) & 4 & (21,1) & \\ \text { Pouca a Moderada } & 26 & (41,9) & 5 & (26,3) & \text { Fisher } \\ \text { Intensa a Muito intensa } & 14 & (22,6) & 10 & (52,6) & \end{array}$

Subindo/descendo escadas

$\begin{array}{lccccc}\text { Nenhuma } & 14 & (22,6) & 2 & (10,5) & \\ \text { Pouca a Moderada } & 17 & (27,4) & 3 & (15,8) & \text { Fisher } \\ \text { Intensa a Muito intensa } & 31 & (50,0) & 14 & (73,7) & \mathrm{p}=0,2\end{array}$

A noite deitado na cama

$\begin{array}{lccccl}\text { Nenhuma } & 33 & (54,1) & 4 & (21,0) & \\ \text { Pouca a Moderada } & 22 & (36,1) & 11 & (58,0) & \text { Fisher } \\ \text { Intensa a Muito intensa } & 6 & (9,8) & 4 & (21,0) & \mathrm{p}=0,03\end{array}$

\section{Sentando-se/ Deitando-se}

Nenhuma

Pouca a Moderada

Intensa a Muito intensa

\section{Ficando em pé}

Nenhuma

Pouca a Moderada

Intensa a Muito intensa

$\begin{array}{ll}20 & (32,3) \\ 28 & (45,1) \\ 14 & (22,6)\end{array}$

Fisher $\mathrm{p}=0,5$
Fisher

$p=0,2$

Abreviações: IS, índice de Staheli; IS GI, 0.3 a 1 centímetro; IS GII > 1 centímetro. Os valores entre parênteses referem-se á porcentagem.

Em relação á dor na região do pé/tornozelo, foi verificada apenas a relação entre IS e dor em repouso no leito $(p=0,007)$. Para as demais subclasses, os resultados não foram significativos (Anexo H, Tabela 14).

A análise dos resultados evidenciou significância estatística entre IS e a função de andar em superfície plana $(p=0,03)$, sendo que indivíduos 
com grau II (pé plano) tem maior dificuldade $(52,6 \%)$, do que aqueles que têm grau I, considerado pé normal (22,6\%). Para as demais subclasses não foi possível verificar associação significativa $(p>0,05)$ (Anexo H, Tabela 15).

\subsection{Resultados encontrados entre Osteoartrite (OA) versus ângulo T1M e Índice de Staheli (IS)}

Neste estudo, não se evidenciou significância estatística entre $O A$ de joelho e o ângulo T1M e IS (Tabela 6).

Tabela 6 - Frequência relativa entre osteoartrite de joelho e ângulo tálusprimeiro metatarso e Índice de Staheli estratificados

\begin{tabular}{|c|c|c|c|c|c|c|}
\hline \multirow[b]{2}{*}{ VARIÁVEIS } & \multicolumn{5}{|c|}{ OSTEOARTRITE (k-L) } & \multirow{2}{*}{ ANÁLISE } \\
\hline & Grau 0 & Grau 1 & Grau 2 & Grau 3 & Grau4 & \\
\hline $\mathrm{T} 1 \mathrm{M}-\mathrm{G} 1$ & $0(0,0)$ & $3(12,5)$ & $12(50,0)$ & $5(20,8)$ & $4(16,7)$ & Fisher \\
\hline $\mathrm{T} 1 \mathrm{M}-\mathrm{G} 2$ & $1(1,7)$ & $11(19,3)$ & $20(35,0)$ & $23(40,3)$ & $2(3,5)$ & $p=0,09$ \\
\hline IS - G I & $1(1,6)$ & $10(16,1)$ & $27(43,5)$ & $20(32,2)$ & $4(6,4)$ & Fisher \\
\hline IS - G II & $0(0,0)$ & $4(21,0)$ & $5(26,3)$ & $8(42,1)$ & $2(10,5)$ & $p=0,6$ \\
\hline
\end{tabular}

Abreviações: IS-GI; Índice de Staheli grupo I; IS-GII; Índice de Staheli grupo II; K-L; Kellgren-Lawrence; T1M-G1; ângulo tálus-primeiro metatarso grupo1; T1M-G2; ângulo tálusprimeiro metatarso grupo 2. Os valores entre parênteses referem-se á porcentagem. 


\subsection{Resultados encontrados entre ângulo T1M e Índice de Staheli (IS)}

De acordo com os resultados observados do ângulo T1M, 100\% dos indivíduos apresentaram ângulo maior que 4 graus (considerado pé plano) enquanto que de acordo com o IS somente $23,5 \%$ foram considerados pés planos. Ao se confrontar estas duas variáveis, independente do IMC, verificou-se não haver equivalência entre as mesmas $(p=0,13)$ (Gráfico 5).

Gráfico 5 - Correlação entre ângulo T1M estratificado versus IS estratificado

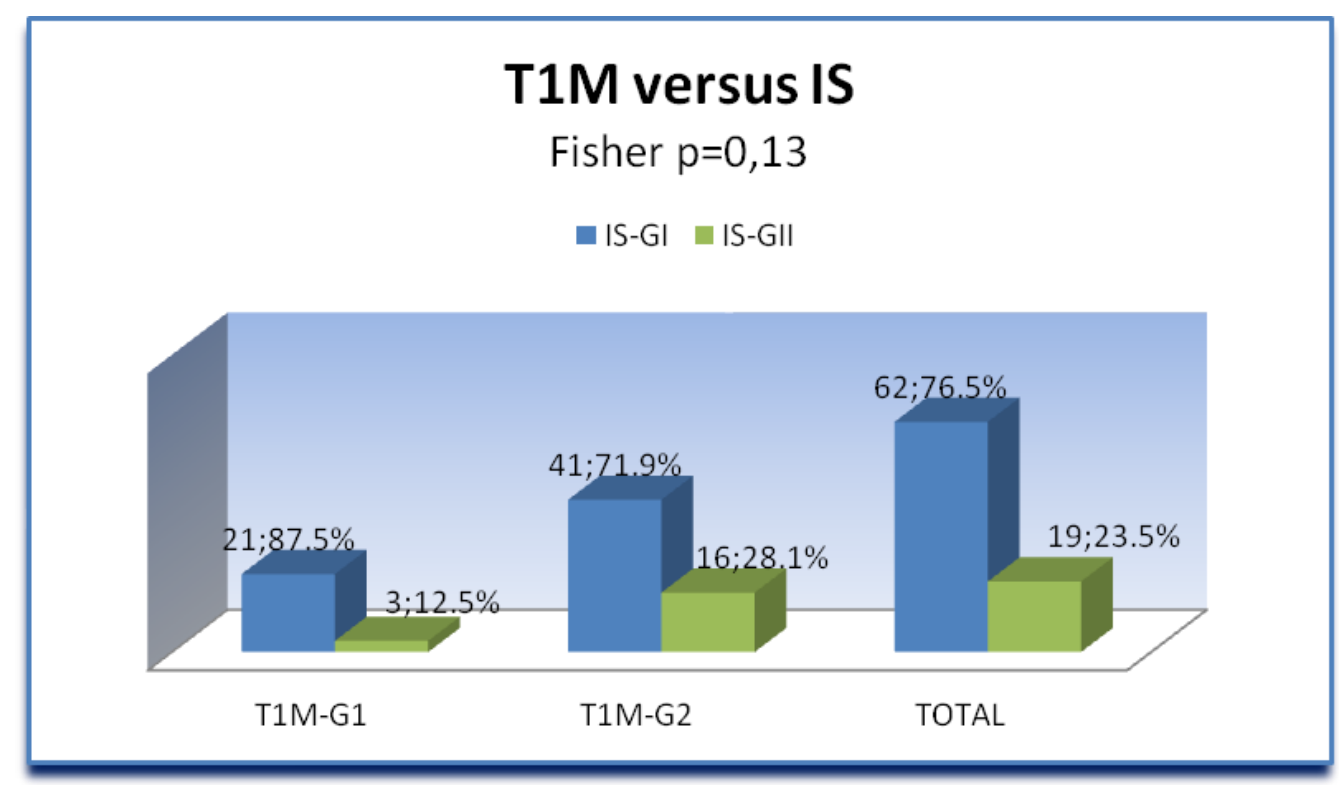




\section{DISCUSSÃO}

A obesidade impõe grandes desafios físicos para 0 sistema musculoesquelético, principalmente nos membros inferiores, em função da sustentação do peso corporal ${ }^{68}$.

A presente pesquisa analisou o impacto de dois níveis de obesidade (40 a $50 \mathrm{Kg} / \mathrm{m}^{2}$ versus maior $50 \mathrm{Kg} / \mathrm{m}^{2}$ ) sobre o sistema músculo esquelético, com enfoque sobre a articulação do joelho e do pé.

A literatura disponível nesta população é escassa, principalmente no que se refere ao pé ${ }^{30}$. Em sua grande maioria está relacionada, principalmente, á dor e osteoartrite de joelho ${ }^{25}$.

A obesidade é um fator preditivo para o início, progressão e sintomas da $\mathrm{OA}$ de joelho ${ }^{27,58}$. Vários estudos transversais e longitudinais têm demonstrado essa associação ${ }^{69-74}$. Quanto maior o valor do IMC maiores os riscos ${ }^{30,58,75}$. Além deste, outros fatores de riscos intrínsecos contribuem para o desenvolvimento desta doença: idade, gênero, genética, hormônios e doenças prévias ${ }^{76}$.

$\mathrm{Na}$ presente pesquisa, ao contrário dos trabalhos relatados na literatura, não foi possível identificar esta associação, apesar de $81 \%$ da amostra em estudo apresentar níveis $\geq 2(\mathrm{~K}-\mathrm{L})$ para $\mathrm{OA}$. Isto pode ter ocorrido devido á distribuição heterogênea entre os graus I - IV. Outro fator 
que pode ter contribuído para esse resultado negativo, pode ter sido a

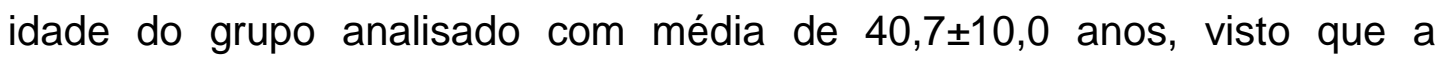
prevalência da OA aumenta com a idade ${ }^{77}$. Em se mantendo o excesso de peso e com o advento do envelhecimento, é de se supor que ocorra a progressão desta doença.

Entretanto, a amostra da população nesta pesquisa, eram candidatos á cirurgia bariátrica. Acredita-se, com base na literatura, na possibilidade de melhora dos sintomas de dor, função e regressão da OA após a perda de peso. Apesar dos poucos estudos realizados em indivíduos submetidos ao tratamento cirúrgico da obesidade, estes ratificam essa melhora ${ }^{11,27,28,29,78}$.

A sustentação excessiva e repetitiva de peso causado pela obesidade pode proporcionar grandes sobrecargas e estresse nas articulações dos joelhos e pés, além de desvantagens mecânicas durante a realização de atividades diárias, em função do excesso de tecido adiposo ${ }^{9,10}$.

Esse excesso de carga contínua sobre a região plantar, pode danificar - ALM, resultando em deformidades ósseas observadas tanto clínica quanto radiologicamente, aumentando o risco de desconforto e o desenvolvimento de patologias podais, dentre elas o pé plano ${ }^{30}$.

Pé plano ou pronado caracteriza-se por um rebaixamento ou perda do ALM, quando em posição ortostática ${ }^{34,58}$. Entretanto, não há consenso sobre os critérios clínicos e/ou radiológicos para definição de pé plano ${ }^{52,79}$. Segundo Snider, o mesmo também pode ser chamado de pé valgo, pé pronado, pé chato ou pé plano valgo ${ }^{80}$. 
Vários métodos são utilizados para se avaliar o ALM, sendo a avaliação radiológica e a impressão plantar os mais comuns ${ }^{79}$. De etiologia ainda não totalmente esclarecida (frouxidão ligamentar, disfunção do tendão tibial posterior, obesidade, compensação de anormalidades ascendentes aos membros inferiores, entre outros) $)^{52}$, acredita-se que o mesmo seja resultante de um suporte estrutural anormal em função de desequilíbrio nas forças que suportam o arco: fraqueza muscular, ligamentar ou nas estruturas ósseas que sustentam o $\operatorname{arco}^{79}$.

De acordo com Mosca, a definição tradicional desta patologia não deve se basear apenas em uma medida anatômica estática, mas considerar também a etiologia do pé plano, a relação entre os ossos do pé, as variações entre crianças, adultos e grupos raciais, visto a incidência ser maior em indivíduos da raça negra ${ }^{52}$.

Portanto, verificamos que o termo "pé plano" engloba aspectos que vão além da mensuração estática da altura do arco plantar. Idade, gênero e raça não foram contempladas especificamente neste estudo. Em função disso, a pesquisadora responsável por esta pesquisa, optou por utilizar o termo "pé pronado" ao invés de "pé plano", o que não altera os resultados obtidos no presente estudo.

A obesidade destaca-se como um dos fatores que contribuem para planificar o arco plantar ${ }^{7}$, influenciando desta forma, o formato do pé ${ }^{57}$.

Isto vem de encontro aos achados no presente estudo, onde se evidenciou, por meio de análise radiológica (T1M), a influência significativa 
da obesidade sobre o arco plantar, onde os valores médios obtidos sugerem uma queda do arco, principalmente nos superobesos.

O peso corporal sustentado pelo pé, força as estruturas ósseas em direção ao solo, favorecendo á pronação do osso tálus com consequente depressão e distensão das estruturas, muscular e ligamentar do mediopé, modificando assim a morfologia do arco e, por conseguinte, a morfologia do pé.

Do ponto de vista biomecânico, isto influencia diretamente na distribuição de peso na região plantar, originando áreas de hiperpressão, causando desconforto e dor ${ }^{36}$. Fabris et al. demonstraram que indivíduos obesos têm maior pico de pressão e área de contato com o solo quando comparados com indivíduos não obesos e em decorrência, uma tendência ao pé pronado ${ }^{34}$.

Villaroya et al. avaliaram o arco plantar de um grupo de 58 crianças/adolescentes (9-16 anos), eutróficos e obesos, por meio de raio-x em perfil do pé (T1M e ângulo de inclinação de calcâneo) e impressão plantar (footprint angle e Chippaux-Smirax Index). Em ambos, o grupo obeso apresentou rebaixamento significativo do $\operatorname{arco~plantar~}^{48}$.

Alguns autores questionam a validade da impressão plantar como método de mensuração do arco plantar ${ }^{56,81}$. Outros, ao contrário, demonstram a validade e fidedignidade, tanto da impressão plantar, como do $\mathrm{IS}^{78,81,82}$ e sua correlação com as medidas radiográficas do $\operatorname{arco}^{38,54}$.

Entretanto, de acordo com os resultados do presente trabalho o Índice de Staheli, obtido por meio de impressão plantar, demonstrou não haver dependência com excesso de peso, assim como, um baixo percentual de 
equivalência com o índice radiográfico T1M. Em nosso entendimento, isso provavelmente ocorreu em função de que ambos são métodos distintos de avaliação: a radiografia avalia o desabamento das estruturas ósseas e a impressão plantar avalia a superfície de contato de apoio do pé ao solo. Isso nos permite inferir que o baixo percentual de pé pronado, obtido no exame de impressão plantar, pode ser devido ao fato de que obesos graves/superobesos apresentam um coxim gorduroso não somente na região de mediopé, como ocorre nas crianças $^{83}$, mas em toda a região plantar, inclusive no retropé, aumentando a área de contato com o solo como um todo, resultando em uma razão (mediopé/retropé) abaixo de um centímetro, considerada pé normal de acordo com o índice de Staheli. Assim sendo, o IMC acentuado dos indivíduos avaliados, pode ter desempenhado um fator de confundimento na avaliação indireta da altura do ALM, por meio do IS, subestimando esses valores.

A avaliação radiológica e/ou baropodométrica são ferramentas importantes para avaliação do ALM. Porém, sabe-se que radiografia pode definir a relação estática entre os ossos, mas não fornece informações clínicas sobre dor, função e flexibilidade ${ }^{52}$. Em decorrência disso, estas informações foram complementadas com a aplicação dos questionários funcionais WOMAC E FAOS.

Estruturas que suportam 0 peso corporal frequentemente são acometidas de dor articular, principalmente na região lombar e membros inferiores, sendo que sua prevalência aumenta progressivamente com o aumento do $\mathrm{IMC}^{84,85}$. A dor articular induzida pela obesidade leva á 
incapacidade funcional, fraqueza muscular e alteração da marcha, contribuindo para o agravamento da obesidade e deterioração da qualidade de vida ${ }^{86,87,88}$

Com base nos resultados obtidos na presente pesquisa, foi possível observar influência deletéria da obesidade, na articulação do joelho e do pé, em relação á sintomatologia de dor, á capacidade e/ou deficiência dos indivíduos em realizar algumas atividades rotineiras da vida diária.

No nível de dor articular de joelho, pôde-se comprovar que a obesidade interferiu de forma significativa, principalmente nos superobesos, durante a função de caminhar e descer/subir escadas. A mesma significância e grau de dor foram observados durante o repouso no leito, demonstrando que mesmo em situação sem suporte do peso corporal, esta persiste, provavelmente em decorrência das alterações estruturais já estabelecidas.

O efeito da dor no joelho refletiu em uma maior dificuldade em caminhar no plano. Evidenciando que a obesidade pode ter um impacto direto na realização de uma das atividades básicas do ser humano, o caminhar. Isso pode justificar, por exemplo, o alto índice de desistência em programas de atividade física, que visem á perda de peso ${ }^{17,18}$, assim como o sedentarismo nesta população.

No presente estudo, foi possível verificar a associação do pé pronado com dor articular na região do joelho ao caminhar no plano. Essa relação funcional entre a altura do arco plantar e as lesões no joelho tem sido cogitada $^{89}$. Um estudo realizado com 213 corredores demonstrou que 164 (77\%) das lesões de joelho estavam relacionadas á disfunção biomecânica 
dos pés ${ }^{90}$, evidenciando, portanto, que alterações ou deformidades podais podem repercutir de forma ascendente ${ }^{91,92}$.

Em um recente estudo transversal, envolvendo 1903 participantes (65 \pm 9 anos; 56 \% feminino), avaliados por meio de impressão plantar (índice de Staheli) e ressonância magnética, determinou que o pé plano tem 1,3 (IC 95\% 1,1-1,6) vezes mais chances de dor no joelho $(p=0,009)$ e 1,4 (IC 95\% 1,1-1,8) vezes mais chances de danos na cartilagem medial do joelho ( $p=0,002)$; sendo que as chances de dor $(p=0,05)$ e danos á cartilagem $(p=0,001)$ aumentaram com o aumento crescente do IS. Os autores concluíram que a morfologia do pé plano está associada com dor frequente no joelho e danos á cartilagem em idosos ${ }^{93}$.

Na presente pesquisa, observou-se o reflexo da obesidade grave sobre o nível de dificuldade para a realização de diversas atividades da vida diária (AVDs). Dificuldades provavelmente em função do excesso de peso, da dor, da instabilidade articular e da fraqueza muscular.

De forma expressiva, nossos resultados demonstram o alto impacto da obesidade sobre a região do pé. Não apenas em relação á mudança estrutural, como demonstrado anteriormente, mas também sobre a dor presente nesta região. Estes achados sugerem que a dor na região podal pode desempenhar um papel-chave na deficiência de obesos severos.

Isto vem de encontro a um estudo transversal (1992 - 1995) que avaliou a relação entre dor crônica do pé e deficiência em 1002 mulheres idosas, onde constatou associação independente de dor no pé, com risco aumentado de dificuldade para caminhar (odds ratio ajustada = 1,69; IC 95\% 
1,10 - 2,59) e deficiência nas atividades de vida diária (odds ratio ajustada igual a 1,$91 ;$ IC de $95 \% 1,21-3,01)^{82}$.

O pé pronado, observado por meio de raio-x, refletiu sobre a função do caminhar, demonstrando que quem tem este tipo de pé pode ter maior dificuldade para executar esta função.

Apesar do IS não ter demonstrado dependência com o IMC, verificouse uma relação significativa entre o IS versus dor/ joelho e dificuldade ao caminhar no plano, sugerindo que a morfologia do pé pode favorecer o processo álgico e disfunção mecânica da articulação do joelho durante a marcha ${ }^{56}$. Entretanto, não se evidenciou até 0 momento, trabalhos utilizando este índice em adultos obesos graves/superobesos, a fim de que fosse possível comparar com os resultados aqui apresentados. 


\section{CONCLUSÕES}

1. A obesidade avançada (superobesidade) promoveu maior alteração da morfologia do arco plantar, favorecendo a instalação de pé pronado. Teve Influência marcante sobre sintomatologia de dor e as alterações funcionais do joelho e do pé.

2. Atividades funcionais do cotidiano também sofreram o impacto da superobesidade, denotando um panorama disfuncional que amplifica em muito a dor e dificuldade de utilização da articulação.

3. Em vários domínios dos testes e questionários demonstrou-se pior escore para os superobesos (IMC $>50 \mathrm{~kg} / \mathrm{m}^{2}$ ), um achado intuitivo que, entretanto não mereceu destaque até o momento.

4. Embora para os testes bioquímicos e metabólicos não se denotasse repercussão negativa da superobesidade, no âmbito de joelho e as influências deletérias foram significativas, justificandose maior atenção para estes problemas nos candidatos á cirurgia bariátrica. 


\title{
8 ANEXOS
}

\section{Anexo A}

\begin{abstract}
HOSPITAL DE BASE - FUNFARME - SÃO JOSÉ DO RIO PRETO
TERMO DE CONSENTIMENTO LIVRE E ESCLARECIDO
\end{abstract}

\section{DADOS DE IDENTIFICAÇÃO DO SUJEITO DA PESQUISA OU RESPONSÁVEL LEGAL}

1. NOME:

DOCUMENTO DE IDENTIDADE № : SEXO : $M \square F \square$ DATA NASCIMENTO:

ENDEREÇO №

APTO: BAIRRO:

CIDADE CEP: TELEFONE: DDD (.....)

2.RESPONSÁVEL LEGAL

NATUREZA (grau de parentesco, tutor, curador etc.)

DOCUMENTO DE IDENTIDADE : SEXO: $M \square F \square$ DATA NASCIMENTO.:

ENDEREÇO: № APTO:

BAIRRO: CIDADE: CEP: TELEFONE:DDD 


\section{DADOS SOBRE A PESQUISA}

1. TÍTULO DO PROTOCOLO DE PESQUISA Impacto de dois níveis de obesidade grave sobre as alterações osteoarticulares e funcionais de joelho e pé

2. PESQUISADOR : Sônia Maria Fabris Luis CARGO/FUNÇÃO: Fisioterapeuta/ Doutoranda da FMUSP INSCRIÇÃO CONSELHO REGIONAL № 4132-F UNIDADE DO HCFMUSP: Divisão de Clínica Cirúrgica II - ICHC

3. AVALIAÇÃO DO RISCO DA PESQUISA:

RISCO MÍNIMO $\mathbf{x}$
RISCO BAIXO

RISCO MÉDIO RISCO MAIOR

4.DURAÇÃO DA PESQUISA : 24 meses

\section{HOSPITAL DE BASE - FUNFARME - SÃO JOSÉ DO RIO PRETO}

1 - Desenho do estudo e objetivo(s): essas informações estão sendo fornecidas para sua participação voluntária neste estudo. $O$ objetivo é verificar o efeito da obesidade severa sobre o joelho e arco plantar do pé. Serão comparadas informações sobre seu peso, sua altura e suas doenças.

2 - Descrição dos procedimentos que serão realizados, com seus propósitos e identificação dos que forem experimentais e não rotineiros: Serão utilizados questionários sobre seu estado de saúde, exame físico, fotografias e exames radiológico e baropodométrico.

3 - Relação dos procedimentos rotineiros e como são realizados - $O$ exame físico e questionários serão conduzidos por profissional capacitado. As fotografias não revelarão seu rosto nem terão seu nome ou identificação reconhecível. $\mathrm{O}$ exame radiológico será executado em aparelho comum de raio-x. Não será realizada nenhuma administração de medicação, operação cirúrgica, endoscopia ou qualquer outra intervenção ou procedimento invasivo.

4 - Descrição dos desconfortos e riscos esperados nos procedimentos dos itens 2 e 3; Os questionários e exame físico devem durar em torno de $5-10$ minutos. As radiografias costumam durar mais 10 a 15 minutos. 
5 - Benefícios para o participante: $O$ estudo não visa benefícios para o paciente, e sim para o futuro, mostrando qual a melhor orientação em longo prazo em pacientes obesos candidatos á cirurgia bariátrica. No entanto todos os achados do estudo estarão ao seu alcance e poderão ajudar a orientar seu acompanhamento fisioterapêutico, caso seja recomendado. 6 - Relação de procedimentos alternativos que possam ser vantajosos, pelos quais o paciente pode optar: Existe a alternativa de não participar do estudo, se não desejar.

7 - Garantia de acesso: em qualquer etapa do estudo, você terá acesso aos profissionais responsáveis pela pesquisa para esclarecimento de eventuais dúvidas. O principal investigador é a fisioterapeuta Sonia Maria Fabris Luis, que pode ser encontrada no endereço Avenida Brigadeiro Faria Lima, 5544, Telefone(s) 32015726 ou 8114 0727. Se você tiver alguma consideração ou dúvida sobre a ética da pesquisa, entre em contato com o Comitê de Ética em Pesquisa (CEP) - Rua Ovídio Pires de Campos, 225 - 5ํandar - tel: (11)3069-6442 ramais 16, 17, 18 ou 20, FAX: (11) 3069-6442 ramal 26 - Email: cappesq@hcnet.usp.br

8 - É garantida a liberdade da retirada de consentimento a qualquer momento e deixar de participar do estudo, sem qualquer prejuízo à continuidade de seu tratamento na Instituição;

9 - Direito de confidencialidade - As informações obtidas serão analisadas em conjunto com outros pacientes, não sendo divulgado a identificação de nenhum paciente;

10 - Direito de ser mantido atualizado sobre os resultados parciais das pesquisas, quando em estudos abertos, ou de resultados que sejam do conhecimento dos pesquisadores; Todos os achados deste estudo poderão ser informados ao paciente caso solicitados.

11 - Despesas e compensações: não há despesas pessoais para o participante em qualquer fase do estudo, incluindo exames e consultas. Também não há compensação financeira relacionada à sua participação. Se existir qualquer despesa adicional, ela será absorvida pelo orçamento da pesquisa.

12 - Compromisso do pesquisador de utilizar os dados e o material coletado somente para esta pesquisa. Esta pesquisa será direcionada unicamente aos fins científicos a que se destina.

Acredito ter sido suficientemente informado a respeito das informações que li ou que foram lidas para mim, descrevendo o estudo "Impacto de dois níveis de obesidade grave sobre as alterações osteoarticulares e funcionais de joelho e pé "

Eu discuti com a fisioterapeuta Sonia Maria Fabris Luis, sobre a minha decisão em participar nesse estudo. Ficaram claros para mim quais são os propósitos do estudo, os procedimentos a serem realizados, seus 
desconfortos e riscos, as garantias de confidencialidade e de esclarecimentos permanentes. Ficou claro também que minha participação é isenta de despesas e que tenho garantia do acesso a tratamento hospitalar quando necessário. Concordo voluntariamente em participar deste estudo e poderei retirar o meu consentimento a qualquer momento, antes ou durante o mesmo, sem penalidades ou prejuízo ou perda de qualquer benefício que eu possa ter adquirido, ou no meu atendimento neste Serviço.

Data

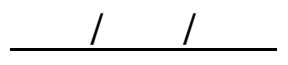

Assinatura do paciente/representante legal

Assinatura da testemunha

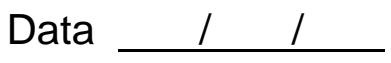

(para casos de pacientes analfabetos, semi-analfabetos ou portadores de deficiência auditiva ou visual)

(Somente para o responsável do projeto)

Declaro que obtive de forma apropriada e voluntária o Consentimento Livre e Esclarecido deste paciente ou representante legal para a participação neste estudo.

Data $\frac{1}{1}$ 


\section{Anexo B}

\section{MEDICINA \\ TSP \\ COMITE DE ETICA EM PESQUISA}

\section{APROVAÇÃO}

C Coordenador do Comitè de Êtica em Pesquisa da Faculdade de Medicina da Universidade de São Patlo, em 31.01.2011, APROVOU adreferendum o Protocolo de Pesquisa $\mathrm{n}^{\circ} 198 / 10$, intitulado: "Impacto da perda de peso sobre o arco longitudinal medial em índividuos obesos submetidos à eirurgia bariátrica", apresentado pelo Departamento de Gastroenterologia.

Cabe ao pesquisador elaborar e apresentar ao CEP-FMUSP, o5 relatórios parciais e finel sobre a pesquisa .

Pesquisador (a) Responsável: Joel Faintuch

Pesquisador (a) Exeeutante! Sonia Maria Fabris

CEP-FMUSP, 31 de janeiro de 2011.

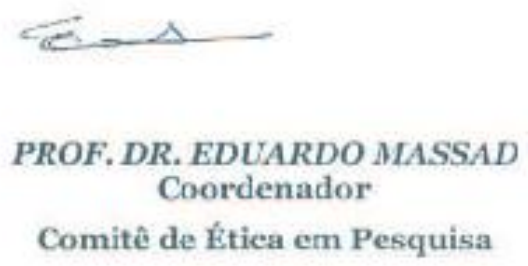

Comite de Etica em Pesquisa da Faculeace da Medcina da Uaversisace ce Sac Padio Av. Dr. Amaldo, 455 - Instato Dscar Freire 1' andar CEP 01246303 - Fone : 3061 - 8004 mait: cep fouseng thcnetusp.br 


\section{Anexo C}

\section{FACULDADE DE MEDICINA DE SÃO JOSÉ DO RIO PRETO \\ Autarquia Estadual-Lei n. ${ }^{\circ} 8899$ de $27 / 09 / 94$ \\ (Reconhecida pelo Decreto Federal $n .{ }^{*} 74.179$ de 14/06/74)}

Parecer n. ${ }^{\circ} 015 / 2011$

\section{COMITÊ DE ÉTICA EM PESQUISA}

\section{O Protocolo CEP $n^{\circ} 6608 / 2010$ sob a responsabilidade de} Sônia Maria Fabris Luiz, com o título "Impacto da perda de peso sobre o Arco Longitudinal Medial em individuos obesos submetidos c̀ cirurgia barićtrica" está de ccordo com a Resolução do CNS 196/96 e foi aprovado por esse CEP

Lembramos ao senhor(a) pesquisador(a) que, no cumprimento da Resolução 251/97, o Comitê de Ética em Pesquisa em Seres Humonos (CEP) deverá receber relatórios semestrais sobre o andamento do Estudo, bem como a qualquer tempo e a critério do pesquisador nos casos de relevância, além do envio dos relatos de eventos adversos, com certeza para conhecimento deste Comitê. Salienfamos ainda, a necessidade de relatório completo ao final do Estudo.

são José do Rio Preto, of de fevereiro de 2011.

Prof. Dr. Feenando Batigália Coordenador do CEP/FAMERP 


\section{Anexo D - QUESTIONÁRIOS}

\section{Questionário Geral}

I) Identificação e dados pessoais Data do questionário:

Nome:

Data nascimento: Sexo Idade:

№. Reg:

Profissão:

Endereço residencial:

Bairro: CEP: Cidade:

Local de trabalho ou estudos:

Trabalha em casa: Sim Não

Telefone residencial: ( ) Telefone comercial: ( )

Celular: ( ) Outro telefone para recados: ( )

II) Dados clínicos

Peso atual:

Alt: IMC:

Peso máximo atingido:

Diabetes: Sim Não HA: Sim Não

Uso de droga contínua: Sim Não há quanto tempo:

Qual:

Outros:

Artrite de coluna Artrite de quadril

Artrite de joelhos Artrite pés Teve quedas ou fraturas Onde:

Linfedema de membros inferiores Varizes

Trombose nas pernas úlcera (ferida nas pernas)

Sente dor: quadril joelhos pés Se sente, de 0 a 10 qual a intensidade da dor Qual a frequência

III) Hábitos

Etilismo (hábito de beber bebida alcoólica): Sim Não

Dose média diária: Tipo de bebida:

Há quanto tempo:

Tabagismo (hábito de fumar): Sim Não 
Quantos cigarros/dia: Há quanto tempo fuma

Já fumou: Sim Não Se sim, há quanto tempo parou de fumar

Atividade física regular: Sim Não Se não, qual motivo

Qual

Quantos quarteirões caminha por dia

Quantos lances de escada por dia 


\section{Questionário Western Ontario and McMaster Universities Osteoarthritis Index (WOMAC)}

\section{DOR : Qual a intensidade de dor nos joelhos durante as últimas $48 \mathrm{hs?}$}

1 Caminhando em um lugar plano: Nenhuma - Pouca - Moderada - Intensa - Muito intensa

2 Subindo ou descendo escadas: Nenhuma - Pouca - Moderada - Intensa - Muito intensa

3 A noite deitado na cama: Nenhuma - Pouca - Moderada - Intensa - Muito intensa

4 Sentando-se ou deitando-se: Nenhuma - Pouca - Moderada - Intensa - Muito intensa

5 Ficando em pé:

Nenhuma - Pouca - Moderada - Intensa - Muito intensa

\section{RIGIDEZ: Rigidez é uma sensação de restrição ou dificuldade para movimentar suas juntas ( não é dor)}

1 Matinal ao acordar : Nenhuma - Pouca - Moderada - Intensa - Muito Intensa

2 Durante o dia (após se sentar, deitar ou repousar) : Nenhuma - Pouca - Moderada -

Intensa - Muito Intensa

\section{Nível de dificuldade para realizar as seguintes funções durante as últimas 48 horas:}

1. Descer escadas: Nenhuma - Pouca - Moderada - Intensa - Muito intensa

2. Subir escadas: Nenhuma - Pouca - Moderada - Intensa - Muito intensa

3. Levantar-se estando sentada: Nenhuma - Pouca - Moderada - Intensa - Muito intensa

4. Ficar em pé: Nenhuma - Pouca - Moderada - Intensa - Muito intensa

5. Abaixa-se para pegar algo chão: Nenhuma - Pouca - Moderada - Intensa - Muito intensa

6. Andar no plano: Nenhuma - Pouca - Moderada - Intensa - Muito intensa

7. Entrar e sair do carro: Nenhuma - Pouca - Moderada - Intensa - Muito intensa

8. Ir fazer compras: Nenhuma - Pouca - Moderada - Intensa - Muito intensa

9. Calçar meias : Nenhuma - Pouca - Moderada - Intensa - Muito intensa

10. Levantar-se da cama: Nenhuma - Pouca - Moderada - Intensa - Muito intensa

11. Tirar as meias: Nenhuma - Pouca - Moderada - Intensa - Muito intensa

12. Ficar deitado na cama: Nenhuma - Pouca - Moderada - Intensa - Muito intensa

13. Entrar e sair do banho: Nenhuma - Pouca - Moderada - Intensa - Muito intensa

14. Se sentar: Nenhuma - Pouca - Moderada - Intensa - Muito intensa

15. Sentar e levantar do vaso sanitário: Nenhuma-Pouca-Moderada- Intensa- Muito intensa

16. Fazer tarefas domésticas pesadas :Nenhuma-Pouca-Moderada- Intensa - Muito intensa

17. Fazer tarefas domésticas leves: Nenhuma- Pouca - Moderada - Intensa - Muito intensa

Os parâmetros WOMAC são:

0 - nenhuma, 1 - leve, 2 - moderada, 3 - severo, 4 - extremo.

O índice é de um total de 96 pontos possíveis, sendo 0 (zero) o melhor e 96 o pior. Nenhuma $=0$; leve $=25$; moderada $=50$; intensa $=75$; muito intensa $=100$. (versão brasileira) 


\section{QUESTIONÁRIO FAOS (Foot and Ankle Outcome Score) para avaliação da função e sintomas do tornozelo e pé.}

DOR

\begin{tabular}{|l|l|}
\hline $\begin{array}{l}\text { P1 Qual a frequência que você sente dor no pé } \\
\text { ou tornozelo? }\end{array}$ & $\begin{array}{l}\text { Nunca, Mensalmente, Semanalmente, } \\
\text { Diariamente, Sempre }\end{array}$ \\
\hline $\begin{array}{l}\text { Qual a intensidade de dor que você sentiu na última semana durante as seguintes } \\
\text { atividades? }\end{array}$ & $\begin{array}{l}\text { Nenhuma, Leve, Moderada, } \\
\text { Acentuada, Extrema }\end{array}$ \\
\hline P2. Rodando sobre o seu pé ou tornozelo & $\begin{array}{l}\text { Nenhuma, Leve, Moderada, } \\
\text { Acentuada, Extrema }\end{array}$ \\
\hline P3. Forçando o pé completamente para baixo & $\begin{array}{l}\text { Nenhuma, Leve, Moderada, } \\
\text { Acentuada, Extrema }\end{array}$ \\
\hline P4. Forçando o pé completamente para cima & $\begin{array}{l}\text { Nenhuma, Leve, Moderada, } \\
\text { Acentuada, Extrema }\end{array}$ \\
\hline P5. Andando em superfície plana & $\begin{array}{l}\text { Nenhuma, Leve, Moderada, } \\
\text { Acentuada, Extrema }\end{array}$ \\
\hline P6. Subindo ou Descendo escadas & $\begin{array}{l}\text { Nenhuma, Leve, Moderada, } \\
\text { Acentuada, Extrema }\end{array}$ \\
\hline P7. Em repouso na cama & $\begin{array}{l}\text { Nenhuma, Leve, Moderada, } \\
\text { Acentuada, Extrema }\end{array}$ \\
\hline P8. Ao sentar-se/deitar-se & $\begin{array}{l}\text { Nenhuma, Leve, Moderada, } \\
\text { Acentuada, Extrema }\end{array}$ \\
\hline P9. Em pé
\end{tabular}

\section{OUTROS SINTOMAS}

S1 Qual o grau de rigidez do seu pé/tornozelo logo quando você acorda?

S2. Qual o grau de rigidez após sentar, deitar ou ao descansar mais tarde durante o dia?

S3. Você tem inchaço no seu pé/tornozelo?

S4. Você sente ranger, estalar ou qualquer outro tipo de som quando o movimenta o pé?

S5. O seu pé trava ou fica bloqueado aos movimentos?

S6. Você consegue forçar o seu pé completamente para baixo?

S7. Você consegue forçar o seu pé completamente para cima?
Nenhuma, Leve, Moderada, Acentuada, Extrema

Nenhuma, Leve, Moderada, Acentuada, Extrema

Nunca, Raramente, Às vezes, Frequentemente, Sempre

Nunca, Raramente, Às vezes, Frequentemente, Sempre

Nunca, Raramente, Às vezes, Frequentemente, Sempre

Sempre, Frequentemente, Às vezes, Raramente, Nunca

Sempre, Frequentemente, Às vezes, Raramente, Nunca 
ATIVIDADES DE VIDA DIÁRIA - Qual a dificuldade que você sentiu na última semana:

\begin{tabular}{|c|c|}
\hline A1. Descendo escadas & Nenhuma, Leve, Moderada, Acentuada, Extrema \\
\hline A2. Subindo escadas & Nenhuma, Leve, Moderada, Acentuada, Extrema \\
\hline $\begin{array}{l}\text { A3. Levantando-se a partir da posição } \\
\text { sentada }\end{array}$ & Nenhuma, Leve, Moderada, Acentuada, Extrema \\
\hline A4. Em pé & Nenhuma, Leve, Moderada, Acentuada, Extrema \\
\hline $\begin{array}{l}\text { A5. Curvando-se para pegar um objeto } \\
\text { no chão }\end{array}$ & Nenhuma, Leve, Moderada, Acentuada, Extrema \\
\hline A6. Andando em superfícies planas & Nenhuma, Leve, Moderada, Acentuada, Extrema \\
\hline A7. Entrando e saindo do carro & Nenhuma, Leve, Moderada, Acentuada, Extrema \\
\hline A8. Indo às compras & Nenhuma, Leve, Moderada, Acentuada, Extrema \\
\hline A9. Colocando meias & Nenhuma, Leve, Moderada, Acentuada, Extrema \\
\hline A10. Levantando-se da cama & Nenhuma, Leve, Moderada, Acentuada, Extrema \\
\hline A11. Tirando as meias & Nenhuma, Leve, Moderada, Acentuada, Extrema \\
\hline $\begin{array}{l}\text { A12. Virando-se na cama, mantendo a } \\
\text { mesma posição do tornozelo/pé }\end{array}$ & Nenhuma, Leve, Moderada, Acentuada, Extrema \\
\hline A13. Entrando ou saindo do banho & Nenhuma, Leve, Moderada, Acentuada, Extrema \\
\hline A14 Sentando & Nenhuma, Leve, Moderada, Acentuada, Extrema \\
\hline $\begin{array}{l}\text { A15. Sentando e levantando do vaso } \\
\text { sanitário }\end{array}$ & Nenhuma, Leve, Moderada, Acentuada, Extrema \\
\hline $\begin{array}{l}\text { A16. Realizando tarefas domésticas } \\
\text { pesadas (deslocando caixas pesadas, }\end{array}$ & Nenhuma, Leve, Moderada, Acentuada, Extrema \\
\hline $\begin{array}{l}\text { A17. Realizando tarefas domésticas } \\
\text { leves (cozinhando, varrendo ..) }\end{array}$ & Nenhuma, Leve, Moderada, Acentuada, Extrema \\
\hline
\end{tabular}

ESPORTES E RECREAÇÕES FUNCIONAIS- Qual a dificuldade que você sentiu nesta última semana:

\begin{tabular}{|l|l|}
\hline Sp1. Agachando & Nenhuma, Leve, Moderada, Acentuada, Extrema \\
\hline Sp2. Correndo & Nenhuma, Leve, Moderada, Acentuada, Extrema \\
\hline Sp3. Pulando & Nenhuma, Leve, Moderada, Acentuada, Extrema \\
\hline Sp4. Mudando de direção sobre o seu & Nenhuma, Leve, Moderada, Acentuada, Extrema \\
\hline Sp5. Ajoelhando-se & Nenhuma, Leve, Moderada, Acentuada, Extrema \\
\hline
\end{tabular}




\section{QUALIDADE DE VIDA EM RELAÇÃO AO PÉ E TORNOZELO}

\begin{tabular}{|l|l|}
\hline $\begin{array}{l}\text { Q1. Com que frequência que você tem percebido } \\
\text { os problemas do seu tornozelo/ pé? }\end{array}$ & $\begin{array}{l}\text { Nunca, mensalmente, } \\
\text { semanalmente, diariamente, sempre }\end{array}$ \\
\hline $\begin{array}{l}\text { Q2. Você tem modificado seu estilo de vida para } \\
\text { evitar atividades potencialmente danosas para o }\end{array}$ & $\begin{array}{l}\text { Não, um pouco, Moderamente, } \\
\text { muito, totalmente }\end{array}$ \\
\hline $\begin{array}{l}\text { Q3. O quanto você está incomodado com a falta de } \\
\text { confiança no seu tornozelo/ pé? }\end{array}$ & $\begin{array}{l}\text { Não, um pouco, Moderamente, } \\
\text { muito, totalmente }\end{array}$ \\
\hline $\begin{array}{l}\text { Q4. No geral, quanto de dificuldade você tem com o } \\
\text { seu tornozelo/pé? }\end{array}$ & $\begin{array}{l}\text { Nenhuma, Leve, Moderada, } \\
\text { Acentuada, Extrema }\end{array}$ \\
\hline
\end{tabular}

Cada questão tem uma pontuação de 0 a 4 . Uma pontuação normal é calculada para cada subescala (100 indica sem sintomas e zero indica sintomas extremos). 


\section{Anexo E - Testes hematológicos e bioquímicos}

Tabela 7 - Características bioquímicas e metabólicas da amostra da população de acordo com o IMC

\begin{tabular}{|c|c|c|c|}
\hline Características & $\begin{array}{c}\text { Total } \\
40 \text { a } 81,3 \\
\left(\mathrm{Kg} / \mathrm{m}^{2}\right) \\
\text { n } 81\end{array}$ & $\begin{array}{c}\text { IMC1 } \\
40 \text { a } 49,6 \\
\left(\mathrm{Kg} / \mathrm{m}^{2}\right) \\
\text { n } 46\end{array}$ & $\begin{array}{c}\text { IMC2 } \\
50 \text { a } 81,3 \\
\left(\mathrm{Kg} / \mathrm{m}^{2}\right) \\
\text { n } 35\end{array}$ \\
\hline Ácido Úrico; mg/dl & $5,6 \pm 1,4$ & $5,4 \pm 1,2$ & $5,9 \pm 1,7$ \\
\hline Albumina; g/dl & $4,17 \pm 0,2$ & $4,2 \pm 0,2$ & $4,1 \pm 0,2$ \\
\hline Colesterol total; mg/dl & $190,7 \pm 36,5$ & $194,9 \pm 38,8$ & $185,2 \pm 33,0$ \\
\hline $\mathrm{HDL} ; \mathrm{mg} / \mathrm{dl}$ & $46,8 \pm 13,0$ & $47,9 \pm 10,2$ & $45,5 \pm 16,1$ \\
\hline LDL; mg/dl & $112,8 \pm 29,9$ & $119,1 \pm 32,2$ & $104,6 \pm 24,7$ \\
\hline Creatinina; mg/dl & $0,8 \pm 0,5$ & $0,8 \pm 0,2$ & $0,9 \pm 0,9$ \\
\hline Glicemia; mg/dl & $149,8 \pm 59,8$ & $144,9 \pm 57,4$ & $156,3 \pm 63,1$ \\
\hline Hematócrito; mg/dl & $39,9 \pm 5,0$ & $39,8 \pm 5,9$ & $40,1 \pm 3,7$ \\
\hline HbA1c; \% & $7,9 \pm 2,7$ & $7,5 \pm 2,2$ & $8,4 \pm 3,2$ \\
\hline Hemoglobina; g/dl & $13,0 \pm 1,4$ & $13,0 \pm 1,4$ & $13,1 \pm 1,4$ \\
\hline Leucócitos; $\mathrm{mm}^{3}$ & $11903 \pm 4588,9$ & $12348 \pm 4480,1$ & $11380 \pm 4729$ \\
\hline Linfócitos típicos;mm³ & $2665,0 \pm 1747,3$ & $2696,5 \pm 1888,8$ & $2623,7 \pm 1568,1$ \\
\hline Triglicérides; mg/dl & $158,1 \pm 67,1$ & $150,6 \pm 53,6$ & $167,9 \pm 81,1$ \\
\hline VLDL;mg/dl & $31,6 \pm 13,4$ & $30,1 \pm 10,7$ & $33,5 \pm 16,3$ \\
\hline
\end{tabular}

Abreviações: \% porcentagem; DP, desvio padrão; g/dl,grama/decilitro; HbA1c Hemoglobina A1c; HDL, High-Density Lipoprotein; LDL, Low-Density Lipoprotein; $\mathrm{mg} / \mathrm{dl}$,miligrama/decilítro; $\mathrm{mm}^{3}$, milímetros cúbicos;VLDL, Very-Low-DensityLipoprotein; 


\section{ANEXO F - Resultados encontrados entre Osteoartrite (OA) versus WOMAC e FAOS}

Tabela 8 - Frequência relativa de OA versus dor no joelho e rigidez articular obtida pelo questionário WOMAC

\begin{tabular}{|c|c|c|c|c|c|c|}
\hline \multirow{2}{*}{ VARIÁVEIS } & \multicolumn{5}{|c|}{ OSTEOARTRITE (k-L) } & \multirow{2}{*}{ ANÁLISE } \\
\hline & Grau 0 & Grau 1 & Grau 2 & Grau 3 & Grau 4 & \\
\hline \multicolumn{7}{|c|}{ Dor nos joelhos durante as últimas $48 \mathrm{hs}$} \\
\hline \multicolumn{7}{|c|}{ Caminhando em lugar plano } \\
\hline Nenhuma & $0(0,0)$ & $5(35,7)$ & $15(46,9)$ & $5(17,9)$ & $1(16,7)$ & \multirow{3}{*}{$\begin{array}{l}\text { Fisher } \\
p=0,08\end{array}$} \\
\hline Pouca a Moderada & $0(0,0)$ & $4(28,6)$ & $13(40,6)$ & $12(42,9)$ & $2(33,3)$ & \\
\hline Intensa a Muito intensa & $1(100,0)$ & $5(35,7)$ & $4(12,5)$ & $11(39,3)$ & $3(50,0)$ & \\
\hline \multicolumn{7}{|l|}{ Subindo/descendo escadas } \\
\hline Nenhuma & $0(0,0)$ & $2(14,3)$ & $9(28,1)$ & $4(14,3)$ & $1(16,7)$ & \multirow{3}{*}{$\begin{array}{l}\text { Fisher } \\
p=0,70\end{array}$} \\
\hline Pouca a Moderada & $0(0,0)$ & $6(42,9)$ & $7(21,9)$ & $6(21,4)$ & $1(16,7)$ & \\
\hline Intensa a Muito intensa & $1(100,0)$ & $6(42,9)$ & $16(50,0)$ & $18(64,3)$ & $4(66,7)$ & \\
\hline \multicolumn{7}{|l|}{ A noite deitado na cama } \\
\hline Nenhuma & $0(0,0)$ & $5(35,7)$ & $21(67,7)$ & $10(35,7)$ & $1(16,7)$ & \multirow{3}{*}{$\begin{array}{l}\text { Fisher } \\
p=0,06\end{array}$} \\
\hline Pouca a Moderada & $1(100,0)$ & $6(42,9)$ & $9(29,0)$ & $13(46,4)$ & $4(66,7)$ & \\
\hline Intensa a Muito intensa & $0(0,0)$ & $3(21,4)$ & $1(3,2)$ & $5(17,9)$ & $1(16,7)$ & \\
\hline \multicolumn{7}{|l|}{ Ao sentar/deitar } \\
\hline Nenhuma & $0(0,0)$ & $6(42,9)$ & $13(40,6)$ & $5(17,9)$ & $1(16,7)$ & \multirow{3}{*}{$\begin{array}{l}\text { Fisher } \\
p=0,35\end{array}$} \\
\hline Pouca a Moderada & $1(100,0)$ & $4(28,6)$ & $14(43,8)$ & $13(46,4)$ & $3(50,0)$ & \\
\hline Intensa a Muito intensa & $0(0,0)$ & $4(28,6)$ & $5(15,6)$ & $10(35,7)$ & $2(33,3)$ & \\
\hline \multicolumn{7}{|l|}{ Ficando em pé } \\
\hline Nenhuma & $0(0,0)$ & $2(14,3)$ & $8(25,0)$ & $4(14,3)$ & $1(16,8)$ & \multirow{3}{*}{$\begin{array}{l}\text { Fisher } \\
p=0,76\end{array}$} \\
\hline Pouca a Moderada & $0(0,0)$ & $6(42,9)$ & $12(37.5)$ & $8(28,6)$ & $1(16,8)$ & \\
\hline Intensa a Muito intensa & $1(100,0)$ & $6(42,9)$ & $12(37.5)$ & $16(57,1)$ & $4(66,7)$ & \\
\hline \multicolumn{7}{|c|}{ Rigidez articular } \\
\hline \multicolumn{7}{|l|}{ Rigidez Matinal } \\
\hline Nenhuma & $0(0,0)$ & $5(35,7)$ & $15(46,9)$ & $3(10,7)$ & $0(0,0)$ & \multirow{3}{*}{$\begin{array}{l}\text { Fisher } \\
p=0,008\end{array}$} \\
\hline Pouca a Moderada & $1(100,0)$ & $4(28,6)$ & $9(28,1)$ & $19(67,9)$ & $3(50,0)$ & \\
\hline Intensa a Muito intensa & $0(0,0)$ & $5(35,7)$ & $8(25,0)$ & $6(21,4)$ & $3(50,0)$ & \\
\hline \multicolumn{7}{|l|}{ Rigidez Durante o dia } \\
\hline Nenhuma & $0(0,0)$ & $7(50,0)$ & $16(50,0)$ & $5(17,9)$ & $0(0,0)$ & \multirow{3}{*}{$\begin{array}{l}\text { Fisher } \\
p=0,05\end{array}$} \\
\hline Pouca a Moderada & $1(100,0)$ & $5(35,7)$ & $12(37,5)$ & $18(64,3)$ & $4(66,7)$ & \\
\hline Intensa a Muito intensa & $0(0,0)$ & $2(14,3)$ & $4(12,5)$ & $5(17,9)$ & $2(33,3)$ & \\
\hline
\end{tabular}

Abreviação: K-L; Kellgren-Lawrence. Os valores entre parênteses referem-se á porcentagem. 
Tabela 9 - Frequência relativa de OA versus dor no pé obtido pelo questionário FAOS

\begin{tabular}{|c|c|c|c|c|c|c|}
\hline \multirow{2}{*}{ VARIÁVEIS } & \multicolumn{5}{|c|}{ OSTEOARTRITE (k-L) } & \multirow{2}{*}{ ANÁLISE } \\
\hline & Grau 0 & Grau 1 & Grau 2 & Grau 3 & Grau4 & \\
\hline \multicolumn{7}{|c|}{ Dor no Pé/Tornozelo na última semana } \\
\hline \multicolumn{7}{|l|}{ Frequência } \\
\hline Nunca & $0(0,0)$ & $2(14,3)$ & $5(15,6)$ & $1(3,6)$ & $1(16,7)$ & \multirow{3}{*}{$\begin{array}{l}\text { Fisher } \\
p=0,08\end{array}$} \\
\hline Mensal/Semanal & $1(100,0)$ & $3(21,4)$ & $3(9,4)$ & $2(7,1)$ & $2(33,3)$ & \\
\hline Diária/Sempre & $0(0,0)$ & $9(64,3)$ & $24(75,0)$ & $25(89,3)$ & $3(50,0)$ & \\
\hline \multicolumn{7}{|l|}{$\begin{array}{l}\text { Rodando sobre seu } \\
\text { pé/tornozelo }\end{array}$} \\
\hline Nenhuma & $0(0,0)$ & $4(28,6)$ & $12(37,5)$ & $1(3,6)$ & $1(16,7)$ & \multirow{3}{*}{$\begin{array}{c}\text { Fisher } \\
p=0,006\end{array}$} \\
\hline Pouca a Moderada & $1(100,0)$ & $5(35,7)$ & $7(21,9)$ & $18(64,3)$ & $4(66,7)$ & \\
\hline Intensa a Muito intensa & $0(0,0)$ & $5(35,7)$ & $13(40,6)$ & $9(32,1)$ & $1(16,7)$ & \\
\hline \multicolumn{7}{|l|}{ Forçando pé baixo } \\
\hline Nenhuma & $0(0,0)$ & $4(28,6)$ & $12(37,5)$ & $2(7,1)$ & $1(16,7)$ & \multirow{3}{*}{$\begin{array}{c}\text { Fisher } \\
p=0,002\end{array}$} \\
\hline Pouca a Moderada & $1(100,0)$ & $6(42,9)$ & $6(18,8)$ & $20(71,4)$ & $4(66,7)$ & \\
\hline Intensa a Muito intensa & $0(0,0)$ & $4(28,6)$ & $14(43,8)$ & $6(21,4)$ & $1(16,7)$ & \\
\hline \multicolumn{7}{|l|}{ Forçando pé cima } \\
\hline Nenhuma & $0(0,0)$ & $4(28,6)$ & $13(40,6)$ & $2(7,1)$ & $1(16,7)$ & \multirow{3}{*}{$\begin{array}{c}\text { Fisher } \\
p=0,004\end{array}$} \\
\hline Pouca a Moderada & $1(100,0)$ & $5(35,7)$ & $7(21,9)$ & $20(71,4)$ & $4(66,7)$ & \\
\hline Intensa a Muito intensa & $0(0,0)$ & $5(35,7)$ & $12(37,5)$ & $6(21,4)$ & $1(16,7)$ & \\
\hline \multicolumn{7}{|c|}{ Andando em superfície plana } \\
\hline Nenhuma & $0(0,0)$ & $3(21,4)$ & $8(25,0)$ & $3(10,7)$ & $1(16,7)$ & \multirow{3}{*}{$\begin{array}{l}\text { Fisher } \\
p=0,72\end{array}$} \\
\hline Pouca a Moderada & $0(0,0)$ & $5(35,7)$ & $13(40,6)$ & $14(50,0)$ & $4(66,7)$ & \\
\hline Intensa a Muito intensa & $1(100,0)$ & $6(42,9)$ & $11(34,4)$ & $11(39,3)$ & $1(16,7)$ & \\
\hline \multicolumn{7}{|l|}{ Subindo/descendo escada } \\
\hline Nenhuma & $0(0,0)$ & $2(14,3)$ & $6(18,8)$ & $2(7,1)$ & $1(16,7)$ & \multirow{3}{*}{$\begin{array}{l}\text { Fisher } \\
p=0,80\end{array}$} \\
\hline Pouca a Moderada & $0(0,0)$ & $6(42,9)$ & $11(34,4)$ & $9(32,1)$ & $3(50,0)$ & \\
\hline Intensa a Muito intensa & $1(100,0)$ & $6(42,9)$ & $15(46,9)$ & $17(60,7)$ & $2(33,3)$ & \\
\hline \multicolumn{7}{|l|}{ Repouso no leito } \\
\hline Nenhuma & $0(0,0)$ & $7(50,0)$ & $18(56,3)$ & $7(25,0)$ & $2(33,3)$ & \multirow{3}{*}{$\begin{array}{l}\text { Fisher } \\
p=0,15\end{array}$} \\
\hline Pouca a Moderada & $1(100,0)$ & $6(42,9)$ & $10(31,3)$ & $19(67,9)$ & $3(50,0)$ & \\
\hline Intensa a Muito intensa & $0(0,0)$ & $1(7,1)$ & $4(12,5)$ & $2(7,1)$ & $1(16,7)$ & \\
\hline \multicolumn{7}{|l|}{ Ao sentar/deitar } \\
\hline Nenhuma & $0(0,0)$ & $4(28,6)$ & $13(40,6)$ & $3(10,7)$ & $1(16,7)$ & \multirow{3}{*}{$\begin{array}{l}\text { Fisher } \\
p=0,33\end{array}$} \\
\hline Pouca a Moderada & $1(100,0)$ & $8(57,1)$ & $15(46,9)$ & $20(71,4)$ & $4(66,7)$ & \\
\hline Intensa a Muito intensa & $0(0,0)$ & $2(14,3)$ & $4(12,5)$ & $5(17,9)$ & $1(16,7)$ & \\
\hline \multicolumn{7}{|l|}{ Em pé } \\
\hline Nenhuma & $0(0,0)$ & $2(14,3)$ & $6(18,8)$ & $0(0,0)$ & $1(16,7)$ & \multirow{3}{*}{$\begin{array}{l}\text { Fisher } \\
p=0,12\end{array}$} \\
\hline Pouca a Moderada & $0(0,0)$ & $3(21,4)$ & $9(28,1)$ & $6(21,4)$ & $3(50,0)$ & \\
\hline Intensa a Muito intensa & $1(100,0)$ & $9(64,3)$ & $17(53,1)$ & $22(78,6)$ & $2(33,3)$ & \\
\hline
\end{tabular}

Abreviação: K-L; Kellgren-Lawrence. Os valores entre parênteses referem-se á porcentagem. 
Tabela 10 - Frequência relativa de OA versus nível dificuldade funcional obtida pelo questionário WOMAC e FAOS

\begin{tabular}{|c|c|c|c|c|c|c|}
\hline \multirow{2}{*}{ VARIÁVEIS } & \multicolumn{5}{|c|}{ OSTEOARTRITE (k-L) } & \multirow{2}{*}{ ANÁLISE } \\
\hline & Grau 0 & Grau 1 & Grau 2 & Grau 3 & Grau4 & \\
\hline \multicolumn{7}{|c|}{ Nível dificuldade para realizar as seguintes funções } \\
\hline \multicolumn{7}{|c|}{ Descer escadas } \\
\hline Nenhuma & $0(0,0)$ & $4(28,6)$ & $8(25,0)$ & $6(21,4)$ & $0(0,0)$ & \multirow{3}{*}{$\begin{array}{l}\text { Fisher } \\
p=0,52\end{array}$} \\
\hline Pouca a Moderada & $0(0,0)$ & $4(28,6)$ & $13(40,6)$ & $7(25,0)$ & $1(16,7)$ & \\
\hline Intensa a Muito intensa & $1(100,0)$ & $6(42,7)$ & $11(34,4)$ & $15(53,6)$ & $5(83,3)$ & \\
\hline \multicolumn{7}{|l|}{ Subir escadas } \\
\hline Nenhuma & $0(0,0)$ & $3(21,4)$ & $5(15,6)$ & $5(17,9)$ & $0(0,0)$ & \multirow{3}{*}{$\begin{array}{l}\text { Fisher } \\
p=0,93\end{array}$} \\
\hline Pouca a Moderada & $0(0,0)$ & $4(28,6)$ & $10(31,3)$ & $6(21,4)$ & $1(16,7)$ & \\
\hline Intensa a Muito intensa & $1(100,0)$ & $7(50,0)$ & $17(53,1)$ & $17(60,7)$ & $5(83,3)$ & \\
\hline \multicolumn{7}{|c|}{ Levantar-se estando sentada } \\
\hline Nenhuma & $0(0,0)$ & $2(14,3)$ & $6(18,8)$ & $4(14,3)$ & $1(16,7)$ & \multirow{3}{*}{$\begin{array}{l}\text { Fisher } \\
p=0,77\end{array}$} \\
\hline Pouca a Moderada & $0(0,0)$ & $10(71,4)$ & $15(46,9)$ & $15(53,6)$ & $3(50,0)$ & \\
\hline Intensa a Muito intensa & $1(100,0)$ & $2(14,3)$ & $11(34,9)$ & $9(32,1)$ & $2(33,3)$ & \\
\hline \multicolumn{7}{|l|}{ Ficar em pé } \\
\hline Nenhuma & $0(0,0)$ & $2(15,4)$ & $4(12,9)$ & $3(10,7)$ & $1(16,7)$ & \multirow{3}{*}{$\begin{array}{l}\text { Fisher } \\
p=0,98\end{array}$} \\
\hline Pouca a Moderada & $0(0,0)$ & $5(38,5)$ & $12(38,7)$ & $11(39,3)$ & $1(16,7)$ & \\
\hline Intensa a Muito intensa & $1(100,0)$ & $6(46,2)$ & $15(48,4)$ & $14(50,0)$ & $4(66,7)$ & \\
\hline \multicolumn{7}{|l|}{ Abaixar-se pegar algo chão } \\
\hline Nenhuma & $0(0,0)$ & $2(14,3)$ & $7(21,9)$ & $2(7,1)$ & $1(16,7)$ & \multirow{3}{*}{$\begin{array}{l}\text { Fisher } \\
p=0,50\end{array}$} \\
\hline Pouca a Moderada & $0(0,0)$ & $1(7,2)$ & $7(21,9)$ & $9(32,1)$ & $2(33,3)$ & \\
\hline Intensa a Muito intensa & $1(100,0)$ & $11(78,6)$ & $18(56,3)$ & $17(60,7)$ & $3(50,0)$ & \\
\hline \multicolumn{7}{|l|}{ Andar no plano } \\
\hline Nenhuma & $0(0,0)$ & $3(21,4)$ & $11(34,4)$ & $5(17,9)$ & $1(16,7)$ & \multirow{3}{*}{$\begin{array}{l}\text { Fisher } \\
p=0,13\end{array}$} \\
\hline Pouca a Moderada & $0(0,0)$ & $8(57,1)$ & $16(50,0)$ & $12(42,9)$ & $1(16,7)$ & \\
\hline Intensa a Muito intensa & $1(100,0)$ & $3(21,4)$ & $5(15,6)$ & $11(39,3)$ & $4(66,7)$ & \\
\hline \multicolumn{7}{|l|}{ Entrar e sair carro } \\
\hline Nenhuma & $0(0,0)$ & $2(14,3)$ & $9(28,1)$ & $3(10,7)$ & $1(16,7)$ & \multirow{3}{*}{$\begin{array}{l}\text { Fisher } \\
p=0,37\end{array}$} \\
\hline Pouca a Moderada & $0(0,0)$ & $7(50,0)$ & $9(28,1)$ & $16(57,1)$ & $2(33,3)$ & \\
\hline Intensa a Muito intensa & $1(100,0)$ & $5(35,7)$ & $14(43,8)$ & $9(32,1)$ & $3(50,0)$ & \\
\hline \multicolumn{7}{|l|}{ Ir fazer compras } \\
\hline Nenhuma & $0(0,0)$ & $4(28,6)$ & $8(25,0)$ & $3(10,7)$ & $1(16,7)$ & \multirow{3}{*}{$\begin{array}{l}\text { Fisher } \\
\mathrm{p}=0,32\end{array}$} \\
\hline Pouca a Moderada & $0(0,0)$ & $6(42,9)$ & $15(46,9)$ & $17(60,7)$ & $1(16,7)$ & \\
\hline Intensa a Muito intensa & $1(100,0)$ & $4(28,6)$ & $9(28,1)$ & $8(28,6)$ & $4(66,7)$ & \\
\hline \multicolumn{7}{|l|}{ Calçar meias } \\
\hline Nenhuma & $0(0,0)$ & $2(14,3)$ & $4(12,5$ & $2(7,1)$ & $1(16,7)$ & \multirow{3}{*}{$\begin{array}{l}\text { Fisher } \\
p=0,86\end{array}$} \\
\hline Pouca a Moderada & $0(0,0)$ & $1(7,1)$ & $8(25,0)$ & $6(21,4)$ & $1(16,7)$ & \\
\hline Intensa a Muito intensa & $1(100,0)$ & $11(78,6)$ & $20(62,5)$ & $20(71,4)$ & $4(66,7)$ & \\
\hline \multicolumn{7}{|l|}{ Levantar-se da Cama } \\
\hline Nenhuma & $0(0,0)$ & $2(14,3)$ & $9(28,1)$ & $4(14,3)$ & $1(16,7)$ & \multirow{3}{*}{$\begin{array}{l}\text { Fisher } \\
p=0,62\end{array}$} \\
\hline Pouca a Moderada & $0(0,0)$ & $9(64,3)$ & $14(43,8)$ & $16(57,1)$ & $2(33,3)$ & \\
\hline Intensa a Muito intensa & $1(100,0)$ & $3(21,4)$ & $9(28,1)$ & $8(28,6)$ & $3(50,0)$ & \\
\hline
\end{tabular}


Tabela 10 - Frequência relativa de OA versus nível dificuldade funcional obtida pelo questionário WOMAC e FAOS - "conclusão"

\begin{tabular}{|c|c|c|c|c|c|c|}
\hline \multirow{2}{*}{ VARIÁVEIS } & \multicolumn{5}{|c|}{ OSTEOARTRITE (k-L) } & \multirow{2}{*}{ ANÁLISE } \\
\hline & Grau 0 & Grau 1 & Grau 2 & Grau 3 & Grau4 & \\
\hline \multicolumn{7}{|c|}{ Nível dificuldade para realizar as seguintes funções } \\
\hline \multicolumn{7}{|l|}{ Tirar meias } \\
\hline Nenhuma & $0(0,0)$ & $2(14,3)$ & $5(15,6)$ & $2(7,1)$ & $1(16,7)$ & \multirow{3}{*}{$\begin{array}{l}\text { Fisher } \\
p=0,96\end{array}$} \\
\hline Pouca a Moderada & $0(0,0)$ & $2(14,3)$ & $7(21,9)$ & $6(21,4)$ & $1(16,7)$ & \\
\hline Intensa a Muito intensa & $1(100,0)$ & $10(71,4)$ & $20(62,5)$ & $20(71,4)$ & $4(66,7)$ & \\
\hline \multicolumn{7}{|l|}{ Ficar deitado leito } \\
\hline Nenhuma & $0(0,0)$ & $5(35,7)$ & $14(43,8)$ & $8(28,6)$ & $1(16,7)$ & \multirow{3}{*}{$\begin{array}{l}\text { Fisher } \\
p=0,14\end{array}$} \\
\hline Pouca a Moderada & $0(0,0)$ & $8(57,1)$ & $10(31,2)$ & $17(60,7)$ & $3(50,0)$ & \\
\hline Intensa a Muito intensa & $1(100,0)$ & $1(7,1)$ & $8(25,0)$ & $3(10,7)$ & $2(33,3)$ & \\
\hline \multicolumn{7}{|l|}{ Entrar/sair banho } \\
\hline Nenhuma & $0(0,0)$ & $6(42,9)$ & $16(50,0)$ & $8(28,6)$ & $1(16,7)$ & \multirow{3}{*}{$\begin{array}{l}\text { Fisher } \\
p=0,13\end{array}$} \\
\hline Pouca a Moderada & $0(0,0)$ & $7(50,0)$ & $10(31,2)$ & $17(60,7)$ & $3(50,0)$ & \\
\hline Intensa a Muito intensa & $1(100,0)$ & $1(7,1)$ & $6(18,8)$ & $3(10,7)$ & $2(33,3)$ & \\
\hline \multicolumn{7}{|l|}{ Se sentar } \\
\hline Nenhuma & $0(0,0)$ & $3(21,4)$ & $9(28,1)$ & $5(17,9)$ & $1(16,7)$ & \multirow{3}{*}{$\begin{array}{l}\text { Fisher } \\
p=0,79\end{array}$} \\
\hline Pouca a Moderada & $0(0,0)$ & $8(57,1)$ & $17(53,1)$ & $18(64,2)$ & $3(50,0)$ & \\
\hline Intensa a Muito intensa & $1(100,0)$ & $3(21,4)$ & $6(18,8)$ & $5(17,9)$ & $2(33,3)$ & \\
\hline \multicolumn{7}{|c|}{ Sentar/ levantar vaso sanitário } \\
\hline Nenhuma & $0(0,0)$ & $2(14,3)$ & $8(25,0)$ & $3(10,7)$ & $1(16,7)$ & \multirow{3}{*}{$\begin{array}{l}\text { Fisher } \\
p=0,65\end{array}$} \\
\hline Pouca a Moderada & $0(0,0)$ & $8(57,1)$ & $16(50,0)$ & $17(60,7)$ & $2(33,3)$ & \\
\hline Intensa a Muito intensa & $1(100,0)$ & $4(28,6)$ & $8(25,0)$ & $8(28,6)$ & $3(50,0)$ & \\
\hline \multicolumn{7}{|c|}{ Fazer tarefas domésticas pesadas } \\
\hline Nenhuma & $0(0,0)$ & $2(14,3)$ & $5(15,6)$ & $2(7,1)$ & $1(16,7)$ & \multirow{3}{*}{$\begin{array}{l}\text { Fisher } \\
p=0,86\end{array}$} \\
\hline Pouca a Moderada & $0(0,0)$ & $3(21,4)$ & $11(34,4)$ & $7(25,0)$ & $1(16,7)$ & \\
\hline Intensa a Muito intensa & $1(100,0)$ & $9(64,3)$ & $16(50,0)$ & $19(67,9)$ & $4(66,7)$ & \\
\hline \multicolumn{7}{|c|}{ Fazer tarefas domésticas leves } \\
\hline Nenhuma & $0(0,0)$ & $3(21,4)$ & $6(18,8)$ & $5(17,9)$ & $1(16,7)$ & \multirow{3}{*}{$\begin{array}{l}\text { Fisher } \\
p=0,87\end{array}$} \\
\hline Pouca a Moderada & $0(0,0)$ & $6(42,9)$ & 12(37.5) & $7(25,0)$ & $3(50,0)$ & \\
\hline Intensa a Muito intensa & $1(100,0)$ & $5(35,7)$ & $14(43,8)$ & $16(57,1)$ & $2(33,3)$ & \\
\hline
\end{tabular}

Abreviação: K-L; Kellgren-Lawrence. Os valores entre parênteses referem-se á porcentagem. 


\section{ANEXO G - Resultados encontrados entre T1M estratificado versus WOMAC E FAOS}

Tabela 11 - Frequência relativa de T1M estratificado versus dor no joelho e rigidez articular obtida pelo questionário WOMAC

\begin{tabular}{|c|c|c|c|c|c|}
\hline \multirow[t]{2}{*}{ VARIÁVEIS } & \multicolumn{2}{|c|}{ IMC1 } & \multicolumn{2}{|c|}{ IMC2 } & \multirow{2}{*}{$\begin{array}{c}\text { ANÁLISE } \\
\text { Fisher - } p \text { valor }\end{array}$} \\
\hline & $\mathrm{T} 1 \mathrm{M}-1$ & T1M-2 & T1M-1 & T1M-2 & \\
\hline & \multicolumn{4}{|c|}{ Dor no joelho nas últimas $\mathbf{4 8}$ horas } & \\
\hline \multicolumn{6}{|c|}{ Caminhando em lugar plano } \\
\hline Nenhuma & $10(55,6)$ & $11(39,3)$ & $0(0,0)$ & $5(17,3)$ & \multirow{3}{*}{$a=0,06 ; b=0,02$} \\
\hline Pouca a Moderada & $7(38,9)$ & $7(25,0)$ & $6(100,0)$ & $11(37,9)$ & \\
\hline Intensa a Muito intensa & $1(5,6)$ & $10(35,7)$ & $0(0,0)$ & $13(44,8)$ & \\
\hline \multicolumn{6}{|l|}{ Subindo/descendo escadas } \\
\hline Nenhuma & $6(33,3)$ & $8(28,6)$ & $0(0,0)$ & $2(6,9)$ & \multirow{3}{*}{$a=0,79 ; b=1,0$} \\
\hline Pouca a Moderada & $4(22,2)$ & $5(17,9)$ & $2(33,3$ & $9(31,0)$ & \\
\hline Intensa a Muito intensa & $8(44,4)$ & $15(53,7)$ & $4(66,7)$ & $18(62,1)$ & \\
\hline \multicolumn{6}{|l|}{ A noite deitado na cama } \\
\hline Nenhuma & $13(72,2)$ & $14(50,0)$ & $1(16,7)$ & $9(32,1)$ & \multirow{3}{*}{$a=0,30 ; b=0,54$} \\
\hline Pouca a Moderada & $4(22,2)$ & $9(32,1)$ & $5(83,3)$ & $15(53,6)$ & \\
\hline Intensa a Muito intensa & $1(5,6)$ & $5(17,9)$ & $0(0,0)$ & $4(14,3)$ & \\
\hline \multicolumn{6}{|l|}{ Ao sentar/deitar } \\
\hline Nenhuma & $9(50,0)$ & $9(32,1)$ & $1(16,7)$ & $6(20,7)$ & \multirow{3}{*}{$a=0,51 ; b=0,20$} \\
\hline Pouca a Moderada & $6(33,3)$ & $11(39,3)$ & $5(83,3)$ & $13(44,8)$ & \\
\hline Intensa a Muito intensa & $3(16,7)$ & $8(28,6)$ & $0(0,0)$ & $10(34,5)$ & \\
\hline \multicolumn{6}{|l|}{ Ficando em pé } \\
\hline Nenhuma & $5(27,8)$ & $6(21,4)$ & $0(0,0)$ & $4(13,8)$ & \multirow{3}{*}{$a=0,74 ; b=1,0$} \\
\hline Pouca a Moderada & $7(38,9)$ & $9(32,1)$ & $2(33,3)$ & $9(31,0)$ & \\
\hline \multirow[t]{2}{*}{ Intensa a Muito intensa } & $6(33,3)$ & $13(46,4)$ & $4(66,7)$ & $16(55,2)$ & \\
\hline & \multicolumn{4}{|c|}{ Rigidez articular } & \\
\hline \multicolumn{6}{|l|}{ Rigidez Matinal } \\
\hline Nenhuma & $7(38,9)$ & $9(32,1)$ & $1(16,7)$ & $6(20,7)$ & \multirow{3}{*}{$a=0,93 ; b=0,07$} \\
\hline Pouca a Moderada & $7(38,9)$ & $13(46,4)$ & $5(83,3)$ & $11(37,9)$ & \\
\hline Intensa a Muito intensa & $4(22,2)$ & $6(21,4)$ & $0(0,0)$ & $12(41,4)$ & \\
\hline \multicolumn{6}{|l|}{ Rigidez Durante o dia } \\
\hline Nenhuma & $7(38,9)$ & $13(46,4)$ & $0(0,0)$ & $8(27,6)$ & \multirow{3}{*}{$a=0,92 ; b=0,22$} \\
\hline Pouca a Moderada & $8(44,4)$ & $10(35,7)$ & $6(17,1)$ & $16(55,1)$ & \\
\hline Intensa a Muito intensa & $3(16,7)$ & $5(17,9)$ & $0(0,0)$ & $5(17,2)$ & \\
\hline
\end{tabular}

Abreviações: IMC, índice de massa corporal; a,IMC1;b,IMC2; T1M, ângulo tálus-primeiro metatarso. Os valores entre parênteses referem-se á porcentagem. 
Tabela 12 - Frequência relativa de T1M estratificado versus dor no pé obtida pelo questionário FAOS

\begin{tabular}{|c|c|c|c|c|c|}
\hline \multirow[t]{2}{*}{ VARIÁVEIS } & \multicolumn{2}{|c|}{ IMC1 } & \multicolumn{2}{|c|}{ IMC2 } & \multirow{2}{*}{$\begin{array}{c}\text { ANÁLISE } \\
\text { Fisher - } p \text { valor }\end{array}$} \\
\hline & T1M-1 & $\mathrm{T} 1 \mathrm{M}-2$ & T1M-1 & $\mathrm{T} 1 \mathrm{M}-2$ & \\
\hline \multicolumn{6}{|c|}{ Dor no pé na última semana } \\
\hline \multicolumn{6}{|l|}{ Frequência } \\
\hline Nunca & $6(33,3)$ & $3(10,7)$ & $0(0,0)$ & $0(0,0)$ & \\
\hline Mensal/Semanal & $3(16,7)$ & $5(17,9)$ & $1(16,7)$ & $2(6,9)$ & $a=0,18 ; b=0,44$ \\
\hline Diária/Sempre & $9(50,0)$ & $20(71,4)$ & $5(83,3)$ & $27(93,1)$ & \\
\hline \multicolumn{6}{|l|}{$\begin{array}{l}\text { Rodando sobre seu } \\
\text { pé/tornozelo }\end{array}$} \\
\hline Nenhuma & $8(44,4)$ & $8(28,6)$ & $0(0,0)$ & $2(6,9)$ & \\
\hline Pouca a Moderada & $5(27,8)$ & $8(28,6)$ & $5(83,3)$ & $17(58,6)$ & $a=0,51 ; b=0,75$ \\
\hline Intensa a Muito intensa & $5(27,8)$ & $12(42,9)$ & $1(16,7)$ & $10(34,5)$ & \\
\hline \multicolumn{6}{|l|}{ Forçando pé baixo } \\
\hline Nenhuma & $8(44,4)$ & $9(32,1)$ & $0(0,0)$ & $2(6,9)$ & \\
\hline Pouca a Moderada & $5(27,8)$ & $8(28,6)$ & $5(83,3)$ & $19(65,5)$ & $a=0,65 ; b=1,00$ \\
\hline Intensa a Muito intensa & $5(27,8)$ & $11(39,3)$ & $1(16,7)$ & $8(27,6)$ & \\
\hline \multicolumn{6}{|l|}{ Forçando pé cima } \\
\hline Nenhuma & $8(44,4)$ & $8(28,6)$ & $1(16,7)$ & $3(10,3)$ & \\
\hline Pouca a Moderada & $7(38,9)$ & $10(35,7)$ & $3(50,0)$ & $17(58,6)$ & $a=0,33 ; 0,84$ \\
\hline Intensa a Muito intensa & $3(16,7)$ & $10(35,7)$ & $2(33,3)$ & $9(31,0)$ & \\
\hline \multicolumn{6}{|c|}{ Andando em superfície plana } \\
\hline Nenhuma & $8(44,4)$ & $6(21,4)$ & $0(0,0)$ & $1(3,5)$ & \\
\hline Pouca a Moderada & $5(27,8)$ & $10(35,7)$ & $5(83,3)$ & $16(55,2)$ & $a=0,29 ; b=0,48$ \\
\hline Intensa a Muito intensa & $5(27,8)$ & $12(42,9)$ & $1(16,7)$ & $12(41,4)$ & \\
\hline \multicolumn{6}{|l|}{ Subindo/descendo escada } \\
\hline Nenhuma & $6(33,3)$ & $5(17,9)$ & $0(0,0)$ & $0(0,0)$ & \\
\hline Pouca a Moderada & $6(33,3)$ & $5(17,9)$ & $2(33,3)$ & $16(55,2)$ & $a=0,13 ; b=0,40$ \\
\hline Intensa a Muito intensa & $6(33,3)$ & $18(64,3)$ & $4(66,7)$ & $13(44,8)$ & \\
\hline \multicolumn{6}{|l|}{ Repouso no leito } \\
\hline Nenhuma & $10(55,6)$ & $15(53,6)$ & $2(33,3)$ & $7(24,1)$ & \\
\hline Pouca a Moderada & $6(33,3)$ & $9(32,1)$ & $4(66,7)$ & $20(69,0)$ & $a=1,0 ; b=1,0$ \\
\hline Intensa a Muito intensa & $2(11,1)$ & $4(14,3)$ & $0(0,0)$ & $2(6,9)$ & \\
\hline \multicolumn{6}{|l|}{ Ao sentar/deitar } \\
\hline Nenhuma & $6(33,3)$ & $10(35,7)$ & $1(16,7)$ & $4(13,8)$ & \\
\hline Pouca a Moderada & $11(61,1)$ & $12(42,9)$ & $5(83,3)$ & $20(69,0)$ & $a=0,33 ; b=0,81$ \\
\hline Intensa a Muito intensa & $1(5,6)$ & $6(21,4)$ & $0(0,0)$ & $5(17,2)$ & \\
\hline \multicolumn{6}{|l|}{ Em pé } \\
\hline Nenhuma & $6(33,3)$ & $3(10,7)$ & $0(0,0)$ & $0(0,0)$ & \\
\hline Pouca a Moderada & $4(22,2)$ & $6(21,4)$ & $2(33,3)$ & $9(31,0)$ & $a=0,17 ; b=1,00$ \\
\hline Intensa a Muito intensa & $8(44,4)$ & $19(67,9)$ & $4(66,7)$ & $20(69,0)$ & \\
\hline
\end{tabular}

Abreviações: IMC, índice de massa corporal; a,IMC1; b,IMC2; T1M, ângulo tálus-primeiro metatarso. Os valores entre parênteses referem-se á porcentagem. 
Tabela 13 - Frequência relativa de T1M estratificado versus nível de dificuldade funcional obtida pelos questionários WOMAC e FAOS

\begin{tabular}{|c|c|c|c|c|c|}
\hline \multirow[t]{2}{*}{ VARIÁVEIS } & \multicolumn{2}{|c|}{ IMC1 } & \multicolumn{2}{|c|}{ IMC2 } & \multirow{2}{*}{$\begin{array}{c}\text { ANÁLISE } \\
\text { Fisher - } p \text { valor }\end{array}$} \\
\hline & T1M-1 & T1M-2 & T1M-1 & T1M-2 & \\
\hline \multicolumn{6}{|c|}{ Nível dificuldade para realizar as seguintes funções } \\
\hline \multicolumn{6}{|l|}{ Descer escadas } \\
\hline Nenhuma & $6(33,3)$ & $4(14,3)$ & $1(16,7)$ & $7(24,1)$ & \\
\hline Pouca a Moderada & $7(38,9)$ & $9(32,1)$ & $1(16,7)$ & $8(27,6)$ & $a=0,18 ; b=0,86$ \\
\hline Intensa a Muito intensa & $5(27,8)$ & $15(53,6)$ & $4(66,7)$ & $14(48,3)$ & \\
\hline \multicolumn{6}{|l|}{ Subir escadas } \\
\hline Nenhuma & $5(27,8)$ & $3(10,7)$ & $1(16,7)$ & $4(13,8)$ & \\
\hline Pouca a Moderada & $5(27,8)$ & $9(32,1)$ & $0(0,0)$ & $7(24,1)$ & $a=0,39 ; b=0,44$ \\
\hline Intensa a Muito intensa & $8(44,4)$ & $16(57,1)$ & $5(83,3)$ & $18(62,1)$ & \\
\hline \multicolumn{6}{|c|}{ Levantar-se estando sentada } \\
\hline Nenhuma & $7(38,9)$ & $3(10,7)$ & $0(0,0)$ & $3(10,3)$ & \\
\hline Pouca a Moderada & $6(33,3)$ & $14(50,0)$ & $6(100,0)$ & $17(58,6)$ & $a=0,10 ; b=0,26$ \\
\hline Intensa a Muito intensa & $5(27,8)$ & $11(39,3)$ & $0(0,0)$ & $9(31,0)$ & \\
\hline \multicolumn{6}{|l|}{ Ficar em pé } \\
\hline Nenhuma & $6(33,3)$ & $3(10,7)$ & $0(0,0)$ & $1(3,7)$ & \\
\hline Pouca a Moderada & $6(33,3)$ & $10(35,7)$ & $3(50,0)$ & $10(37,0)$ & $a=0,19 ; b=0,73$ \\
\hline Intensa a Muito intensa & $6(33,3)$ & $15(53,6)$ & $3(50,0)$ & $16(59,3)$ & \\
\hline \multicolumn{6}{|l|}{ Abaixar-se pegar algo chão } \\
\hline Nenhuma & $6(33,3)$ & $4(14,3)$ & $1(16,7)$ & $1(3,5)$ & \\
\hline Pouca a Moderada & $4(22,2)$ & $8(28,6)$ & $1(16,7)$ & $6(20,7)$ & $a=0,35 ; b=0,38$ \\
\hline Intensa a Muito intensa & $8(44,4)$ & $16(57,1)$ & $4(66,7)$ & $22(75,9)$ & \\
\hline \multicolumn{6}{|l|}{ Andar no plano } \\
\hline Nenhuma & $9(50,0)$ & $7(25,0)$ & $0(0,0)$ & $4(13,8)$ & \\
\hline Pouca a Moderada & $8(44,4)$ & $11(39,3)$ & $4(66,7)$ & $14(48,3)$ & $a=0.04 ; b=0,84$ \\
\hline Intensa a Muito intensa & $1(5,6)$ & $10(35,7)$ & $2(33,3)$ & $11(37,9)$ & \\
\hline \multicolumn{6}{|l|}{ Entrar e sair carro } \\
\hline Nenhuma & $6(33,3)$ & $6(21,4)$ & $1(16,7)$ & $2(6,9)$ & \\
\hline Pouca a Moderada & $7(38,9)$ & $9(32,1)$ & $3(50,0)$ & $15(51,7)$ & $a=0,50 ; b=0,65$ \\
\hline Intensa a Muito intensa & $5(27,8)$ & $13(46,5)$ & $2(33,3)$ & $12(41,4)$ & \\
\hline \multicolumn{6}{|l|}{ Ir fazer compras } \\
\hline Nenhuma & $7(38,9)$ & $6(21,4)$ & $0(0,0)$ & $3(10,3)$ & \\
\hline Pouca a Moderada & $8(44,4)$ & $12(42,9)$ & $4(66,7)$ & $15(51,7)$ & $a=0,28 ; b=1,0$ \\
\hline Intensa a Muito intensa & $3(16,7)$ & $10(35,7)$ & $2(33,3)$ & $11(37,9)$ & \\
\hline \multicolumn{6}{|l|}{ Calçar meias } \\
\hline Nenhuma & $6(33,3)$ & $2(7,1)$ & $0(0,0)$ & $1(3,5)$ & \\
\hline Pouca a Moderada & $4(22,2)$ & $8(28,6)$ & $2(33,3)$ & $2(6,9)$ & $a=0,10 ; b=0,28$ \\
\hline Intensa a Muito intensa & $8(44,4)$ & $18(64,3)$ & $4(66,7)$ & $26(89,7)$ & \\
\hline
\end{tabular}


Tabela 13 - Frequência relativa de T1M estratificado versus nível de dificuldade funcional obtida pelos questionários WOMAC e FAOS "conclusão"

\begin{tabular}{|c|c|c|c|c|c|}
\hline \multirow{2}{*}{ VARIÁVEIS } & \multicolumn{2}{|c|}{ IMC1 } & \multicolumn{2}{|c|}{ IMC2 } & \multirow{2}{*}{$\begin{array}{c}\text { ANÁLISE } \\
\text { Fisher - } \mathrm{p} \text { valor } \\
\end{array}$} \\
\hline & $\mathrm{T} 1 \mathrm{M}-1$ & T1M-2 & $\mathrm{T} 1 \mathrm{M}-1$ & $\mathrm{~T} 1 \mathrm{M}-2$ & \\
\hline \multicolumn{6}{|c|}{ Nível dificuldade para realizar as seguintes funções } \\
\hline \multicolumn{6}{|c|}{ Levantar-se da Cama } \\
\hline Nenhuma & $6(33,3)$ & $5(17,9)$ & $1(16,7)$ & $4(13,8)$ & \\
\hline Pouca a Moderada & $7(38,9)$ & $14(50,0)$ & $5(83,4)$ & $15(51,7)$ & $a=0,47 ; b=0,19$ \\
\hline Intensa a Muito intensa & $5(27,8)$ & $9(32,1)$ & $0(0,0)$ & $10(34,5)$ & \\
\hline \multicolumn{6}{|l|}{ Tirar meias } \\
\hline Nenhuma & $6(33,3)$ & $2(7,1)$ & $1(16,7)$ & $1(3,5)$ & \\
\hline Pouca a Moderada & $4(22,2)$ & $8(28,6)$ & $1(16,7)$ & $3(10,3)$ & $a=0,10 ; b=0,27$ \\
\hline Intensa a Muito intensa & $8(44,5)$ & $18(64,3)$ & $4(66,7)$ & $25(86,2)$ & \\
\hline \multicolumn{6}{|l|}{ Ficar deitado leito } \\
\hline Nenhuma & $8(44,4)$ & $11(39,3)$ & $2(33,3)$ & $7(24,1)$ & \\
\hline Pouca a Moderada & $8(44,4)$ & $8(28,6)$ & $4(66,7)$ & $18(62,0)$ & $a=0,24 ; b=1,00$ \\
\hline Intensa a Muito intensa & $2(11,1)$ & $9(32,1)$ & $0(0,0)$ & $4(13,8)$ & \\
\hline \multicolumn{6}{|l|}{ Entrar/sair banho } \\
\hline Nenhuma & $11(61,1)$ & $11(39,3)$ & $1(16,7)$ & $8(27,6)$ & \multirow{3}{*}{$a=0,33 ; b=0,68$} \\
\hline Pouca a Moderada & $5(27,8)$ & $10(35,7)$ & $5(83,3)$ & $17(58,6)$ & \\
\hline Intensa a Muito intensa & $2(11,1)$ & $7(25,0)$ & $0(0,0)$ & $4(13,8)$ & \\
\hline \multicolumn{6}{|l|}{ Se sentar } \\
\hline Nenhuma & $7(38,9)$ & $6(21,4)$ & $1(16,7)$ & $4(13,8)$ & \multirow{3}{*}{$a=0,37 ; b=1,00$} \\
\hline Pouca a Moderada & $9(50,0)$ & $15(53,6)$ & $4(66,7)$ & $18(62,1)$ & \\
\hline Intensa a Muito intensa & $2(11,1)$ & $7(25,0)$ & $1(16,7)$ & $7(24,1)$ & \\
\hline \multicolumn{6}{|c|}{ Sentar/ levantar vaso sanitário } \\
\hline Nenhuma & $7(38,9)$ & $4(14,3)$ & $1(16,7)$ & $2(6,9)$ & \multirow{3}{*}{$a=0.08 ; b=0.62$} \\
\hline Pouca a Moderada & $8(44,4)$ & $12(42,9)$ & $4(66,7)$ & $19(65,5)$ & \\
\hline Intensa a Muito intensa & $3(16,7)$ & $12(42,9)$ & $1(16,7)$ & $8(27,6)$ & \\
\hline \multicolumn{6}{|c|}{ Fazer tarefas domésticas pesadas } \\
\hline Nenhuma & $6(33,3)$ & $2(7,1)$ & $0(0,0)$ & $2(6,9)$ & \multirow{3}{*}{$a=0,08 ; b=0,74$} \\
\hline Pouca a Moderada & $5(27,8)$ & $9(32,1)$ & $2(33,3)$ & $6(20,7)$ & \\
\hline Intensa a Muito intensa & $7(38.9)$ & $17(60,7)$ & $4(66,7)$ & $21(72,4)$ & \\
\hline \multicolumn{6}{|c|}{ Fazer tarefas domésticas leves } \\
\hline Nenhuma & $8(44,4)$ & $5(17,9)$ & $0(0,0)$ & $2(6,9)$ & \multirow{3}{*}{$a=0,13 ; b=0,12$} \\
\hline Pouca a Moderada & $5(27,8)$ & $8(28,6)$ & $5(83,3)$ & $10(34,5)$ & \\
\hline Intensa a Muito intensa & $5(27,8)$ & $15(53,6)$ & $1(16,7)$ & $17(58,6)$ & \\
\hline
\end{tabular}

Abreviações: IMC, índice de massa corporal; a,IMC1; b,IMC2; T1M, ângulo tálus-primeiro metatarso. Os valores entre parênteses referem-se á porcentagem. 
ANEXO H - Resultados encontrados entre Índice de Staheli (IS) versus WOMAC E FAOS

Tabela 14 - Frequência relativa do IS versus dor no pé obtida pelo questionário FAOS

\begin{tabular}{|c|c|c|c|c|c|}
\hline VARIÁVEIS & \multicolumn{2}{|c|}{$\begin{array}{l}I S=I \\
n=62\end{array}$} & \multicolumn{2}{|c|}{$\begin{array}{l}I S=I I \\
n=19\end{array}$} & \multirow[t]{2}{*}{$\begin{array}{l}\text { ANÁLISE } \\
\text { FISHER }\end{array}$} \\
\hline \multirow{2}{*}{\multicolumn{6}{|c|}{ Dor no pé/tornozelo durante a última semana }} \\
\hline & & & & & \\
\hline Nunca & 9 & $(14,5)$ & 0 & $(0,0)$ & \\
\hline Mensal/Semanal & 7 & $(11,3)$ & 4 & $(21,0)$ & $p=0,14$ \\
\hline Diária/Sempre & 46 & $(74,2)$ & 5 & $(79,0)$ & \\
\hline \multicolumn{6}{|c|}{ Rodando sobre seu pé/tornozelo } \\
\hline Nenhuma & 16 & $(25,8)$ & 2 & $(10,6)$ & \\
\hline Pouca a Moderada & 25 & $(40,3)$ & 10 & $(52,6)$ & $\mathrm{p}=0,35$ \\
\hline Intensa a Muito intensa & 21 & $(33,9)$ & 7 & $(36,8)$ & \\
\hline \multicolumn{6}{|l|}{ Forçando pé baixo } \\
\hline Nenhuma & 17 & $(27,4)$ & 2 & $(10,5)$ & \\
\hline Pouca a Moderada & 25 & $(40,3)$ & 12 & $(63,2)$ & $\mathrm{p}=0,18$ \\
\hline Intensa a Muito intensa & 20 & $(32,3)$ & 5 & $(26,3)$ & \\
\hline \multicolumn{6}{|l|}{ Forçando pé cima } \\
\hline Nenhuma & 18 & $(29,0)$ & 2 & $(10,5)$ & \\
\hline Pouca a Moderada & 25 & $(40,3)$ & 12 & $(63,2)$ & $p=0,17$ \\
\hline Intensa a Muito intensa & 19 & $(30,7)$ & 5 & $(26,3)$ & \\
\hline \multicolumn{6}{|c|}{ Andando em superfície plana } \\
\hline Nenhuma & 13 & $(21,0)$ & 2 & $(10,5)$ & \\
\hline Pouca a Moderada & 27 & $(43,6)$ & 9 & $(47,4)$ & $p=0,69$ \\
\hline Intensa a Muito intensa & 22 & $(35,4)$ & 8 & $(42,1)$ & \\
\hline \multicolumn{6}{|l|}{ Subindo/descendo escada } \\
\hline Nenhuma & 10 & $(16,1)$ & 1 & $(5,3)$ & \\
\hline Pouca a Moderada & 22 & $(35,5)$ & 7 & $(36,8)$ & $p=0,59$ \\
\hline Intensa a Muito intensa & 30 & $(48,4)$ & 11 & $(57,9)$ & \\
\hline \multicolumn{6}{|l|}{ Repouso no leito } \\
\hline Nenhuma & 30 & $(48,4)$ & 4 & $(21,0)$ & \\
\hline Pouca a Moderada & 24 & $(38,7)$ & 15 & $(79,0)$ & $p=0,007$ \\
\hline Intensa a Muito intensa & 8 & $(12,9)$ & 0 & $(0,0)$ & \\
\hline \multicolumn{6}{|l|}{ Ao sentar/deitar } \\
\hline Nenhuma & 17 & $(27,4)$ & 4 & $(21,0)$ & \\
\hline Pouca a Moderada & 37 & $(59,7)$ & 11 & $(58,0)$ & $p=0,66$ \\
\hline Intensa a Muito intensa & 8 & $(12,9)$ & 4 & $(21,0)$ & \\
\hline \multicolumn{6}{|l|}{ Em pé } \\
\hline Nenhuma & 8 & $(12,9)$ & 1 & $(5,3)$ & \\
\hline Pouca a Moderada & 16 & $(25,8)$ & 5 & $(26,3)$ & $\mathrm{p}=0,79$ \\
\hline Intensa a Muito intensa & 38 & $(61,3)$ & 13 & $(68,4)$ & \\
\hline
\end{tabular}

Abreviações: IS, Índice de Staheli. Os valores entre parênteses referem-se á porcentagem. 
Tabela 15 - Frequência relativa do IS versus nível de dificuldade funcional obtida pelo questionário FAOS

\begin{tabular}{|c|c|c|c|c|c|}
\hline VARIÁVEIS & \multicolumn{2}{|c|}{$\begin{array}{l}I S=I \\
n=62\end{array}$} & \multicolumn{2}{|c|}{$\begin{array}{l}I S=I I \\
n=19\end{array}$} & $\begin{array}{c}\text { ANÁLISE } \\
\text { FISHER }\end{array}$ \\
\hline \multicolumn{6}{|c|}{ Dor no pé/tornozelo durante a última semana } \\
\hline \multicolumn{6}{|l|}{ Descer escadas } \\
\hline Nenhuma & 16 & $(25,8)$ & 2 & $(10,5)$ & \\
\hline Pouca a Moderada & 21 & $(33,9)$ & 4 & $(21,1)$ & $p=0,13$ \\
\hline Intensa a Muito intensa & 25 & $(40,3)$ & 13 & $(68,4)$ & \\
\hline \multicolumn{6}{|l|}{ Subir escadas } \\
\hline Nenhuma & 12 & $(19,4)$ & 1 & $(5,2)$ & \\
\hline Pouca a Moderada & 15 & $(24,2)$ & 6 & $(31,6)$ & $\mathrm{p}=0,36$ \\
\hline Intensa a Muito intensa & 35 & $(56,4)$ & 12 & $(63,2)$ & \\
\hline \multicolumn{6}{|c|}{ Levantar-se estando sentada } \\
\hline Nenhuma & 11 & $(17,7)$ & 2 & $(10,5)$ & \\
\hline Pouca a Moderada & 35 & $(56,5)$ & 8 & $(42,1)$ & $p=0,20$ \\
\hline Intensa a Muito intensa & 16 & $(25,8)$ & 9 & $(47,4)$ & \\
\hline \multicolumn{6}{|l|}{ Ficar em pé } \\
\hline Nenhuma & 10 & $(16,4)$ & 0 & $(0,0)$ & \\
\hline Pouca a Moderada & 24 & $(39,3)$ & 5 & $(27,8)$ & $\mathrm{p}=0,05$ \\
\hline Intensa a Muito intensa & 27 & $(44,3)$ & 13 & $(72,2)$ & \\
\hline \multicolumn{6}{|l|}{ Abaixar-se pegar algo chão } \\
\hline Nenhuma & 10 & $(16,1)$ & 2 & $(10,5)$ & \\
\hline Pouca a Moderada & 14 & $(22,6)$ & 5 & $(26,3)$ & $\mathrm{p}=0,87$ \\
\hline Intensa a Muito intensa & 38 & $(61,3)$ & 12 & $(63,2)$ & \\
\hline \multicolumn{6}{|l|}{ Andar no plano } \\
\hline Nenhuma & 18 & $(29,0)$ & 2 & $(10,5)$ & \\
\hline Pouca a Moderada & 30 & $(48,4)$ & 7 & $(36,8)$ & $p=0,04$ \\
\hline Intensa a Muito intensa & 14 & $(22,6)$ & 10 & $(52,7)$ & \\
\hline \multicolumn{6}{|l|}{ Entrar e sair carro } \\
\hline Nenhuma & 13 & $(21,0)$ & 2 & $(10,5)$ & \\
\hline Pouca a Moderada & 28 & $(45,1)$ & 6 & $(31,6)$ & $p=0,19$ \\
\hline Intensa a Muito intensa & 21 & $(33,9)$ & 11 & $(57,9)$ & \\
\hline \multicolumn{6}{|l|}{ Ir fazer compras } \\
\hline Nenhuma & 14 & $(22,6)$ & 2 & $(10,5)$ & \\
\hline Pouca a Moderada & 30 & $(48,4)$ & 9 & $(47,4)$ & $p=0,40$ \\
\hline Intensa a Muito intensa & 18 & $(29,0)$ & 8 & $(42,1)$ & \\
\hline \multicolumn{6}{|l|}{ Calçar meias } \\
\hline Nenhuma & 8 & $(12,9)$ & 1 & $(5,3)$ & \\
\hline Pouca a Moderada & 14 & $(22,6)$ & 2 & $(10,5)$ & $p=0,38$ \\
\hline Intensa a Muito intensa & 40 & $(64,5)$ & 16 & $(84,2)$ & \\
\hline \multicolumn{6}{|l|}{ Levantar-se da Cama } \\
\hline Nenhuma & 14 & $(22,6)$ & 2 & $(10,5)$ & \\
\hline Pouca a Moderada & 33 & $(53,2)$ & 8 & $(42,1)$ & $p=0,16$ \\
\hline Intensa a Muito intensa & 15 & $(24,2)$ & 9 & $(47,4)$ & \\
\hline
\end{tabular}


Tabela 15 - Frequência relativa do IS versus nível de dificuldade funcional obtida pelo questionário FAOS - "conclusão"

\begin{tabular}{|c|c|c|c|c|c|}
\hline VARIÁVEIS & \multicolumn{2}{|c|}{$\begin{array}{l}\text { IS }=I \\
n=62\end{array}$} & \multicolumn{2}{|r|}{$\begin{array}{l}I S=I I \\
n=19\end{array}$} & $\begin{array}{c}\text { ANÁLISE } \\
\text { FISHER }\end{array}$ \\
\hline \multicolumn{6}{|c|}{ Dor no pé/tornozelo durante a última semana } \\
\hline \multicolumn{6}{|l|}{ Tirar meias } \\
\hline Nenhuma & 9 & $(14,5)$ & 1 & $(5,3)$ & \\
\hline Pouca a Moderada & 14 & $(22,6)$ & 2 & $(10,5)$ & $p=0,28$ \\
\hline Intensa a Muito intensa & 39 & $(62,9)$ & 16 & $(84,2)$ & \\
\hline \multicolumn{6}{|l|}{ Ficar deitado leito } \\
\hline Nenhuma & 20 & $(32,3)$ & 8 & $(42,1)$ & \\
\hline Pouca a Moderada & 31 & $(50,0)$ & 7 & $(36,8)$ & $\mathrm{p}=0,60$ \\
\hline Intensa a Muito intensa & 11 & $(17,7)$ & 4 & $(21,1)$ & \\
\hline \multicolumn{6}{|l|}{ Entrar/sair banho } \\
\hline Nenhuma & 24 & $(38,7)$ & 7 & $(36,8)$ & \\
\hline Pouca a Moderada & 29 & $(46,8)$ & 8 & $(42,1)$ & $p=0,78$ \\
\hline Intensa a Muito intensa & 9 & $(14,5)$ & 4 & $(21,1)$ & \\
\hline \multicolumn{6}{|l|}{ Se sentar } \\
\hline Nenhuma & 15 & $(24,2)$ & 3 & $(15,8)$ & \\
\hline Pouca a Moderada & 34 & $(54,8)$ & 12 & $(63,2)$ & $p=0,72$ \\
\hline Intensa a Muito intensa & 13 & $(21,0)$ & 4 & $(21,0)$ & \\
\hline \multicolumn{6}{|c|}{ Sentar/ levantar vaso sanitário } \\
\hline Nenhuma & 12 & $(19,3)$ & 2 & $(10,5)$ & \\
\hline Pouca a Moderada & 35 & $(56,5)$ & 8 & $(42,1)$ & $p=0,20$ \\
\hline Intensa a Muito intensa & 15 & $(24,2)$ & 9 & $(47,4)$ & \\
\hline \multicolumn{6}{|c|}{ Fazer tarefas domésticas pesadas } \\
\hline Nenhuma & 9 & $(14,5)$ & 1 & $(5,2)$ & \\
\hline Pouca a Moderada & 19 & $(30,7)$ & 3 & $(15,8)$ & $\mathrm{p}=0,21$ \\
\hline Intensa a Muito intensa & 34 & $(54,8)$ & 15 & $(79,0)$ & \\
\hline \multicolumn{6}{|c|}{ Fazer tarefas domésticas leves } \\
\hline Nenhuma & 12 & $(19,4)$ & 3 & $(17,8)$ & \\
\hline Pouca a Moderada & 24 & $(38,7)$ & 4 & $(21,0)$ & $p=0,28$ \\
\hline Intensa a Muito intensa & 26 & $(41,9)$ & 12 & $(63,2)$ & \\
\hline
\end{tabular}

Abreviações: IS, Índice de Staheli. Os valores entre parênteses referem-se á porcentagem. 


\section{REFERÊNCIAS}

1. World Health Organization (WHO). Obesity: preventing and managing the global epidemic. WHO Technical Report Series. 2000;894:I - XII, 1-253.

2. Chang G; Chen CT. Musculoskeletal effects of obesity. Curr Opin Pediatr. 2009;21:65-70.

3. National Institutes of Health. The practical guide: Identification, evaluation and treatment of overweight and obesity in adults. Bethesda, MD: National Institutes of Health, National Heart, Lung, and Blood Institute and North American Association for the Study of Obesity. 2000. NIH Publication Number 00-4084.

4. World Health Organization. Physical status: the use and interpretation of anthropometry. Report of a WHO Expert Committee. Genebra: WHO, 1995. (Technical Report Series, No. 854).

5. Fisher BL, Schauer P. Medical and surgical options in the treatment of severe obesity. Am J Surg. 2002;184:S9-S16.

6. Baumgarten KM, Carlson WO, Watson ES. The effect of obesity on orthopaedic conditions. S D Med. 2011; Spec $\mathrm{N}_{0}$ : 41-44.

7. Van Boerum DH, Sangeorzan BJ. Biomechanics and pathophysiology of flat foot. Foot Ankle Clin. 2003;8:419-30.

8. Frey C, Zamora J. The effects of obesity on orthopedic foot and ankle pathology. Foot and Ankle Int. 2007;28:996-9. 
9. Hills AP, Hennig EM, Byrne NM, Steele JR. The biomechanics of adiposity - structural and functional limitations of obesity and implications for movement. Obes Rev. 2002; 3:35-43.

10. Wearing SC, Hennig EM, Byrne NM, Steele JR, Hills AP. Musculoskeletal disorders associated with obesity: a biomechanical perspective. Obes Rev. 2006;7:239-250.

11. Hooper MM, Stellato TA, Hallowell PT, Seitz BA, Moskowitz RW. Musculoskeletal findings in obese subjects before and after weight loss following bariatric surgery. Int J Obes. 2007;31:114-20.

12. Anandacoomarasamy A, Caterson I, Sambrook P, Fransen M, March L. The impact of obesity on the musculoskeletal system. Int $J$ Obes. 2008;32:211-22.

13. Creamer $P$, Lethbridge-Cejku M, Hochberg MC. Factors associated with functional impairment in symptomatic knee osteoarthritis. Rheumatol (Oxford). 2000;39:490-6.

14. Jinks $C$, Jordan K, Croft P. Measuring the population impact of knee pain and disability with the Western Ontario and McMaster Universities Osteoarthritis Index (WOMAC). Pain. 2002;100:55-64.

15. Andriacchi TP. Dynamics of knee malalignment. Orthop Clin North Am. 1994;25:395-403.

16. Fabris de Souza SA, Faintuch J, Valezi AC, Sant'Anna AF, GamaRodrigues JJ, de Batista Fonseca IC, de Melo RD. Postural changes in morbidly obese patients. Obes Surg. 2005;15:1013-6.

17. McGoey BV, Deitel M, Saplys RJ, Klinman ME. Effects of weight loss on musculoskeletal pain in the morbidly obese. J Bone Joint Surg $\mathrm{Br}$ 1990;72:322-3. 
18. Messier SP, Loeser RF, Mitchell MN, et al. Exercise and weight loss in obese older adults with knee osteoarthritis: a preliminary study. J Am Geriatr Soc. 2000;48:1062-72.

19. Brasil. Ministério da Saúde. Secretaria de Atenção à Saúde. Departamento de Atenção Básica. Obesidade. Brasília (DF): Ministério da Saúde; 2006.

20. Brasil. Ministério do Planejamento, Orçamento e Gestão. Instituto Brasileiro de Geografia e Estatística [Internet]. Pesquisa de Orçamentos Familiares 2008-2009: antropometria e estado nutricional de crianças, adolescentes e adultos no Brasil. Rio de Janeiro: IBGE; 2010 [citado 2010 Fev 27]. Disponível em: http://www.ibge.gov.br/home/estatistica/populacao/condicaodevida/pof/2 008_2009_encaa/pof_20082009_encaa.pdf.

21. Santos LMP, Oliveira IV, Peters LR, Conde WL. Trends in Morbid Obesity and in Bariatric Surgeries Covered by the Brazilian Public Health System. Obes Surg. 2010;20:943-48.

22. Marcon ER, Gus I, Neumann CR. Impacto de um programa mínimo de exercícios físicos supervisionados no risco cardiometabólico de pacientes com obesidade mórbida. Arq Bras Endocrinol Metab. 2011; 55:331-8.

23. Taylor ED, Theim KR, Mirch M, Ghorbani S, Tanofsky-Kraff M, AdlerWailes $D$ et al. Orthopedic complications of overweight in children and adolescents. Pediatrics. 2006;117:2167-74.

24. Ding C, Cicuttini F, Scott F, Cooley H, Jones G. Knee structural alteration and BMI: a crossectional study. Obes Res. 2005;13:350-61. 
25. Teichtahl AJ, Wang Y, Wluka AE, Cicuttini FM. Obesity and Knee Osteoarthritis: New Insights Provided by Body Composition Studies. Obesity (Silver Spring). 2008;16:232-40.

26. Namba RS, Paxton L, Fithian DC, Stone ML. Obesity and Perioperative Morbidity in Total Hip and Total Knee Arthroplasty Patients. $J$ Arthroplasty. 2005;20:46-50.

27. Christensen R, Bartels EM, Astrup A, Bliddal $H$. Effect of weight reduction in obese patients diagnosed with knee osteoarthritis: a systematic review and meta-analysis. Ann Rheum Dis. 2007;66:433-9.

28. Messier SP, Loeser RF, Miller GD, Morgan TM, Rejeski WJ, Sevick MA et al. Exercise and dietary weight loss in overweight and obese older adults with knee osteoarthritis: the arthritis, diet, and activity promotion trial. Arthritis Rheum. 2004;50:1501-10.

29. Abu-Abeid S, Wishnitzer N, Szold A, Liebergall M, Manor O. The influence of surgically-induced weight loss on the knee joint. Obes Surg. 2005;15:1437-42.

30. Dowling AM, Steele JR, Baur LA. Does obesity influence foot structure and plantar pressure patterns in prepubescent children? Int J Obes Relat Metab Disord. 2001;25:845-52.

31. Morioka EH; Onodera AN; Sacco ICN; Sá MR; Amadio AC. Avaliação do arco longitudinal medial através da impressão plantar em crianças de 3 a 10 anos [CD-ROM]. In: XI Congresso Brasileiro de Biomecânica; 2005 Jun 19-22; João Pessoa, Brasil. Congresso Brasileiro de Biomecânica, 2005.

32. Hill CL, Gill TK, Menz HB, Taylor AW. Prevalence and correlates of foot pain in a population-based study: the North West Adelaide health study. J Foot Ankle Res. 2008.; 1:1-7. 
33. Menz HB, Barr EL, Brown WJ. Predictors and persistence of foot problems in women aged 70 years and over: A prospective study. Maturitas. 2011;68: 83-7.

34. Fabris SM, Valezi AC, Souza SAF, Faintuch J, Cecconelo I, Junior MP. Computerized Baropodometry in Obese patients. Obes Surg, 2006; 16: 1574-78.

35. Tanamas SK, Wluka AE, Berry P, Menz HB, Strauss BJ, Davies-Tuck M, Projetto J, Dixon JB, Jones G, Cicuttini FM. Relationship between obesity and foot pain and its association with fat mass, fat distribution and muscle mass. Arthritis Care Res (Hoboken). 2012;64:262-8.

36. Cavanagh PR, Rodgers MM. The arch index: a useful measure from footprints. J Biomech. 1987;20:547-51.

37. McCrory JL, Young MJ, Boulton AJM, Cavanagh PR. Arch index as a predictor of arch height. Foot. 1997;7:79-81.

38. Queen RM, Mall NA, Hardaker WM, Nunley JA 2nd. Describing the medial longitudinal arch using footprint indices and a clinical grading system. Foot Ankle Int. 2007;28:456-62.

39. Williams DS, McClay IS. Measurements used to characterize the foot and the medial longitudinal arch: reliability and validity. Phys Ther. 2000;80:864-71.

40. Richards CJ, Card K, Song J, Hillstrom H, Butler R, Davis IM. A novel arch height index measurement system (AHIMS): Intra and inter-rater reliability. In: American Society of biomechanics Meeting; 2003 September; Toledo, $\mathrm{OH}$. 
41. Kim HW, Weinstein SL. Flatfoot in children: differential diagnosis and management. Curr Orthop. 2000;14:441-7.

42. Abdel-Fattah MM, Hassanin MM, Felembane FA, Nassaane MT. Flat foot among Saudi Arabian army recruits: prevalence and risk factors. East Mediterr Health J. 2006;12:211-7.

43. Gilmour JC, Burns Y. The measurement of the medial longitudinal arch in children. Foot Ankle Int. 2001; 22:493-8.

44. Kanatli $U$, Yetkin $\mathrm{H}$, Cila E. Footprint and radiographic analysis of the feet. J Pediatr Orthop. $2001 ; 21: 225-38$.

45. Huang CK, Kitaoka HB, An KN, Chao EY. Biomechanical evaluation of longitudinal arch stability. Foot Ankle. 1993; 14:353-7.

46. Menz HB. Alternative techniques for the clinical assessment of foot pronation. J Am Podiatr Med Assoc. 1998;88:119-29.

47. Saltzman CL, Nawoczenski DA, Talbot KD. Measurement of the medial longitudinal arch. Arch Phys Med Rehabil. 1995;76:45-9.

48. Villarroya MA, Esquivel JM, Tomás C, Moreno LA, Buenafé A, Bueno G. Assessment of the medial longitudinal arch in children and adolescents with obesity: footprints and radiographic study. Eur $J$ Pediatr. 2009;168(5):559-67.

49. Chi TD, Toolan BC, Sangeorzan BJ, Hansen ST Jr. The lateral column lengthening and medial column stabilization procedures. Clin Orthop Relat Res. 1999;(365):81-90.

50. Meary R. On the measurement of the angle between the talus and the first metatarsal. Rev Chir Orthop Reparatrice Appar Mot. 1967;53:390-419. 
51. Younger AS, Sawatzky B, Dryden P. Radiographic assessment of adult flatfoot. Foot Ankle Int. 2005;26:820-5.

52. Mosca VS. Flexible flatfoot in children and adolescents. J Child Orthop. 2010; 4:107-21.

53. Forriol F, Pascual J. Footprint analysis between three and seven years of age. Foot Ankle. 1990; 11:101-4.

54. Chen $\mathrm{CH}$, Huang $\mathrm{MH}$, Chen TW, Weng MC, Lee CL, Wang GJ. The correlation between selected measurements from footprint and radiograph of flatfoot. Arch Phys Med Rehabil. 2006; 87:235-40.

55. Staheli LT, Chew DE, Corbett M. The longitudinal arch. A survey of eight hundred and eighty-two feet in normal children and adults. $J$ Bone Joint Surg Am. 1987;69:426-8.

56. Hawes MR, Nachbauer W, Sovak D, Nigg BM. Footprint parameters as a measure of arch height. Foot Ankle. 1992;13:22-6.

57. Kopelman P. Health risks associated with overweight and obesity. Obes Rev. 2007;8:13-7.

58. Peltonen M, Lindroos AK, Torgerson JS. Musculoskeletal pain in the obese: a comparison with a general population and long-term changes after conventional and surgical obesity treatment. Pain. 2003;104; 549-57.

59. World Health Organization. Obesity: preventing and managing the global epidemic: report of a WHO consultation on Obesity. Geneva: WHO;1998.

60. Kellgren JH, Lawrence, JS. Radiological assessment of osteo-arthrosis. Ann Rheum Dis. 1957;16:494-502. 
61. Pedowitz WJ, Kovatis P. Flatfoot in the adult. J Am Acad Orthop Surg. 1995;3:293-302.

62. Menz HB. Alternative techniques for the clinical assessment of foot pronation. J Am Podiatr Med Assoc. 1998; 88:119-29.

63. Ribeiro AP, Trombini-Souza F, lunes DH, Monte-Raso VV. Confiabilidade inter e intra-examinador da fotopodometria e intraexaminador da fotopodoscopia. Rev. Bras. Fisioter. 2006;10:435-9.

64. Fernandes Ml. Tradução e validação do questionário de qualidade de vida específico para osteoartrose WOMAC (Western Ontario McMaster Universities) para a língua portuguesa [dissertação]. São Paulo: Escola Paulista de Medicina, Universidade Federal de São Paulo; 2003.

65. Imoto AM, Peccin MS, Rodrigues R, Mizusaki JM. Translation, cultural adaptation and validation of foot and ankle outcome score (FAOS) questionnaire into Portuguese. Acta Ortop Bras. [online]. 2009; 17:232-5. Available from URL: http://www.scielo.br/aob

66. Roos EM, Brandsson S, Karlsson J. Validation of the foot and ankle outcome score for ankle ligament reconstruction. Foot Ankle Int. 2001; 22:788-94.

67. Curi PR. Metodologia e análise da pesquisa em ciências biológicas. Botucatu (SP): Tipomic; 1997.

68. Vincent HK, Lamb KM, Day TI, Tillman SM, Vincent KR, George SZ. Morbid obesity is associated with fear of movement and lower quality of life in patients with knee pain-related diagnoses. PM R. 2010; 2:713-22. 
69. Felson DT, Anderson JJ, Naimark A, Walker AM, Meenan RF. Obesity and knee osteoarthritis. The Framingham Study. Ann Intern Med 1988;109:18-24.

70. Felson DT, Zhang Y, Anthony JM, Naimark A, Anderson JJ. Weight loss reduces the risk for symptomatic knee osteoarthritis in women. The Framingham Study. Ann Intern Med. 1992;116:535-9.

71. Felson DT, Zhang $\mathrm{Y}$, Hannan MT et al. Risk factors for incident radiographic knee osteoarthritis in the elderly: the Framingham Study. Arthritis Rheum. 1997;40:728-733.

72. Hart DJ, Spector TD. The relationship of obesity, fat distribution and osteoarthritis in women in the general population: the Chingford Study. J Rheumatol. 1993;20:331-335.

73. Anderson JJ, Felson DT. Factors associated with osteoarthritis of the knee in the first national Health and Nutrition Examination Survey (HANES I). Evidence for an association with overweight, race, and physical demands of work. Am J Epidemiol. 1988;128:179-189.

74. Hart DJ, Doyle DV, Spector TD. Incidence and risk factors for radiographic knee osteoarthritis in middle-aged women: the Chingford Study. Arthritis Rheum.1999;42:17-24.

75. Spector TD, Hart DJ, Doyle DV. Incidence and progression of osteoarthritis in women with unilateral knee disease in the general population: the effect of obesity. Ann Rheum Dis. 1994; 53: 565-68.

76. Lübbeke A, Duc S, Garavaglia G, Finckh A, Hoffmeyer P. BMI and Severity of Clinical and Radiographic Signs of Hip Osteoarthritis. Obesity. 2009,17:1414-19 
77. SBTO. Artrose do joelho: tratamento cirúrgico [on-line]. São Paulo: Associação Médica Brasileira. Projeto Diretrizes; 2007(1) [citado 15 out. 2011]. Disponível em: http://www.projetodiretrizes.org.br/7_volume/ 01Artrose_de_oelho_TraC.pdf

78. Gill RS, Al-Adra DP, Shi X, Sharma AM, Birch DW, Karmali S. The benefits of bariatric surgery in obese patients with hip and knee osteoarthritis: a systematic review. Obes Rev. 2011;12:1083-9.

79. Chou LW, Chen FF, Lo SF, Yang PY, Meng NH, Lin CL, Liao FY, Kao MJ. The prevalence of four common pathomechanical foot deformities in primary school students in Taichung County. Mid Taiwan $J$ Med. 2009;14:1-9.

80. Snider RK. Tratamento das doenças do sistema musculoesquelético. São Paulo: Manole; 2000.

81. Cobey JC, Sella E. Standardizing methods of measurement of foot shape by including the effects of subtalar rotation. Foot Ankle. 1981;2:30-6.

82. Leveille SG, Guralnik JM, Ferrucci L, Hirsch R, Simonsick E, Hochberg MC. Foot pain and disability in older women. Am J Epidemiol. 1998; 148: 657-65.

83. Mickle KJ, Steele JR, Munro BJ. The feet of overweight and obese young children: are they flat or fat? Obesity. 2006;14:1949-53.

84. Andersen RE, Crespo CJ, Bartlett SJ, Bathon JM, Fontaine KR. Relationship between body weight gain and significant knee, hip, and back pain in older Americans. Obes Res. 2003;11:1159-62 . 
85. Hitt HC, McMillen RC, Thornton-Neaves T, Koch K, Cosby AG. Comorbidity of obesity and pain in a general population: results from the Southern Pain Prevalence Study. J Pain. 2007; 8:430-6.

86. Nebel MB, Sims EL, Keefe FJ, Kraus VB, Guilak F, Caldwell DS, Pells JJ, Queen R, Schimitt D. The relationship of self-reported pain and functional impairment to gait mechanics in overweight and obese persons with knee osteoarthritis. Arch Phys Med Rehabil. 2009; 90:1874-9.

87. Heo M, Allison DB, Faith MS, Zhu S, Fontaine KR. Obesity and quality of life: mediating effects of pain and comorbidities. Obes Res. 2003;11:209-16.

88. Anandacoomarasamy A, Caterson ID, Leibman S, Smith GS, Sambrook PN, Fransen M, March LM. Influence of BMI on health- related quality of life: comparison between an obese adult cohort and age-matched population norms. Obesity (Silver Spring). 2009;17: 2114-8.

89. Kaufman KR, Brodine SK, Shaffer RA, Johnson CW, Cullison TR. The effect of foot structure and range of motion on musculoskeletal overuse injuries. Am J Sports Med. 1999; 27:585-93.

90. Lutter LD. Foot-related knee problems in the long distance runner. Foot Ankle. 1980;1:112-6.

91. Bricot B. Posturologia. São Paulo: Ícone, 1998.

92. Bird AR, Payne CB. Foot function and low back pain. Foot.1999; 9:175-80.

93. Gross KD, Felson DT, Niu J, Hunter DJ, Guermazi A, Roemer FW, Duffour AB, Gensure RH, Hannan MT. Association of flat feet with knee pain and cartilage damage in older adults. Arthritis Care Res (Hoboken). $2011 ; 63: 937-44$. 